\title{
The Catalytic Role of D-block Elements and Their Compounds for Improving Sorption Kinetics of Hydride Materials: A Review
}

\author{
Pratibha Pal ${ }^{1}$, Jyh-Ming Ting ${ }^{1}$, Shivani Agarwal ${ }^{2}$, Takayuki Ichikawa ${ }^{3}$ and Ankur Jain ${ }^{4,5, *(1)}$ \\ 1 Department of Material Science and Engineering, National Cheng Kung University, Tainan 107, Taiwan; \\ pratibha.mbd@gmail.com (P.P.); jting@mail.ncku.edu.tw (J.-M.T.) \\ 2 Department of Physics, JECRC University, Jaipur 303905, India; shivaniphy@gmail.com \\ 3 Graduate School of Engineering, Hiroshima University, Higashi-Hiroshima 739-8527, Japan; \\ tichi@hiroshima-u.ac.jp \\ 4 Natural Science Centre for Basic Research \& Development, Hiroshima University, \\ Higashi-Hiroshima 739-8530, Japan \\ 5 Center for Renewable Energy Storage \& Technologies, Suresh Gyan Vihar University, Jaipur 302015, India \\ * Correspondence: ankur@hiroshima-u.ac.jp
}

check for updates

Citation: Pal, P.; Ting, J.-M.; Agarwal, S.; Ichikawa, T.; Jain, A. The Catalytic Role of D-block Elements and Their Compounds for Improving Sorption Kinetics of Hydride Materials: A Review. Reactions 2021, 2, 333-364. https://doi.org/10.3390/ reactions 2030022

Academic Editors: Luis G. Alves and Tiago A. Fernandes

Received: 16 August 2021

Accepted: 13 September 2021

Published: 18 September 2021

Publisher's Note: MDPI stays neutral with regard to jurisdictional claims in published maps and institutional affiliations.

Copyright: (c) 2021 by the authors. Licensee MDPI, Basel, Switzerland. This article is an open access article distributed under the terms and conditions of the Creative Commons Attribution (CC BY) license (https:/ / creativecommons.org/licenses/by/ $4.0 /)$.

\begin{abstract}
The goal of finding efficient and safe hydrogen storage material motivated researchers to develop several materials to fulfil the demand of the U.S. Department of Energy (DOE). In the past few years, several metal hydrides, complex hydrides such as borohydrides and alanates, have been researched and found efficient due to their high gravimetric and volumetric density. However, the development of these materials is still limited by their high thermodynamic stability and sluggish kinetics. One of the methods to improve the kinetics is to use catalysts. Among the known catalysts for this purpose, transition metals and their compounds are known as the leading contender. The present article reviews the d-block transition metals including $\mathrm{Ni}, \mathrm{Co}, \mathrm{V}, \mathrm{Ti}, \mathrm{Fe}$ and $\mathrm{Nb}$ as catalysts to boost up the kinetics of several hydride systems. Various binary and ternary metal oxides, halides and their combinations, porous structured hybrid designs and metal-based Mxenes have been discussed as catalysts to enhance the de/rehydrogenation kinetics and cycling performance of hydrogen storage systems.
\end{abstract}

Keywords: metal hydrides; complex hydrides; hydrogen storage; kinetics; catalysts; activation energy

\section{Introduction}

The search for clean and abundant energy sources to compete with fossil fuels brings us to hydrogen as a next-generation energy carrier. Hydrogen is a promising alternative energy carrier as a long-term solution with the only product as water and not $\mathrm{CO}_{2}$. To establish hydrogen infrastructure, its efficient storage is warranted. There are several technologies available in the market for hydrogen storage, but these technologies are still not good in terms of cost and handling, which are critical issues. To guide the technological and scientific community, the U.S. Department of Energy (DOE) set targets for onboard hydrogen storage to achieve the required capacity by the year. For example, $5.5 \mathrm{wt} \%$ gravimetric capacity or a $40 \mathrm{~g} \mathrm{H}_{2}$ / L volumetric capacity is the target by the end of 2025, whereas it is set to be $6.5 \mathrm{wt} \%$ gravimetric capacity or a $55 \mathrm{~g} \mathrm{H}_{2} / \mathrm{L}$ volumetric capacity as ultimate target [1]. The technologies involved in hydrogen storage are liquefied hydrogen storage, gaseous hydrogen storage and solid-state hydrogen storage as shown in Figure 1. Hydrogen in the liquid state requires more than twice the space in comparison to gasoline to run the car up to 300 miles. In the gaseous state, hydrogen is even more complicated to handle, with the cost more than 4-5 times of the gasoline storage [2]. Hydrogen storage in the compressed state needs heavy and large cylinders with special coatings which add more cost to the method. In addition, the safety risks due to high pressure cannot be 
avoided. Thus, both techniques, i.e., compressed hydrogen gas and low-temperature liquefied hydrogen gas, have their own disadvantages and are unrealistic for commercial use. Consequently, researchers have been attracted by solid-state hydrogen storage in materials due to its high gravimetric and volumetric capacities, ease of handling and safety. In the last few years, researchers have been more focused to achieve the DOE targets and to understand the hydrogen de/adsorption properties of physically and chemically bounded hydrogen in solid materials. The mechanism of solid-state hydrogen storage materials can be classified based on the state of hydrogen in the materials, i.e., physisorption (physically bounded hydrogen) and chemisorption (chemically bounded hydrogen). In physisorption, molecular hydrogen is adsorbed onto the surface of the material by the weak van der Waals interactions. Due to the weak interaction of the nonpolar hydrogen molecule with the adsorbent surface, it is easy to desorb hydrogen at high temperature. To avoid this quick release of hydrogen, cryogenic temperatures $(\sim 77 \mathrm{~K})$ are usually applied for the hydrogen storage process [3]. However, room temperature hydrogen desorption for storage and onboard vehicular applications is desired and difficult to achieve. As we can see in Figure 2, physisorption systems commonly attract attention due to their porous structures and high surface area. For example, carbon-related materials and carbon nanotubes (CNTs) were investigated because of their high surface area and high capacity up to $6.5 \mathrm{wt} \%$, but due to desorption at low temperature, these are not suitable practically [4]. Zeolites and metal organic frameworks (MOFs) $[5,6]$ and organic polymers $[7,8]$ have been investigated due to their good porosity and high surface area (low density) which is helpful to increase hydrogen storage capacity. However, the requirement of cryogenic temperature makes them unsuitable for commercial use. On the other hand, in chemisorption, strong chemical interaction occurs between the atomic hydrogen and the solid material (high interaction energy $100-200 \mathrm{~kJ} \mathrm{~mol}^{-1}$ ). Hydrogen is stored by strong bonding with the solid material and is released at specified conditions through a chemical reaction. As shown in Figure 2, chemisorption systems include two broad categories, i.e., metal hydrides and complex hydrides.

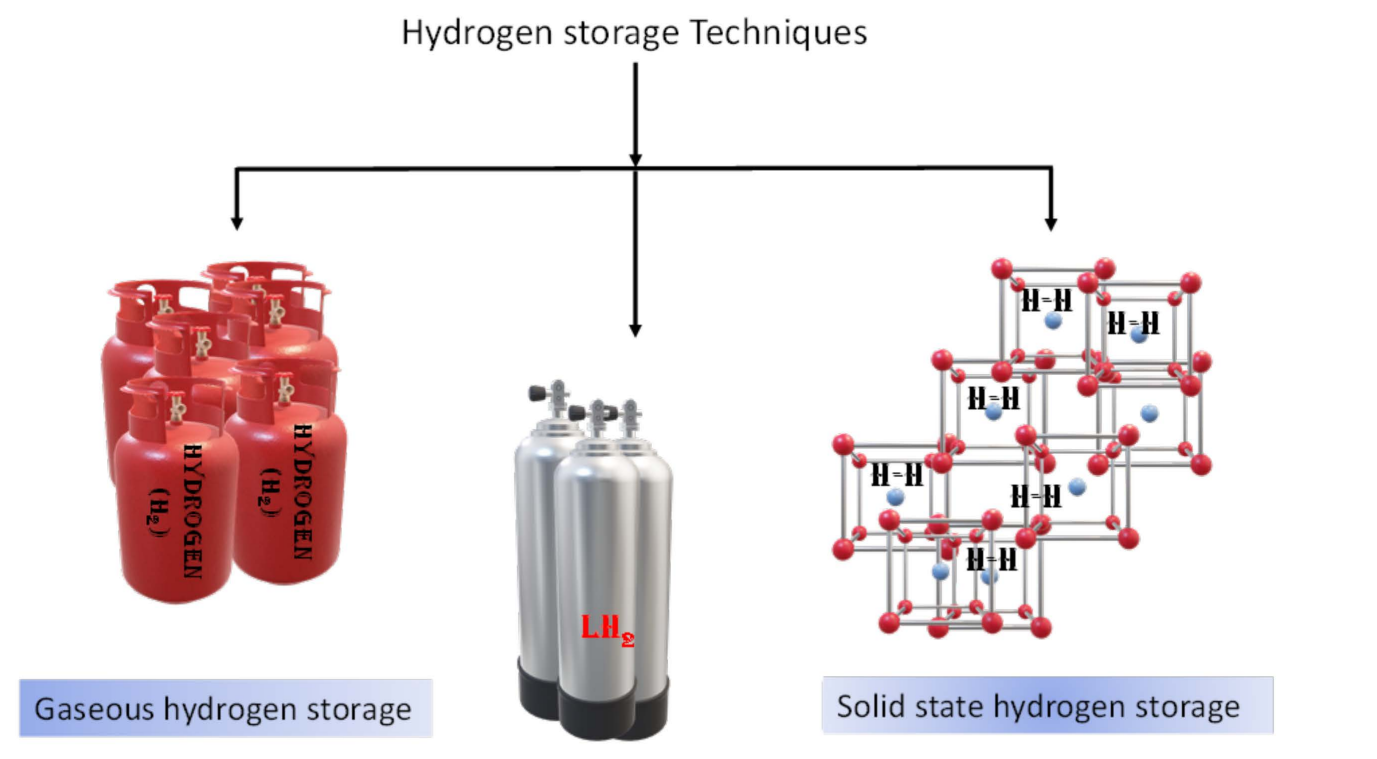

Liquefied hydrogen storage

Figure 1. Different hydrogen storage methods. 


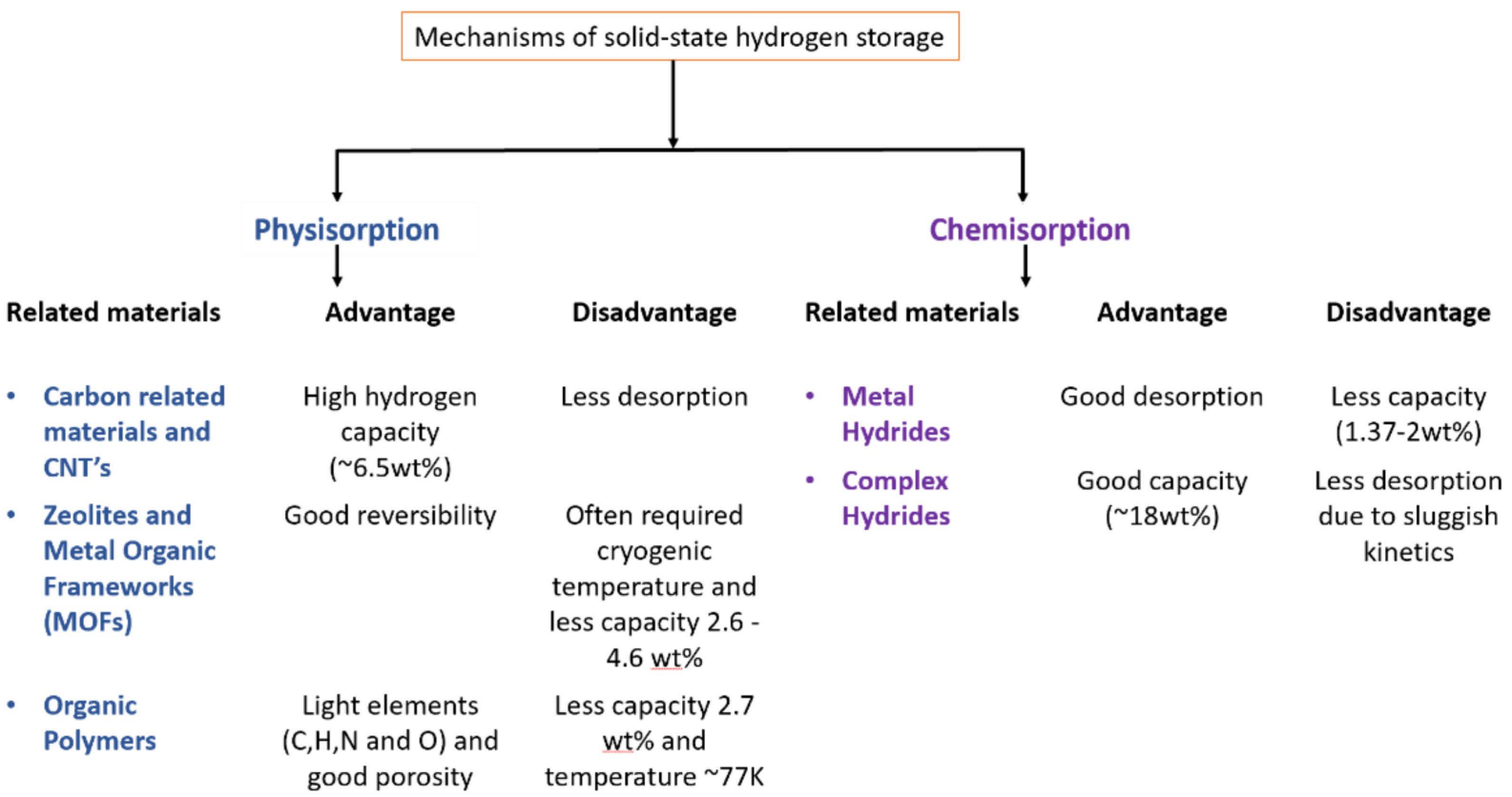

Figure 2. Solid-state hydrogen storage mechanisms, related materials and their advantages and disadvantages.

Metal hydrides are commonly in the form of $\mathrm{MH}_{\mathrm{x}}$ where $\mathrm{M}=$ metal, $\mathrm{H}$ is hydrogen atom and $\mathrm{x}$ is the number of hydrogen atoms. To form metal hydride, hydrogen reacts with the metal (or metal alloy) and transfers the H- (hydride ion) as per Equation (1).

$$
\mathrm{M}+\frac{\mathrm{x}}{2} \mathrm{H}_{2} \Leftrightarrow \mathrm{MH}_{\mathrm{x}}
$$

Typical metal hydrides (interstitial hydrides) such as $\mathrm{LaNi}_{5}$, $\mathrm{TiCrMn}, \mathrm{VTiCr}$, TiFe and vanadium-based hydrogen storage alloys have been studied for a long time and are reversible under moderate conditions [9-13]. However, due to the lower (up to $2 \mathrm{wt} \%$ ) gravimetric capacity of such conventional metal hydrides, they are restricted to use in stationary applications only, such as hydrogen tanks and compressors. On the other hand, light metal hydrides $\left(\mathrm{LiH}, \mathrm{NaH}\right.$ and $\left.\mathrm{MgH}_{2}\right)$ and complex hydrides such as borohydrides and alanates (for e.g., $\mathrm{LiBH}_{4}, \mathrm{NaBH}_{4}, \mathrm{NaAlH}_{4}, \mathrm{LiAlH}_{4}, \mathrm{Na}_{3} \mathrm{AlH}_{6}$ and $\mathrm{Mg}_{2} \mathrm{FeH}_{6}$ ) have high gravimetric capacities (7-18.6 wt\%). Regardless of the high gravimetric capacity, these materials possess serious thermodynamic and kinetic issues that create problems such as high stability (requiring high operating temperature) and slow reaction rate (causing slow charging/discharging). The research on metal/complex hydrides has been carried out for a long time. However, the material selection and design of metal hydrides are still important to optimize the thermodynamics and kinetics. To solve the thermodynamics issues, several approaches are described by many researchers. One of them is nanosizing $(<10 \mathrm{~nm})$ as well as nanoconfinement (support on matrix) [14]. Nanosizing greatly influences the size of particles (generally by using the high-energy ball milling technique) and nanoconfinement is where the nanoparticles are supported on the porous catalyst. These techniques not only improve the thermodynamics and reversibility of the system but are also helpful to enhance the rate of reaction. However, high sensitivity towards oxidation and less cyclic stability (due to agglomeration, which loses the benefits of nanostructure) are the main disadvantages of such techniques [14]. Thus, people investigated other techniques to improve the thermodynamics of the hydrogen systems such as insertion of a third element as described well by Jain et al. in 2018 [15]. On the other hand, many metal/complex hydrides have high gravimetric capacity but due to the complex nature and existence of multiple phases after dehydrogenation they often face kinetic and reversibility issues. Several noble metal catalysts have been employed to resolve these issues; however, the high cost and lower abundancy of such catalysts make them irrelevant [16-20]. Therefore, 
the choice of d-block elements is appropriate due to their abundance on earth, feasible cost and high activity, which make them a suitable candidate to improve the sluggish kinetics of hydrogen storage materials [21-23]. There are many factors which affect the kinetics of the hydrogen storage system. To understand the problems related to kinetics in detail, we will move towards the next section of this article.

\section{Basic Understanding of Kinetics and a Light on the Kinetics of Metal Hydride}

Kinetics is not easy to understand and is something which defines the rate of hydrogen absorption and desorption by the metal. It is clearly different from the thermodynamics of the hydride materials. Thermodynamics can be understood by two factors: enthalpy of formation $(\triangle H)$ and entropy of hydride $(\triangle S)$, whereas kinetics can be understood by the activation energy $\left(E_{a}\right)$ of the reaction. There are two equations which can help to calculate the activation of reaction $\left(E_{a}\right)$ as mentioned below, (2) and (3):

(1). Arrhenius equation:

$$
k=A \exp \left[-\frac{E_{a}}{R T}\right]
$$

(2). Kissinger equation:

$$
\ln \left(\frac{\beta}{T_{p}^{2}}\right)=\ln \left(\frac{A R}{E_{a}}\right)-\frac{E_{a}}{R T_{p}} .
$$

where $E_{a}=$ activation energy, $k=$ rate constant, $A=$ frequency factor, $R=$ gas constant $\left(8.3145 \mathrm{~J} \mathrm{~mol}^{-1} \mathrm{~K}^{-1}\right), T=$ temperature, $\beta=$ heating rate and $T_{p}=$ peak temperature.

The issue of kinetics in hydrogen storage materials has been investigated for a long time by continuous inventions of different techniques such as (nanosizing) ball milling and nanoconfinement, use of catalyst and thin films [24-27]. The problem of kinetics occurs because of the complexity of these hydride materials. These complex structures made of different elements have a different-sized ionic radius which creates highly directional bonding in these hydride materials [28]. Due to this, a diffusion barrier may form which will enhance the very slow rate of reaction for hydrogen uptake and release [15]. Moreover, other than complexity, many other reasons that may affect the kinetics of hydrogen absorption and desorption will be discussed later. Light metal hydrides such as $\mathrm{Li}, \mathrm{Na}$ and $\mathrm{Mg}$ have high capacity (in comparison with the other metal hydrides) due to their light weight, abundance and recyclability of parent metal/materials [29]. These metals/materials are connected with hydrogen via different bonds including ionic, polar covalent and metallic. Due to the high strength and stability in ionic and covalent bonds, the metal hydride does not easily show good reversibility. However, in the case of metallic bonding, it is possible to alter the strength by providing the required high temperature and other properties of hydrogen storage materials. There are several issues one needs to understand with the metal hydride reaction system. Firstly, hydrogen absorption is an exothermic reaction, i.e., intake of hydrogen by metal hydride evolves some heat during the reaction. That simply indicates that during the absorption process, the generated heat increases the operating temperature. If this heat does not dissipate in a timely manner, the absorption rate is reduced. On the other hand, in the case of desorption, the rate is affected by the desorption of hydrogen by the metal hydride system due to the endothermic reaction [30]. It is easy to understand that stronger bonding between hydrogen and metal enhances the requirement of temperature to desorb hydrogen [31,32]. Many factors are involved that affect the kinetics of metal hydride; one of them is the hydrogen dissociation that happens on the outer surface of the metal. For a specific temperature and pressure, the hydrogen absorption/desorption rate is influenced by the intrinsic properties of the material. The metal-hydrogen interaction through several steps is explained in the next section. Mg-based materials that are not only cheap and abundant, but also have large mass and volume densities for hydrogen storage, are useful for understanding the kinetic problem. Mg-based materials often have sluggish kinetics due to the surface oxidation in the air, resulting in the formation of oxides and hydroxides which creates a barrier to diffuse hydrogen. Usually, the activation process 
is employed to break the oxide layer on the surface of the material which provides the absorption of hydrogen [33]. For example, TiFe alloy is superior because of its low cost and abundancy but it requires activation to remove the cover of the oxide layer $[11,34,35]$. As discussed above, Mg-based materials require high temperature because their kinetics is slow with hydrogen and requires activation before absorption of hydrogen. Addition of a tiny amount of catalyst dramatically increases the rate of dissociation of $\mathrm{H}_{2}$ molecule to $\mathrm{H}$ atom [33]. Another reason for slow kinetics is illustrated through the diffusion coefficient of $\mathrm{MgH}_{2}\left(1.5 \times 10^{-16} \mathrm{~m}^{2} / \mathrm{s}\right)$, which is smaller than $\mathrm{Mg}\left(4 \times 10^{-13} \mathrm{~m}^{2} / \mathrm{s}\right)$. After the formation of the hydride layer $\left(\mathrm{MgH}_{2}\right)$, it prevents the diffusion of hydrogen further into the metal. After this, hydrogen is not absorbed from the upper layer, but it absorbs through the interface of $\mathrm{Mg}-\mathrm{MgH}_{2}$, which limits the kinetics. To overcome this problem, many researchers have suggested the use of small particles in place of bulk magnesium to accomplish easy absorption and desorption of $\mathrm{H}$ atom from the stable nanocluster [36-38]. Researchers have proposed many steps to illustrate the absorption and desorption steps for hydrogen storage materials as described in the next section.

\section{Mechanism of Hydrogen Absorption/Desorption and Need of Catalyst}

The mechanism of hydrogen absorption and desorption can be understood through several steps as shown in Figure 3. The hydride phase is formed from the metal/gas interface to the center as shown in Figure 3 (left). Initially, hydrogen forms a solid solution ( $\alpha$ phase) when a small amount of hydrogen occupies the interstitial sites of the host metal $\mathrm{M}$ as shown in the figure. When the hydrogen content is increased further, $\beta$-phase is formed with the saturation of the solid solution and hydride phase is formed.
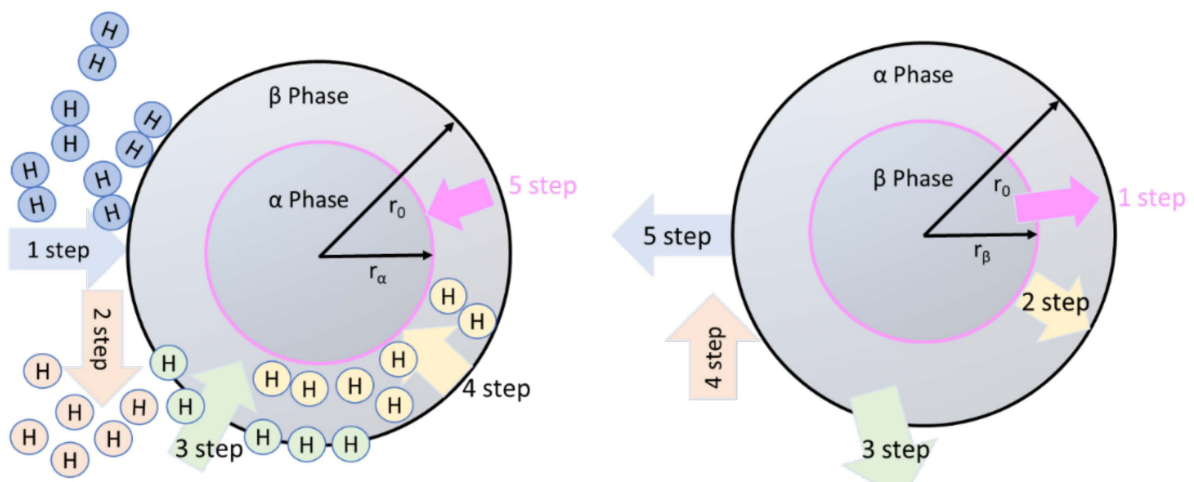

Figure 3. Hydrogen absorption steps (left) and desorption (right) by a metal/hydride.

In the case of absorption, hydrogen gas is absorbed by the solid material by following these steps [15,39]:

(1). Physisorption;

(2). Chemisorption;

(3). Surface penetration;

(4). Diffusion through hydride layer to the metal/hydride interface;

(5). Formation of hydride at interface of metal hydride.

In the case of desorption, reverse steps are followed as shown in Figure 3 (right) after chemical reaction. These steps are as follows:

(1). Hydride decomposition;

(2). Diffusion of hydrogen atom through metal;

(3). Surface penetration;

(4). Recombination of hydrogen atom into molecule;

(5). Desorption to the gas phase.

These steps indicate that in the desorption process, hydrogen diffuses through the metal phase and the diffusion coefficient is higher than that of the hydride phase (ab- 
sorption case). After that, hydrogen recombines instead of dissociating and in this recombination step, the hydrogen atom does not need to cross any energy barrier. This is the simple reason for why it does not face a high kinetic barrier in dehydrogenation (in comparison to hydrogenation). However, due to the exothermic nature of hydrogenation (such as hydrogen absorption by $\mathrm{Mg}$ ), it is thermodynamically possible. To understand the hydrogenation steps, let us take an example of $\mathrm{MgH}_{2} . \mathrm{Mg}$ absorbs hydrogen by simply following the equation and the model shown in Figure 4 [40]:

$$
\mathrm{Mg}+\mathrm{H}_{2} \Leftrightarrow \mathrm{MgH}_{2}
$$

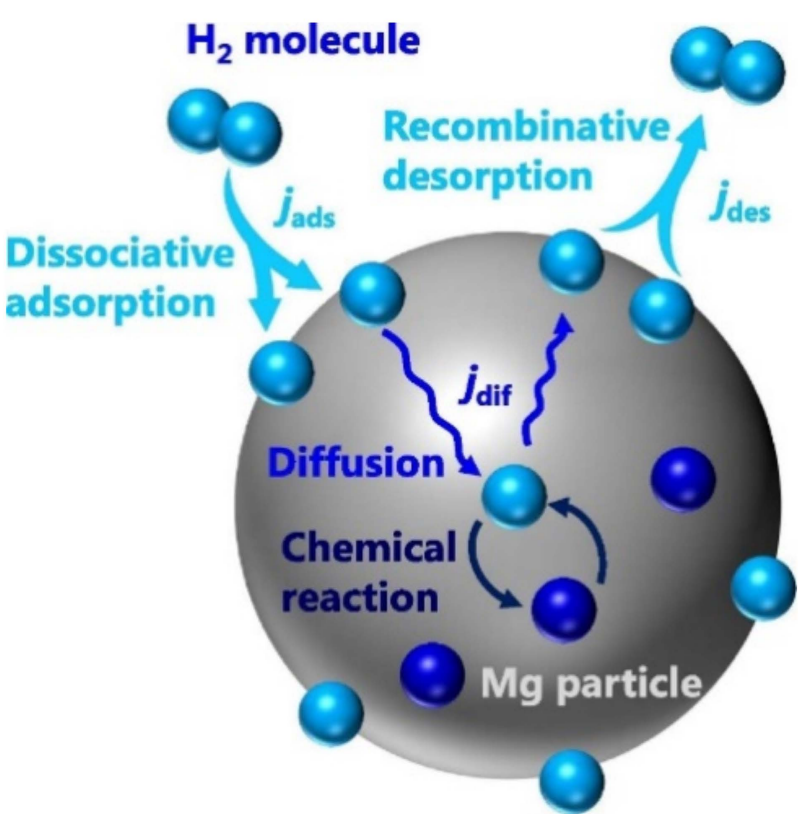

Figure 4. Conceptual schematic of our hydrogen-dynamic model. $j_{\text {ads }}, j_{\text {des }}$, and $j_{\text {dif }}$ denote the fluxes of hydrogen dissociative adsorption, recombinative desorption and diffusion, respectively [40]. (Reprinted with permission from Elsevier).

Dissociation of the hydrogen molecule into the hydrogen atom in the absorption process and recombination in the case of desorption are the first steps of hydrogen $\mathrm{ab} /$ desorption by $\mathrm{Mg}$. The second step is the transportation between the surface and bulk regions/surface penetration of magnesium metal. It follows with the diffusion in the bulk of magnesium as the third step and then the fourth step is hydriding and dehydriding reactions, becoming $\mathrm{MgH}_{2} / \mathrm{Mg}$. The rate-limiting step is the one with the largest energy barrier between the dissociation and diffusion and could be any of them. Physisorption of $\mathrm{H}_{2}$ molecule onto the metal surface only requires a small amount of activation energy and consequently it is not often considered as the rate-limiting step. For hydrogen absorption, steps 2, 3, 4 and 5 could be rate-limiting steps and thus will be elucidated here. Physisorption (step 1) is usually a fast process and hence it is not a rate-limiting step. However, concentration of hydrogen is an important parameter which affects the metal surface and is directly proportional to the applied hydrogen pressure. When nucleation plays an important role at the initial stage towards the hydride formation, then steps 3 and 5 could be a rate-limiting step, which happens rarely. In most of the cases, diffusion of hydrogen through the hydride to the interface with the metallic phase is a rate-limiting step. Similar steps can be considered as rate-limiting steps for hydrogen dehydrogenation, such as steps 1, 2 and 3 (see Figure 3 (right)) [14,41]. There is a phenomenon called "hydrogen spillover" that also happens on the surface of metal while hydrogen dissociates into atom and tries to insert itself into bulk from the catalyzed surface. During this process, some barriers still exist to stop or slow down the process of hydrogen migration to bulk, thus realizing the hydrogen spillover effect. However, it is often difficult to analyze such effects 
easily. Many people used spillover agents (carbonaceous allotropes, activated carbon and carbon nanotubes) to improve the kinetics due to spillover effect [42-44]. Efrat Ruse et al. investigated the $\mathrm{Mg}$ de/hydriding kinetics by using a spillover catalyst and found that nanometric $\mathrm{Pd} / \mathrm{CNT}$ was superior to microsized $\mathrm{Pd} / \mathrm{AC}$ for accelerating Mg de/hydriding kinetics [42]. So, how should one decide which element or catalyst should be added to improve the kinetics of hydrogen de/absorption materials? It is still a difficult question, which motivates researchers to develop more catalysts. To design the optimum catalyst, Sabatier explained that the absorption energy or bonding between catalyst and adsorbed gas (hydrogen) should have an intermediate strength that is neither too strong nor too weak [45]. This leads to a volcano plot between rate and bond strength as illustrated in Figure 5.

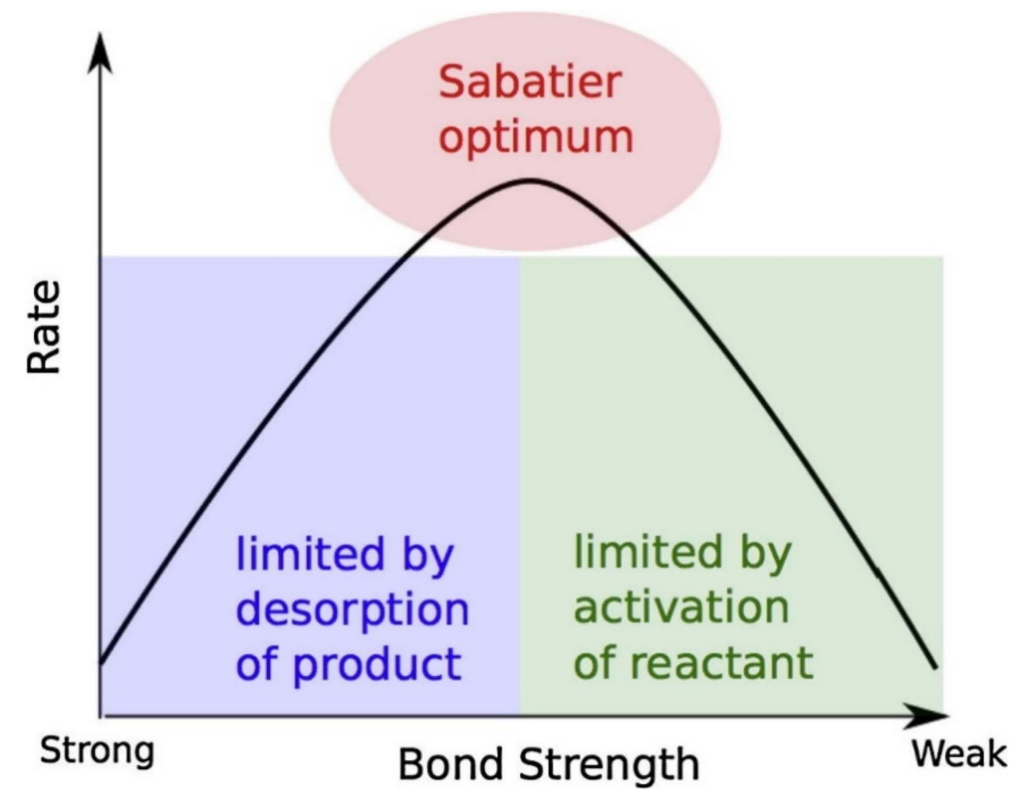

Figure 5. Schematic representation of the qualitative Sabatier principle [45]. (Reprinted with permission from Springer).

Sergio Trasatti proved such a volcano plot for hydrogen evolution reaction experimentally (see Equation (5)), i.e., the M-H bond strength is directly related to the rate of electrolytic evolution of hydrogen (see Figure 6) [46].

$$
\mathrm{H}^{+}+\mathrm{e}^{-} \rightarrow \mathrm{H}_{2}
$$

Such a model could help to design more effective catalysts and it has been investigated by many researchers $[47,48]$. However, experimental evidence showed the reverse of the volcano plot in the case of $\mathrm{Mg}$ hydride for hydrogen storage due to several reasons. These include the formation of intermediate magnesium/catalyst phases [49,50], and transportation of atomic hydrogen to the $\mathrm{Mg}$ phase by intermediate catalytic phase [51,52] or restricting hydrogen diffusion elsewhere from the catalytic site. Pozzo et al. [53] proposed an inverse volcano plot (Figure 7), combining the effects of hydrogen dissociation and hydrogen diffusion energy barriers mentioned on the $y$-axis in the figure which is strongly related to the $\mathrm{x}$-axis, i.e., $\mathrm{d}$ band center. From the figure, it could be analyzed that $\mathrm{Ni}$ and $\mathrm{Pd}$ have good catalytic activities but experimentally Ti and V have been found to have good catalytic activity like Ni and Pd [53]. Moreover, we could observe that Ni, Fe and $\mathrm{Rh}$ are sitting near the peak of the inverse volcano plot and have the lowest energy barriers, thus the most active catalyst. Therefore, one still needs to analyze and understand the catalytic behavior to develop the effective catalyst for hydrogen de/absorption. Coming towards the second step of hydrogen de/adsorption, i.e., surface penetration, there is an oxide layer (creating $\mathrm{MgO} / \mathrm{Mg}(\mathrm{OH})_{2}$ ) on the surface of $\mathrm{Mg} / \mathrm{MgH}_{2}$ due to the small traces of $\mathrm{O}_{2} / \mathrm{H}_{2} \mathrm{O}$. However, this oxide layer could be caused to vanish during several cycles or by using the 
efficient catalyst doping. The catalyst could provide active sites to the hydride surface and create a clear path to transport $\mathrm{H}_{2}$ from surface to bulk $\mathrm{Mg} / \mathrm{MgH}_{2}$. The process is usually known as the gateway effect as recently discussed by Biasetti et al. [54]. They mentioned that the combined effect of nanosizing and addition of transition metal (TM) as catalyst could improve the kinetics via gateway effect. TM successfully generates an interface of $\mathrm{Mg} / \mathrm{TM}$ and $\mathrm{MgH}_{2} / \mathrm{TM}$ that could act as a gateway or spillover mechanism during the de/hydrogenation reactions for $\mathrm{Mg} / \mathrm{MgH}_{2}[55,56]$. Addition of catalyst is not only helpful in providing the path to allow $\mathrm{H}_{2}$ to penetrate into the surface but also helps in accelerating the hydrogen rate in the next step. Due to the partial hydride formation layer, the hydrogen diffusion rate becomes slow in the case of $\mathrm{MgH}_{2}$. For de/hydrogenation it is believed that nanosized catalytic components could alter the sluggish kinetics involved in the hydrogen diffusion step. This mechanism is often famed as the "hydrogen pathway" effect. Friedrichs et al. proposed a "pathway model" through $\mathrm{MgH}_{2} / \mathrm{Nb}_{2} \mathrm{O}_{5}$ nanopowder system by lowering the oxidation state of $\mathrm{Nb}_{2} \mathrm{O}_{5}$ which could help form a pathway to facilitate hydrogen transportation into the sample [57]. There are two important factors to consider here, reduction in particle size and grain size. The reduction of particle size could reduce the diffusion distance which is helpful to enhance hydrogen absorption. However, reducing the grain size may help to obtain more grain boundaries. A greater number of grain boundaries itself could act as a pathway to transport hydrogen, which directly helps to control the slow process of diffusion and enhance the rate of reaction [58]. Moving towards the last step of hydrogen absorption, i.e., nucleation and growth of $\mathrm{MgH}_{2}$ phase, it is still not clear if this is a rate-controlling step or not. Many studies have strongly recommended Johnson-Mehl-Avrami-Kolmogorov (JMAK), which is a suitable nucleation and growth model for many catalyzed $\mathrm{MgH}_{2}$ systems [59,60]. Other diffusion models include "Jander diffusion model" which has been used to fit the kinetics of catalyzed $\mathrm{MgH}_{2}$ systems [41,61,62]. Interestingly, Mooij et al. explained the nucleation and growth mechanisms of nano $\mathrm{MgH}_{2}$ by using the JMAK model and claimed that the absorption and desorption mechanisms are not exactly reverse to each other, i.e., asymmetry exists between desorption and absorption [63]. They showed that the energy barrier for nucleation of $\mathrm{Mg}$ is smaller than that for the nucleation of $\mathrm{MgH}_{2}$.

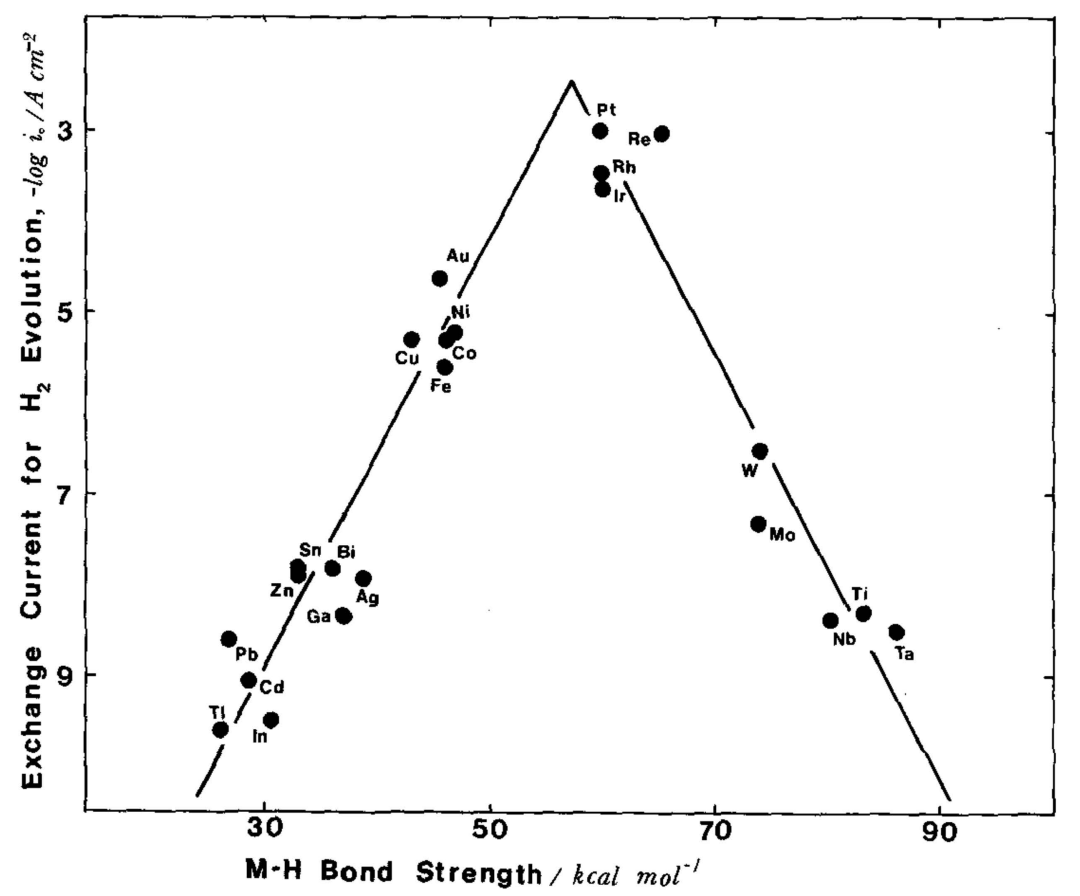

Figure 6. Volcano plot for the hydrogen evolution reaction as a function of the M-H bond strength [46]. (Reprinted with permission from Elsevier). 


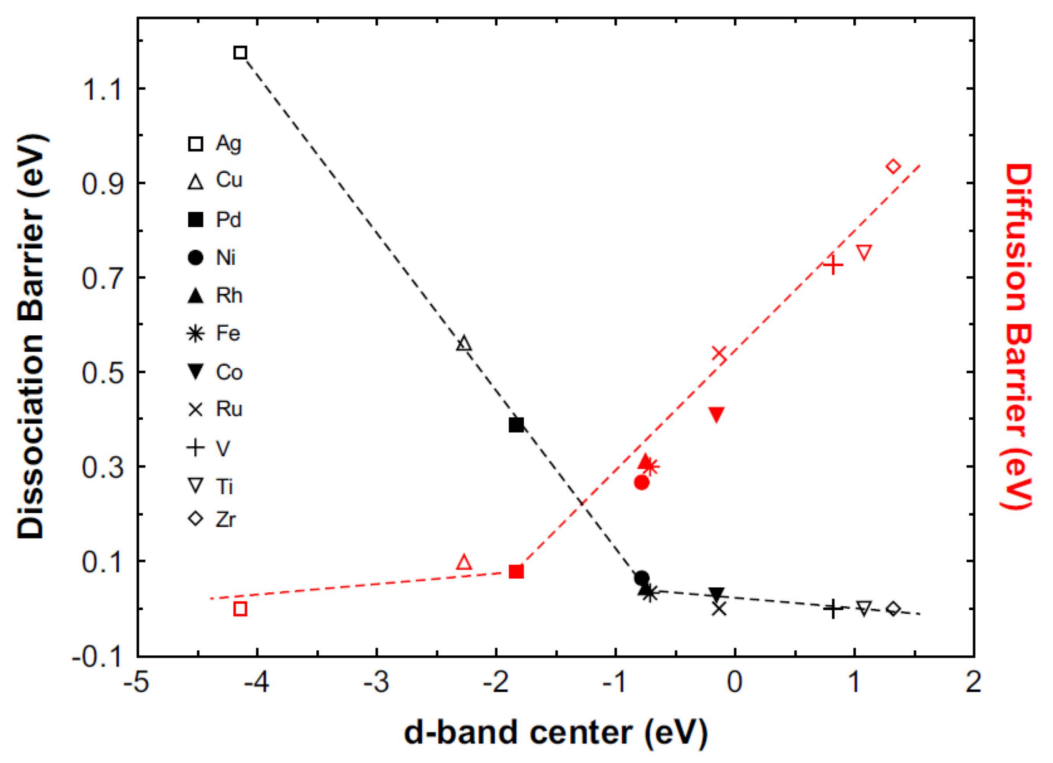

Figure 7. Activation energy barrier for hydrogen dissociation (black) and diffusion (red) of hydrogen on pure $\mathrm{Mg}$ and metal-doped $\mathrm{Mg}$ surfaces as a function of the d-band center positions [53]. (Reprinted with permission from Elsevier).

In summary, it can be understood that improving the hydrogen de/absorption kinetics means reducing the activation barrier involved with the rate-limiting steps. There are many techniques and methods to improve kinetics reported by different groups such as nanoscaling, nanoconfinement, use of catalyst, doping and alloying [24-27,64]. However, in our perspective, alloying is basically a way to alter the thermodynamics of the system and does not affect the kinetics directly. Alloying is one of the best strategies to improve the thermodynamics and to destabilize the hydrogen storage systems $[65,66]$. The remaining two strategies, i.e., nanosizing and use of catalyst, are both effective techniques. However, our focus in this review is on the use of catalyst, especially d-block elements as catalyst to improve the kinetics of metal hydrides. The role of catalyst in reducing the activation barrier can be seen in Figure 8, where the black color curve shows the activation energy for the non-catalyzed sample, which is reduced for the catalyzed sample (shown by the red curve). The next section sheds light on the role of transition metals and their alloys as catalyst for hydrides.

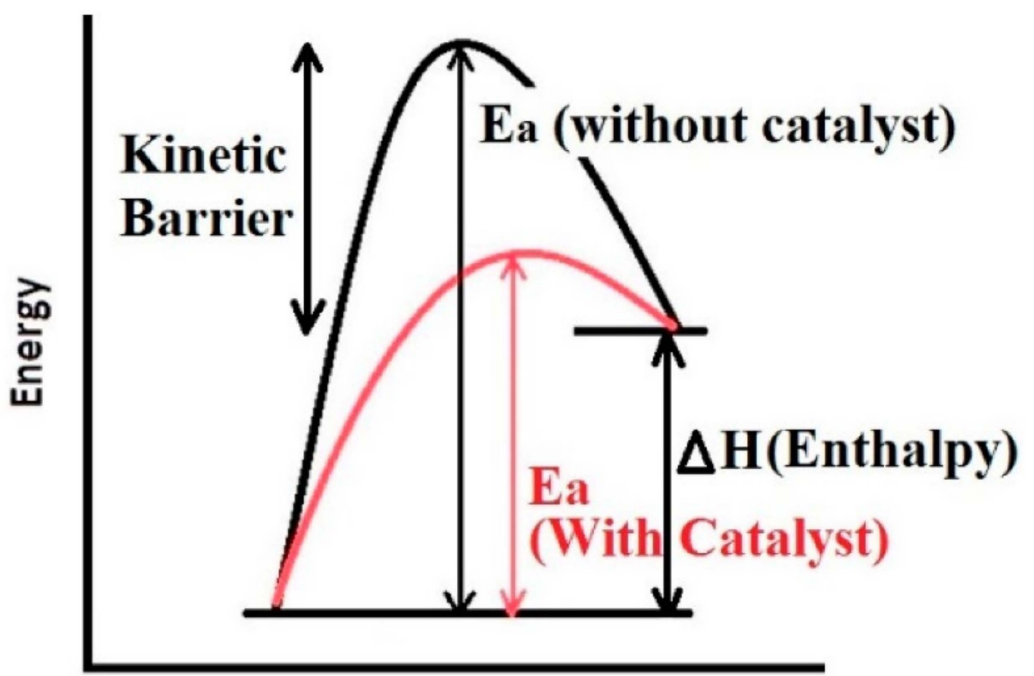

Figure 8. Representation of the kinetic barrier of the reaction and lowering the activation energy (Ea) using catalyst [15]. 


\section{D-block (Transition Metal) Elements as Catalyst}

It is well known that many different materials, alloys, complex hydrides and composites have been used for the purpose of hydrogen storage [11,15,24,26,67-72]. Even if surface oxidation can be fixed by sample activation and other related methods, it takes a long time to desorb/absorb hydrogen by hydride materials and hence this makes it almost impossible for practical usage. Besides, the use of nanosizing technique is also not practical as it is not easy to prepare such small particles when it comes to preparing material in tons. Due to the above reasons, use of catalyst is the most decent choice to enhance the kinetics of these hydrides. Usually d-block elements have the presence of vacant d-orbital, thus they have the ability to exhibit variable valencies [73]. Induced vacancies may help to absorb hydrogen in blank space and release them when needed at certain temperatures and pressures. The d-block elements have a tendency to form complex compounds and have been used in various applications related to energy harvesting, storage and transportation $[73,74]$. In this section, the use of d-block elements and their alloys for improving the kinetics of hydride materials will be reviewed one by one.

\subsection{Transition Unary Metals as Catalyst}

Unary catalyst is the single metal catalyst, and many transition metal unary catalysts show good performance in improving the hydrogen storage properties of $\mathrm{MgH}_{2}$. Transition metals including $\mathrm{Ni}, \mathrm{Ti}, \mathrm{Fe}, \mathrm{Zr}, \mathrm{Nb}, \mathrm{V}, \mathrm{Cr}, \mathrm{Co}, \mathrm{Mo}, \mathrm{Rh}, \mathrm{Pd}, \mathrm{Cu}, \mathrm{Ag}$ and their nano forms have been developed to improve the hydrogen storage properties of $\mathrm{MgH}_{2}$ [53,72,75-88]. In 2005, Haneda et al. mixed Ni nanoparticles as catalyst with $\mathrm{MgH}_{2}$ by adopting a ball milling technique [89]. They confirmed that the desorption peak was found at $270{ }^{\circ} \mathrm{C}$ on addition of Ni nanoparticles into the $\mathrm{MgH}_{2}$ which is much lower than the pure $\mathrm{MgH}_{2}$. Superior catalytic effect of $\mathrm{Ni}$ was confirmed in terms of several parameters such as particle size and amount of catalyst. Later, in 2010, Yang et al. studied the effect of fine Ni particles (90-200 nm) on hydrogen desorption of $\mathrm{MgH}_{2}$ [90]. $\mathrm{MgH}_{2}$ mixed with 2 at\% Ni particles started hydrogen desorption rapidly at $200{ }^{\circ} \mathrm{C}$ and around $6.5 \mathrm{wt} \%$ hydrogen was released up to $340^{\circ} \mathrm{C}$ temperature. In this study, they concluded that site density of the catalyst over the $\mathrm{MgH}_{2}$ particle was the key factor to enhance the efficiency of the catalyst and improve the sorption kinetics of $\mathrm{MgH}_{2}$. Later, Liu et al. also reported their investigation on doping $\mathrm{Ni}$ in $\mathrm{Mg} / \mathrm{MgH}_{2}$ system by synthesizing $\mathrm{Mg}-\mathrm{Ni}$ nanocomposite by the coprecipitation method. According to the results, $\mathrm{Mg}-\mathrm{Ni}$ nanocomposite revealed quite fast hydrogen absorption, $85 \%$ of its maximum capacity was achieved at lower temperature at $125{ }^{\circ} \mathrm{C}$ within $45 \mathrm{~s}$. They also calculated activation energy of Mg-Ni nanocomposite as $57.4 \mathrm{~kJ} / \mathrm{mol}$ $\mathrm{H}_{2}$. It was concluded that the nano size of $\mathrm{Mg}$, formation of gama- $\mathrm{MgH}_{2}$ phase and $\mathrm{Mg}_{2} \mathrm{Ni}$ formation after de/hydrogenation cycles were the main factors to obtain the superior hydrogen sorption properties of Mg-Ni [91]. In 2018, Sun et al. investigated the properties of $\mathrm{Ni}$ nanobelts as catalyst with the aim of improving the hydrogen storage properties of magnesium [92]. Hydrogen was observed to release at $174{ }^{\circ} \mathrm{C}$ temperature and they also calculated activation energy $69.2 \pm 2.5 \mathrm{~kJ} \mathrm{~mol}^{-1} \mathrm{H}_{2}$ which was found to be lower in comparison to the reported values for pure $\mathrm{Mg} / \mathrm{H}_{2}$ reaction. This was considered to be evidence of the catalytic properties of the Ni nanobelts. More recently, Yang et al. put their efforts towards improving the kinetics of $\mathrm{MgH}_{2}$ via doping with a flake Ni nanocatalyst [93]. They claimed $6.7 \mathrm{wt} \%$ of hydrogen release at $300{ }^{\circ} \mathrm{C}$ within $3 \mathrm{~min}$ starting from $180{ }^{\circ} \mathrm{C}$ by $\mathrm{MgH}_{2}+5 \mathrm{wt} \% \mathrm{Ni}$ composites. They also checked the absorption, which was started below $50{ }^{\circ} \mathrm{C}$ after complete dehydrogenation and found that $4.6 \mathrm{wt} \%$ of hydrogen was absorbed by the composite at $125^{\circ} \mathrm{C}$ within $20 \mathrm{~min}$ at $3 \mathrm{MPa}$ hydrogen pressure. They put forth Ni nanoflakes as a catalyst which covered $\mathrm{MgH}_{2}$ and acted as a "hydrogen pump" to accelerate the rates of hydrogen absorption and desorption. Besides $\mathrm{MgH}_{2}$, several other hydrogen storage materials were explored to observe the effect of transition metals on their hydrogen storage properties. In 2015, our group investigated the effect of different nanometals $(\mathrm{Ni}, \mathrm{Co}, \mathrm{Nb})$ as catalyst on the absorption-desorption properties of $\mathrm{KSiH}_{3}$ [78]. Among them, nano $\mathrm{Ni}$ was found to be the most effective catalyst, having minimum 
activation energy $106 \mathrm{~kJ} \mathrm{~mol}^{-1}$ compared with the others. Recently, the effect of Fe was also found to be exciting for the improvement of the sorption properties of $\mathrm{KSiH}_{3}$ [24]. Pozzo et al. verified the superior catalytic properties by DFT calculations of $\mathrm{Ni}$ and $\mathrm{Fe}$ from d-block elements and announced $\mathrm{Ni}$ and $\mathrm{Fe}$ as the most active catalysts [53]. Recently, Gasnier et al. designed a catalyst containing d-block elements combined with N-doped graphene-rich aerogels to improve the sorption kinetics of $\mathrm{LiBH}_{4}$ [94]. Obviously, carbonor graphene-rich components could help to spread nanomaterials homogeneously and to avoid any kind of agglomeration. The presence of metallic nanoparticles such as $\mathrm{Ni}$ and $\mathrm{Co}$ helped to shift desorption at lower temperature. It was mentioned that the presence of $\mathrm{Ni}$ is more favorable (70\%) than the Co (30\%), as Ni could desorb $6.5 \mathrm{wt} \%$ and Co releases $1 \mathrm{wt} \%$ of hydrogen at temperature $325^{\circ} \mathrm{C}$ and $226^{\circ} \mathrm{C}$, respectively. Meng et al. also mentioned that $\mathrm{Ni}$ nanoparticles play a crucial role in lowering the onset temperature (around $180^{\circ} \mathrm{C}$ ) of $\mathrm{LiBH}_{4}$ and reported porous Ni@C derived from bimetallic metal organic frameworks (MOF) catalyst as shown in Figure 9 [95].

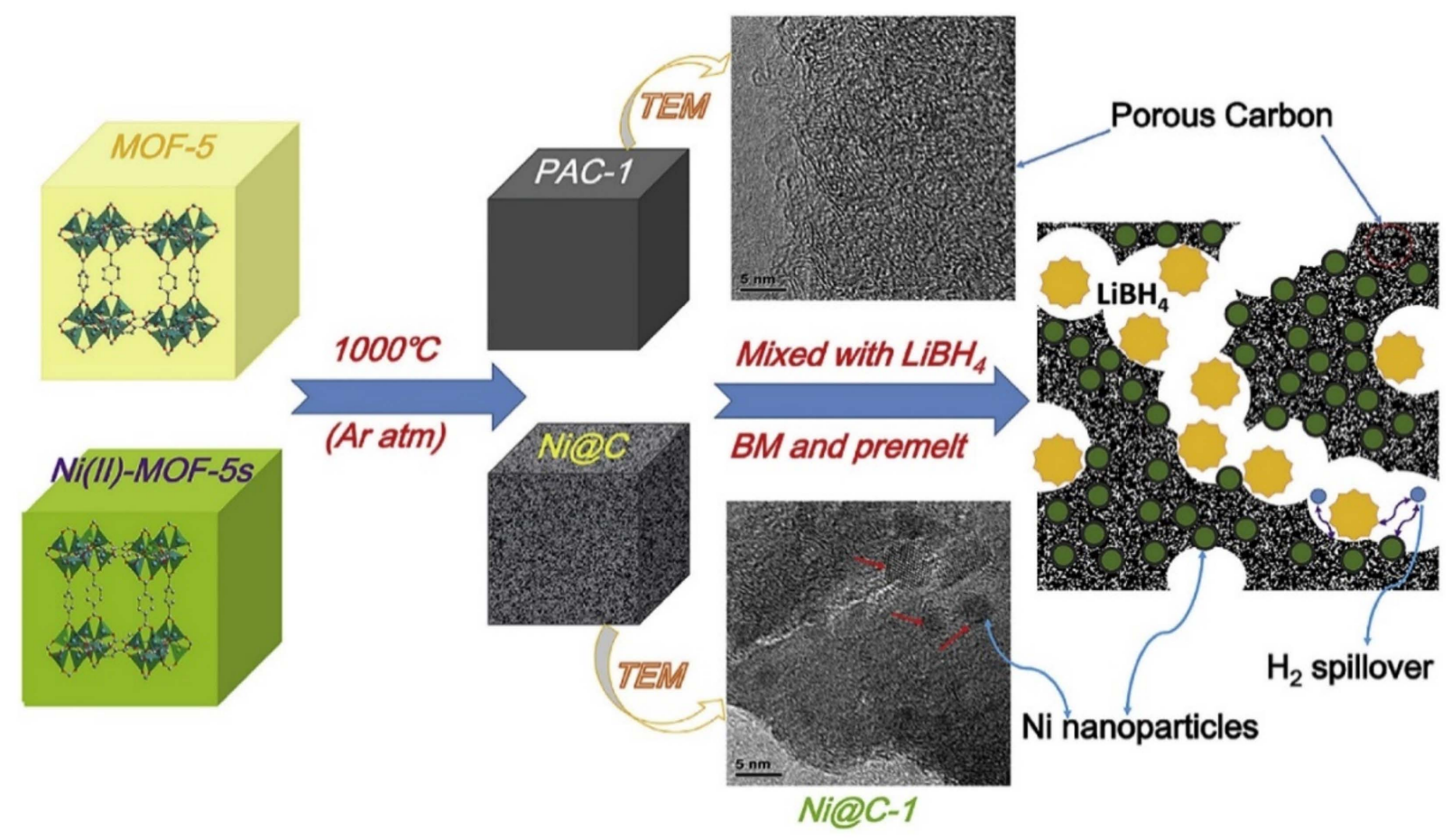

Figure 9. The schematic illustration of the products derived from MOF-5 and Ni(II)-MOF-5s and application in $\mathrm{LiBH}_{4}$ hydrogen release [95]. (Reprinted with permission from Elsevier).

High specific surface area and pore size distribution were found to play the key roles to boost up the kinetics and $11 \mathrm{wt} \% \mathrm{H}_{2}$ was released at $375{ }^{\circ} \mathrm{C}$ by $\mathrm{LiBH}_{4} / \mathrm{Ni} @ \mathrm{C}-1$. Iron $(\mathrm{Fe})$, which is the most common metal element in life, has been broadly exercised for many applications for a long time. In 1999, Zaluska et al. studied the catalytic effect of Pd and Fe on magnesium surface for hydrogen storage [85]. They stated that by using a small amount of catalyst (palladium or iron) the need for activation can be eliminated because the catalyst offsets the negative impact of surface oxidation. They also suggested the use of other catalysts such as $\mathrm{V}$ and $\mathrm{Zr}$ and a mixture of $\mathrm{Mn}$ and $\mathrm{Zr}$ for the improvement of sorption conditions of Mg. In 2012, Montone et al. studied the hydrogenation of $5 \mathrm{wt} \% \mathrm{Fe}$-added $\mathrm{MgH}_{2}$ and doped $\mathrm{MgH}_{2}$ nanocomposite was cycled under maximum hydrogen pressure up to 47 de/absorption cycles at $300{ }^{\circ} \mathrm{C}$ [96]. They concluded that the rate-limiting step was affected during hydrogen de/absorption, due to the morphological and structural growth of the material; however, the maximum storage capacity was mostly unaffected. Recently, Gattia et al. reported reduced activation energy of $\mathrm{MgH}_{2}+5 \mathrm{wt} \%$ Fe sample, which was found to be the main reason for the improvement of the sorption kinetics [97]. In 2020, Antiqueira et al. also 
reported extremely fast kinetics of $\mathrm{MgH}_{2}$ catalyzed by Fe [98]. They claimed that $10 \mathrm{~h}$ and $24 \mathrm{~h}$ nanocomposites showed fast kinetics under mild conditions: $300-350{ }^{\circ} \mathrm{C}$ temperature under 10 bar $\mathrm{H}_{2}$ for absorption and 0.13 bar $\mathrm{H}_{2}$ for desorption. Besides $\mathrm{Ni}$ and $\mathrm{Fe}$, there are many unary metal catalysts such as $\mathrm{Ti}, \mathrm{Nb}, \mathrm{V}, \mathrm{Co}, \mathrm{Mo}$ and $\mathrm{Zr}$ [99]. In 2004, Wang et al. revealed that $\mathrm{NaAlH}_{4}$ endures the kinetics and cycling properties when transition metal, especially $\mathrm{Ti}$, is added as a catalyst to it. The $4 \mathrm{~mol} \%$ Ti-doped $\mathrm{NaAlH}_{4}$ was recharged at $120{ }^{\circ} \mathrm{C}$ under $12 \mathrm{MPa}$ hydrogen within 8-10 h; however, hydrogen capacity faded with the number of increasing cycles and was found as $2.8 \mathrm{wt} \%$ after eight cycles. They investigated and proposed that the improved kinetics was possible due to the localized surface of the catalytic species containing $\mathrm{Ti}$ [100]. Chaudhuri et al. also confirmed that the $\mathrm{Ti}$ atoms and local arrangement of $\mathrm{Ti}$ atoms have an important catalytic role to play in the chemisorption of the molecular hydrogen process [101]. Blomqvist et al. studied the dehydrogenation from 3d-(TM) transition-metals (Sc, Ti, V, Cr, Mn, Fe, Co, $\mathrm{Ni}$ and $\mathrm{Cu}$ )-doped $\mathrm{NaAlH}_{4}$ [102]. They came up with two important findings related to bond length (TM-Al) and binding energy $\left(\mathrm{TM}-\mathrm{NaAlH}_{4}\right)$. The shortening of the TM-Al bond has an impact on lowering the hydrogen binding energy due to the common inclination towards formation of new phase and thus the kinetics is improved in this process. They concluded that the binding energy in TM-doped $\mathrm{NaAlH}_{4}$ was lower than that of undoped $\mathrm{NaAlH}_{4}$. They also suggested that $\mathrm{Fe}$ and $\mathrm{Cr}$ as a catalyst are better than Ti for efficient hydrogen desorption [102]. Huang et al. reported the influence of transition metals (TMs) and reported a significant improvement in this sequence $(\mathrm{Pd}>\mathrm{Co}>\mathrm{Zr}>\mathrm{Ni}>\mathrm{Nb}>\mathrm{Hf}>\mathrm{Ti}>\mathrm{Mn}>\mathrm{Fe}>\mathrm{V}>\mathrm{Cu}>\mathrm{Cr}$ ) on the de/hydriding critical point of $\mathrm{NaAlH}_{4}$ [103]. Moreover, Cui el al. proposed $\mathrm{Mg}-\mathrm{TM}$ core shell nanostructures (where $\mathrm{TM}$ : $\mathrm{Ti}, \mathrm{Nb}, \mathrm{V}, \mathrm{Co}, \mathrm{Mo}$ or $\mathrm{Ni}$ ) prepared by a wet-chemical method [104]. They have reported Mg-TM dehydrogenation curves for all samples below $225{ }^{\circ} \mathrm{C}$ as shown in Figure 10. The reported performance was arranged in higher rank order (superior catalyst) as $\mathrm{Mg}-\mathrm{Ti}>\mathrm{Mg}-\mathrm{Nb}>\mathrm{Mg}-\mathrm{Ni}>\mathrm{Mg}-\mathrm{V}>\mathrm{Mg}-\mathrm{Co}>\mathrm{Mg}-\mathrm{Mo}$. Recently, Dmytro Korablov et al. also proposed $\mathrm{Mg}-25 \% \mathrm{TM}$ (where $\mathrm{TM}=\mathrm{Ti}$, $\mathrm{Nb}$ or $\mathrm{V}$ ) composites and their kinetic studies [105]. They suggested that $0.75 \mathrm{Mg}-0.25 \mathrm{~V}$ composite showed extraordinarily fast kinetics of hydrogen absorption at room temperature as shown in Figure 11. Pd was also reported as a superior catalyst by many researchers [106]. Liu et al. used $\mathrm{Pd}$ nanoparticles with $\mathrm{Mg}$, i.e., $\mathrm{Mg}$-Pd that could absorb up to $3 \mathrm{wt} \%$ hydrogen in $2 \mathrm{~h}$ at the lowest temperature $50{ }^{\circ} \mathrm{C}$ [107]. However, due to the cost of $\mathrm{Pd}$, it is recommended to preferentially design the abundant and cost-effective metal catalyst for the long term. Apart from the hydride/complex hydrides, transition metal (catalyst) mixed metal organic frameworks (TM-MOFs), due to a large specific surface area, are also effective for hydrogen storage application [108-111]. The $\mathrm{Co}, \mathrm{Fe}, \mathrm{Ni}, \mathrm{Cu}, \mathrm{Pd}$ and $\mathrm{Nb}$ metals have been reported as efficient catalysts to improve the catalytic properties of MOFs. Recently, Wang et al. manifested the synergistic and catalytic effect of Mg-TM/ZIF-67 $(\mathrm{TM}=\mathrm{Ni}, \mathrm{Cu}, \mathrm{Pd}, \mathrm{Nb})$ nanocomposites to achieve excellent hydrogen storage properties [87]. The calculated dehydrogenation activation energy was reduced up to $75.8 \mathrm{~kJ} \mathrm{~mol}^{-1} \mathrm{H}_{2}$ for $\mathrm{Mg}-\mathrm{Nb} / \mathrm{ZIF}-67$ nanocomposite and thus $\mathrm{Nb}$ was found to be the most effective catalyst for hydrogen storage performance. It was claimed that the core-shell structure was helpful to suppress the activation barrier of $\mathrm{Mg}$ and blocked the grain growth of the particle. Therefore, this kind of single metal catalyst is also helpful along with the combinatorial designed structure to inhibit the lattice expansion and this could enhance the retention rate of the hydrogen absorption desorption cycle [87]. In summary, it could be understood that different d-block elements are effective due to the above discussed reasons depending on the systems. However costly elements such as Pd should be avoided while designing the efficient catalyst. The interesting and cost-effective elements include $\mathrm{Ni}, \mathrm{Co}, \mathrm{V}, \mathrm{Ti}, \mathrm{Fe}$ and $\mathrm{Nb}$, which were commonly used as the unary catalyst to enhance the sluggish kinetics of various hydrogen storage systems. 

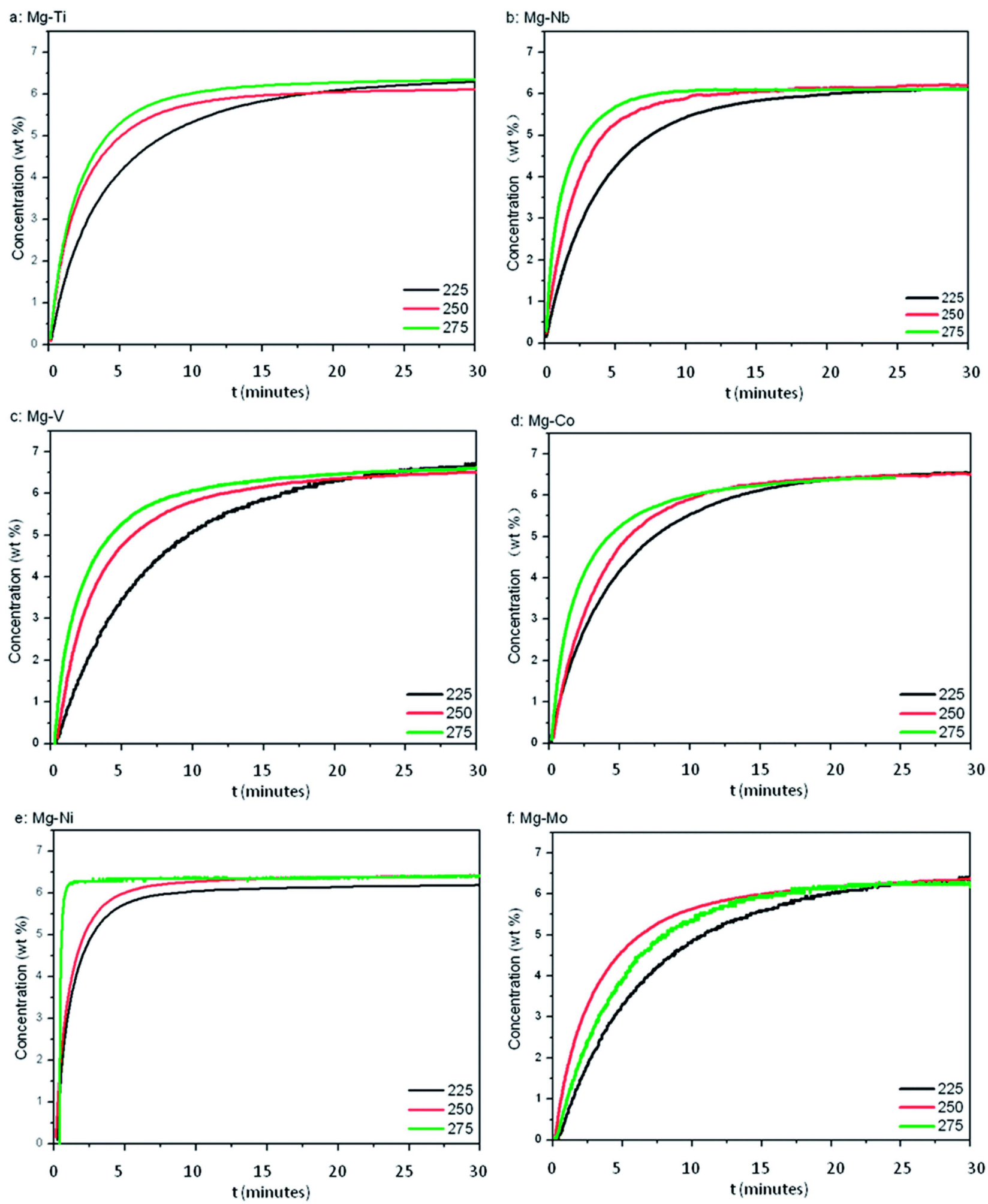

Figure 10. Isothermal hydrogenation curves of $\mathrm{Mg}-\mathrm{TM}$ samples at 225,250 and $275{ }^{\circ} \mathrm{C}$. (a) $\mathrm{Mg}-\mathrm{Ti} ;(\mathbf{b}) \mathrm{Mg}-\mathrm{Nb}$; (c) $\mathrm{Mg}-\mathrm{V}$; (d) Mg-Co; (e) Mg-Ni; (f) Mg-Mo [104]. (Reprinted with permission from the Royal Society of Chemistry). 


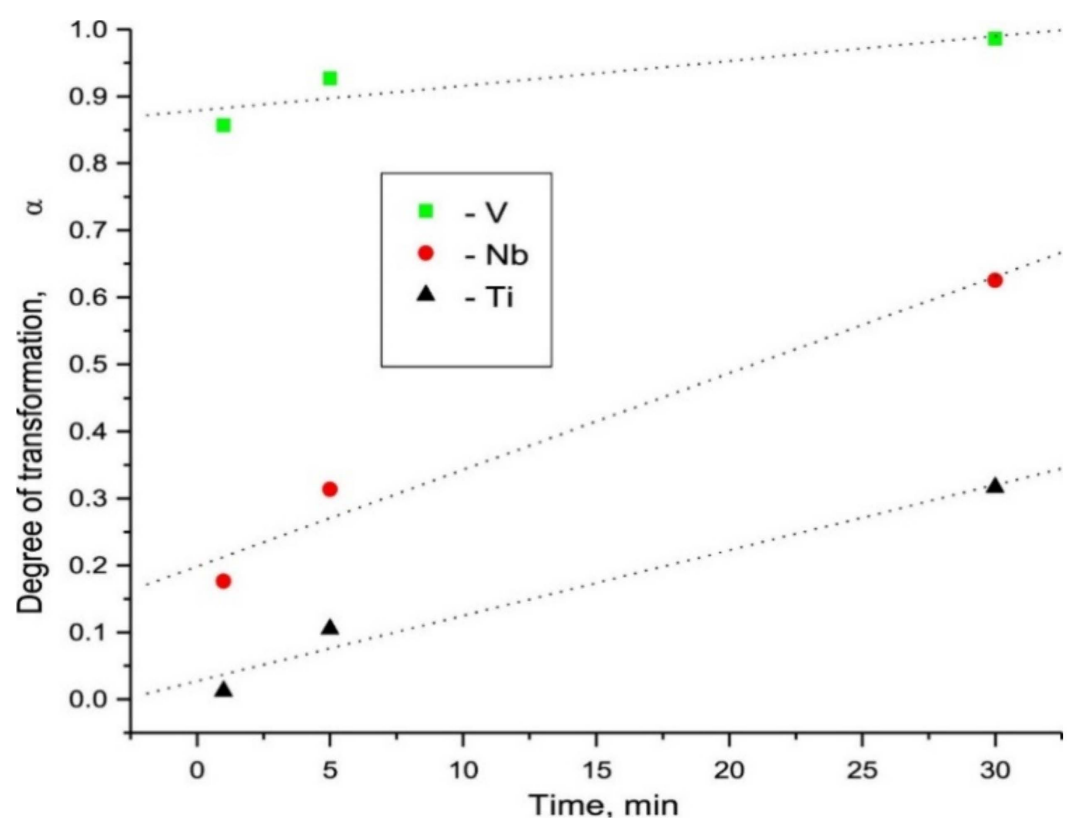

Figure 11. Dependences of the degree of transformation of $\mathrm{Mg}$ into its hydride on hydrogenation time during $\mathrm{RT}$ absorption with $\mathrm{Ti}, \mathrm{Nb}$ or $\mathrm{V}$ additives [105]. (Reprinted with permission from Elsevier).

\subsection{D-block Binary Metal Catalyst (Metal-Metal, Metal Oxides, Metal Halides, etc.)}

Transition metals are good catalysts, not only in their elemental form, but also in compound form. Several compounds such as metal oxides, halides and carbides have been used to improve the sorption kinetics of almost all the families of hydrides, which will be reviewed in this section. Recently, several reports have been published seeking to improve the hydrogen sorption properties of $\mathrm{MgH}_{2}$ by using binary transition metals as catalysts such as $\mathrm{NiCu}$ [112], $\mathrm{ZrH}_{2}$ [113], $\mathrm{HfCl}_{4}$ [114], $\mathrm{Nb}_{2} \mathrm{O}_{5}$ [115], [116], $\mathrm{Mn}_{3} \mathrm{O}_{4}$ [117], $\mathrm{FeCo}$ [118], $\mathrm{TiO}_{2}$ [119], $\mathrm{Ti}_{3} \mathrm{C}_{2}$ [120], $\mathrm{FeCl}_{3}$ [121], $\mathrm{Nb}$ (V) ethoxide [122], $\mathrm{ZrCo}$ [123], $\mathrm{Fe}_{2} \mathrm{O}_{3}$ [124], $\mathrm{YH}_{2}$ [125], $\mathrm{TiH}_{2}$ [54] and many more. Zhang et al. used NiCu catalyst with different molar ratios and found that among them $5 \mathrm{~h}$ milled $\mathrm{MgH}_{2} / \mathrm{Ni}-50 \% \mathrm{Cu}$ system desorbed hydrogen at $205.8^{\circ} \mathrm{C}$, which is $96.9^{\circ} \mathrm{C}$ lower than the pure $\mathrm{MgH}_{2}$ as shown in Figure 12 [112]. Many researchers predicted the effect of these transition metal catalysts by theoretical calculations in order to support and find the possible reason for such improvements observed in experimental studies. Zhang et al. proposed that $10 \mathrm{wt} \% \mathrm{ZrCo}$-nanosheets-added $\mathrm{MgH}_{2}$ could desorb around $6.3 \mathrm{wt} \% \mathrm{H}_{2}$ within $5 \mathrm{~min}$ at $300{ }^{\circ} \mathrm{C}$ and absorb $4.4 \mathrm{wt} \% \mathrm{H}_{2}$ under $3 \mathrm{MPa}$ hydrogen pressure in $10 \mathrm{~min}$ even at $120^{\circ} \mathrm{C}$ [123]. Theoretical calculations performed for this study revealed the stable adsorption configurations of $\mathrm{MgH}_{2}$ molecule on $\mathrm{ZrCo}$ (110) surface. They concluded that the ss orbital overlap of $\mathrm{Mg}$ and $\mathrm{H}$ bond was weakened, which was suggested to be a boon for enhancing the sorption kinetics of $\mathrm{MgH}_{2}$ (see Figure 13). Chen et al. proposed and confirmed by experimental means as well as DFT calculations that $\mathrm{ZrH}_{2}$ nanocatalyst homogeneously spread on the surface of $\mathrm{MgH}_{2}$ (see Figure 14), which exhibited fast kinetics due to the lattice distortion between $\mathrm{ZrH}_{2}$ and $\mathrm{MgH}_{2} / \mathrm{Mg}$ phases [113]. They claimed that $\mathrm{ZrH}_{2}-\mathrm{MgH}_{2}$ was able to absorb $5.90 \mathrm{wt} \%$ hydrogen at $65{ }^{\circ} \mathrm{C}$ under 65 bar $\mathrm{H}_{2}$ back pressure within $100 \mathrm{~min}$. Rehydrogenation pressure was decreased down to 6 bars; however, $\mathrm{ZrH}_{2}-\mathrm{MgH}_{2}$ could still absorb $3.96 \mathrm{wt} \%$ hydrogen at $65{ }^{\circ} \mathrm{C}$ within $120 \mathrm{~min}$, which confirms the excellent hydrogen absorption properties of catalyzed $\mathrm{MgH}_{2}$. Iron and Co mixed binary catalysts in the form of nanosheets were investigated for their catalytic effectiveness and sorption properties of catalyzed $\mathrm{MgH}_{2}$ system by Yang et al. [118]. The nanocatalyst FeCo with $\mathrm{MgH}_{2}$ desorbed $6 \mathrm{wt} \%$ hydrogen within $9.5 \mathrm{~min}$ at $300{ }^{\circ} \mathrm{C}$. In the case of absorption, $\mathrm{FeCo}-\mathrm{MgH}_{2}$ started taking up hydrogen at room temperature and absorbed a total $5.4 \mathrm{wt} \%$ hydrogen while heating up to $200{ }^{\circ} \mathrm{C}$ temperature. They found reduced activation energies for dehydrogenation 
$\left(65.3 \pm 4.7 \mathrm{~kJ} \mathrm{~mol}^{-1}\right)$ and rehydrogenation $\left(53.4 \pm 1.0 \mathrm{~kJ} \mathrm{~mol}^{-1}\right)$ for this system. In 2014, Cai et al. mentioned the benefits of combining d-block element Co (electron-rich) with boron (electron-deficient) and used this combination to catalyze $\mathrm{LiBH}_{4}$ [125]. The electronic structure of $\mathrm{CoB}$, its morphology and specific surface area have been suggested to play the main role in improving the sorption properties of $\mathrm{LiBH}_{4}$ (see Figure 15). The best kinetics was shown by the mulberry-like CoB-catalyzed $\mathrm{LiBH}_{4}$, which desorbed $10.4 \mathrm{wt} \%$ hydrogen within $1 \mathrm{~h}$ at $350^{\circ} \mathrm{C}$. Many halides and oxides were also investigated as efficient catalysts. Iron chloride was considered to be an excellent catalyst for $\mathrm{MgH}_{2}$ and reduced desorption temperature up to $90^{\circ} \mathrm{C}$ lower than the pure $\mathrm{MgH}_{2}$. M. Ismail [121] reported $10 \mathrm{wt} \% \mathrm{FeCl}_{3}$-doped $\mathrm{MgH}_{2}$ system which displayed a faster dehydrogenation rate than the pristine $\mathrm{MgH}_{2}$. Iron oxides $\left(\mathrm{Fe}_{2} \mathrm{O}_{3}\right)$ were found capable of increasing the rate of hydrogen absorption and desorption of $\mathrm{MgH}_{2}$. Song et al. [124] demonstrated the increased rate of hydrogen charging and discharging by the addition of $\mathrm{Fe}_{2} \mathrm{O}_{3}$ catalyst to $\mathrm{Mg}\left(\mathrm{MgH}_{2}\right.$-forming mechanical milling). They also confirmed that the chemisorption of hydrogen molecule was the rate-determining step in the case of charging of $\mathrm{Mg}-10 \mathrm{Fe}_{2} \mathrm{O}_{3}$. Apart from these, $\mathrm{Nb}_{2} \mathrm{O}_{5}$ has secured its own place, being an excellent catalyst for many hydrogen storage systems. Recently, $\mathrm{Gi}$ et al. shed light on the effective factors of $\mathrm{Nb}_{2} \mathrm{O}_{5}$ catalyst for $\mathrm{Mg}$ [116]. It was revealed that metastable amorphous $\mathrm{Nb}_{2} \mathrm{O}_{5}$ was easily converted to the reduced state and could provide more catalytic active sites for the reaction. Later, Zhang et al. also demonstrated synthesis of $\mathrm{Nb}_{2} \mathrm{O}_{5}$ hollow spheres $\left(\mathrm{o}-\mathrm{Nb}_{2} \mathrm{O}_{5}\right)$ and showed high catalytic activity on $\mathrm{MgH}_{2}$ for hydrogen storage application [115]. The enhanced catalytic activity could be seen by fast hydrogen desorption, i.e., a total $5.5 \mathrm{wt} \%$ within $5 \mathrm{~min}$ at $300{ }^{\circ} \mathrm{C}$. Rafi-ud-din et al. reported $\mathrm{Nb}_{2} \mathrm{O}_{5}, \mathrm{TiO}_{2}$ and $\mathrm{Cr}_{2} \mathrm{O}_{3}$ nanoparticles as catalyst to improve the hydrogen sorption properties of $\mathrm{NaAlH}_{4}$ [126]. Among them, $\mathrm{Cr}_{2} \mathrm{O}_{3}$ was not found to be that much more effective in terms of enhancing dehydriding/rehydriding kinetics and reducing the dehydrogenation temperature; however, the other two oxide-added systems showed kinetic improvement, i.e., $5 \mathrm{~mol} \% \mathrm{TiO}_{2}$-mixed $\mathrm{NaAlH}_{4}$ (onset desorption temperature $100{ }^{\circ} \mathrm{C}$ ) and $5 \mathrm{~mol} \% \mathrm{Nb}_{2} \mathrm{O}_{5}$-added $\mathrm{NaAlH}_{4}$ (onset desorption temperature $80^{\circ} \mathrm{C}$ ). It was explained that $\mathrm{Cr}_{2} \mathrm{O}_{3}$ acted as a surface catalyst and stayed stable in the agglomerated form during the milling and cycling process as well; thus, it was shown to have very limited catalytic activity. On the other hand, hydrogen cycling has confirmed the reduction of $\mathrm{TiO}_{2}$ and $\mathrm{Nb}_{2} \mathrm{O}_{5}$, which promoted the formation of the oxygen-deficient reduced niobium and titanium oxide species. These oxygen-deficient reduced species contributed to enhancing the kinetics by facilitating the diffusion of hydrogen through the barriers during de/hydrogenation [126]. The catalytic enhancement by $\mathrm{Nb}_{2} \mathrm{O}_{5}$ and $\mathrm{TiO}_{2}$ was also attributed to their reduced particle size with high dispersion. In 2016, Khan et al. also studied $\mathrm{Nb}_{2} \mathrm{O}_{5}$-doped $\mathrm{NaAlH}_{4}$ and found the reduced desorption temperature ranging from $285^{\circ} \mathrm{C}$ (pure $\mathrm{NaAlH}_{4}$ ) to $250^{\circ} \mathrm{C}$ for doped $\mathrm{NaAlH}_{4}$ [127]. They mentioned the four regions of the cycle at $100{ }^{\circ} \mathrm{C}, 125^{\circ} \mathrm{C}, 150{ }^{\circ} \mathrm{C}$ and $175^{\circ} \mathrm{C}$; the amount of hydrogen desorbed was up to $1.2 \mathrm{wt} \%$. The hydrogen desorption was increased in the second region up to $4.0 \mathrm{wt} \%$ in just $30 \mathrm{~min}$, and within $60 \mathrm{~min}$ a maximum of $4.5 \mathrm{wt} \% \mathrm{H}_{2}$ was released. Rafi-ud-din et al. also reported d-block metal oxides such as $\mathrm{Cr}_{2} \mathrm{O}_{3}$ and $\mathrm{Nb}_{2} \mathrm{O}_{5}$ in which $\mathrm{Nb}_{2} \mathrm{O}_{5}$ was found to be more effective than $\mathrm{Cr}_{2} \mathrm{O}_{3}$ [128]. In addition, $1 \mathrm{~mol} \%$ and $2 \mathrm{~mol} \%$ doped $\mathrm{LiAlH}_{4}$ samples showed lower desorption temperature with little reduction in hydrogen capacity and approx. $6.9 \mathrm{wt} \% \mathrm{H}_{2}$ was released at $193{ }^{\circ} \mathrm{C}$. While talking about oxides, $\mathrm{TiO}_{2}$ cannot be ignored as a superior catalyst to improve the sorption kinetics of metal/complex hydride. In 2011, Ismail et al. reported a significant improvement in kinetics by releasing $5.2 \mathrm{wt} \%$ hydrogen within $30 \mathrm{~min}$ at $100{ }^{\circ} \mathrm{C}$ from $5 \mathrm{wt} \% \mathrm{TiO}_{2}$-mixed $\mathrm{LiAlH}_{4}$ [129]. Activation energy was reduced to $49 \mathrm{~kJ} / \mathrm{mol}$ for $5 \mathrm{wt} \% \mathrm{TiO}_{2}$-added $\mathrm{LiAlH}_{4}$ in comparison to $114 \mathrm{~kJ} / \mathrm{mol}$ for pristine $\mathrm{LiAlH}_{4}$. The improved desorption was achieved by the catalytic properties on the surface of $\mathrm{TiO}_{2}$. Recently, Berezovets et al. reported nano- $\mathrm{TiO}_{2}$ and some other Ti-related catalysts for $\mathrm{Mg}$ [119]. According to them, $5 \mathrm{~mol} \%$ $\mathrm{TiO}_{2}$-added $\mathrm{Mg}$ showed $5.7 \mathrm{wt} \%$ hydrogenation. Desorption was found to occur at a $90{ }^{\circ} \mathrm{C}$ lower temperature than the pure $\mathrm{MgH}_{2}$. In 2017, our group also investigated the effect of 
$\mathrm{TiF}_{4}$ on decomposition of $\mathrm{MgH}_{2}$ and related compounds [130]. We investigated the fact that $10 \mathrm{wt} \% \mathrm{TiF}_{4}$-added $\mathrm{MgH}_{2}$ started desorption around $150{ }^{\circ} \mathrm{C}$ temperature and thus enhanced the sorption kinetics. We also investigated the mechanism of this enhancement using XPS and it was revealed that $\mathrm{Ti}^{4+}$ was reduced to $\mathrm{Ti}^{3+}$ and $\mathrm{Ti}^{2+}$ (lower oxidation state) in this process. Other than Ti-based binary catalysts, $\mathrm{Mn}_{3} \mathrm{O}_{4}$ showed good catalytic activities for $\mathrm{MgH}_{2}$. Zhang et al. stated that by adding $10 \mathrm{wt} \% \mathrm{Mn}_{3} \mathrm{O}_{4}$ nanoparticles, the catalyzed $\mathrm{MgH}_{2}$ started desorbing hydrogen at $200{ }^{\circ} \mathrm{C}$ and approx. $6.8 \mathrm{wt} \% \mathrm{H}_{2}$ was released within $8 \mathrm{~min}$ at $300{ }^{\circ} \mathrm{C}$ [117]. The same group also studied the effect of $\mathrm{ZrMn}_{2}$ nanoparticles on $\mathrm{MgH}_{2}$ and prepared $\mathrm{MgH}_{2}+10 \mathrm{wt} \%$ nano- $\mathrm{ZrMn}_{2}$ composite, which released hydrogen at $181.9^{\circ} \mathrm{C}$ [131]. Moreover, El-Eskandarany et al. [132] claimed $\mathrm{MgH}_{2}$ catalyzed with nano- $\mathrm{LaNi}_{3}$, i.e., $\mathrm{MgH}_{2}-7 \mathrm{wt} \% \mathrm{LaNi}_{3}$ sample, could release $5.6 \mathrm{wt} \% \mathrm{H}_{2}$ within $37 \mathrm{~min}$ at $225^{\circ} \mathrm{C}$. In addition, the $\mathrm{MgH}_{2}-\mathrm{LaNi}_{3}$ sample showed an extremely long cycle-life $(2000 \mathrm{~h})$ at $225^{\circ} \mathrm{C}$ with no degradation of its hydrogen storage capacity. As discussed above, the development of binary transition metal catalysts is quite useful and beneficial to enhance the catalytic effect on the sorption properties of various systems for hydrogen storage.

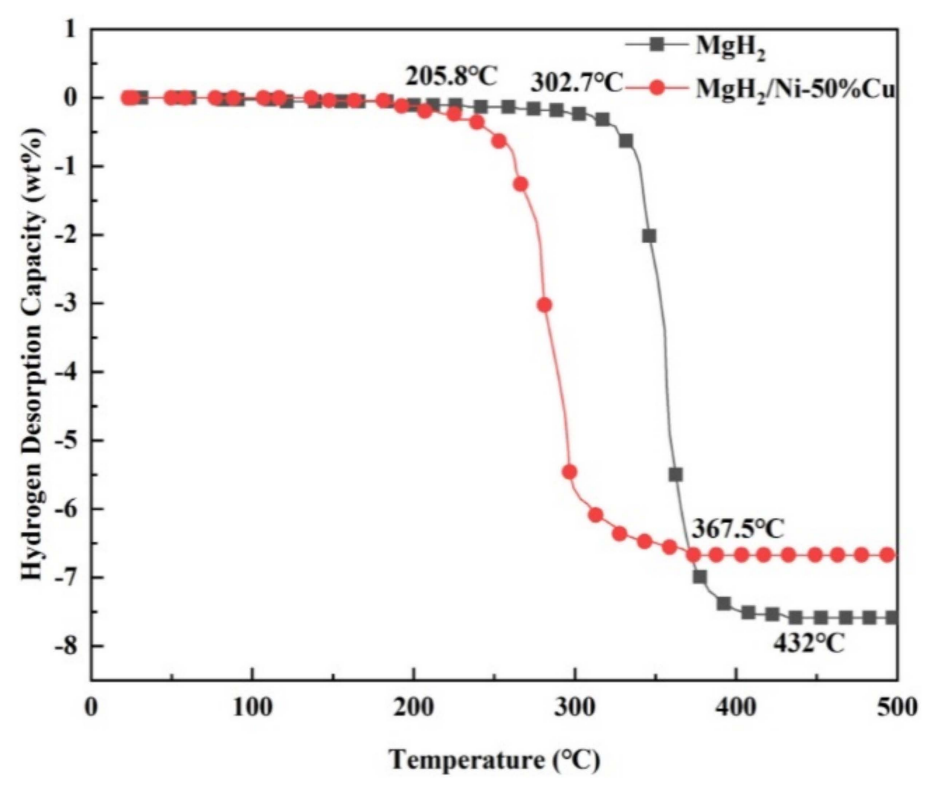

Figure 12. TPD curves of the as-milled $\mathrm{MgH}_{2}$ and $\mathrm{MgH}_{2} / \mathrm{Ni}-50 \% \mathrm{Cu}$ systems with a heating rate of $3^{\circ} \mathrm{C} / \mathrm{min}$ [112]. (Reprinted with permission from Elsevier).

a

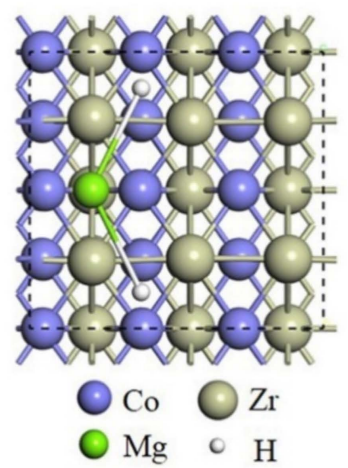

b

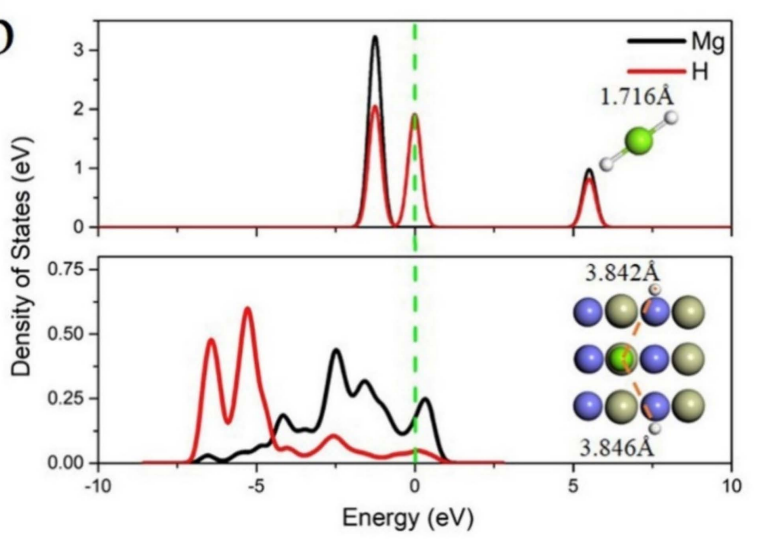

Figure 13. The $\mathrm{MgH}_{2}$ absorption on $\mathrm{ZrCo}$ (110). The adsorption configuration (a) and the corresponding density of states (b) [123]. (Reprinted with permission from Elsevier). 


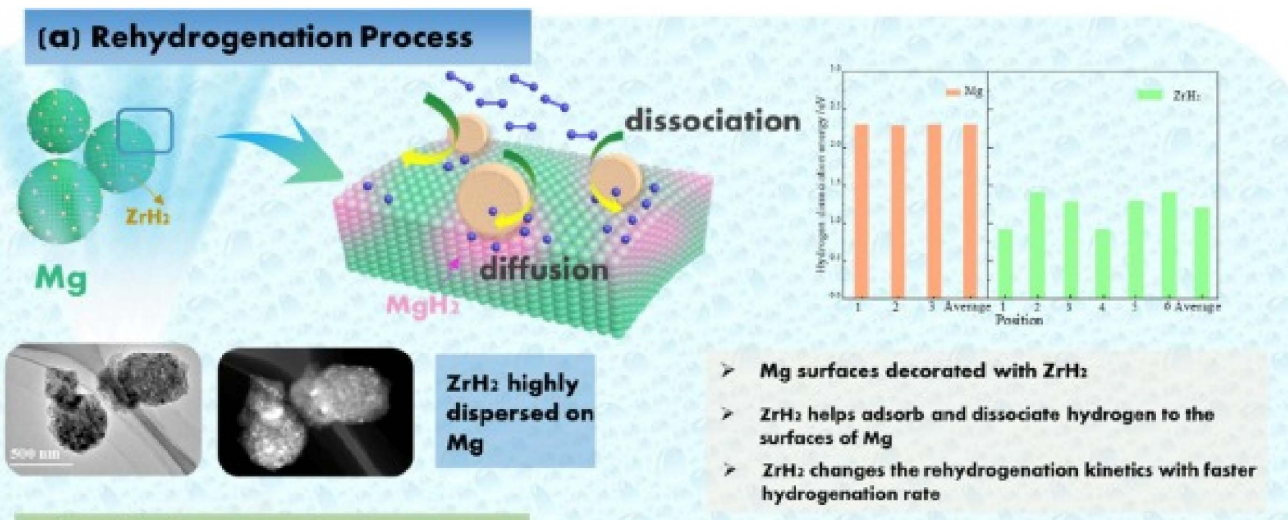

(b) Dehydrogenation Process

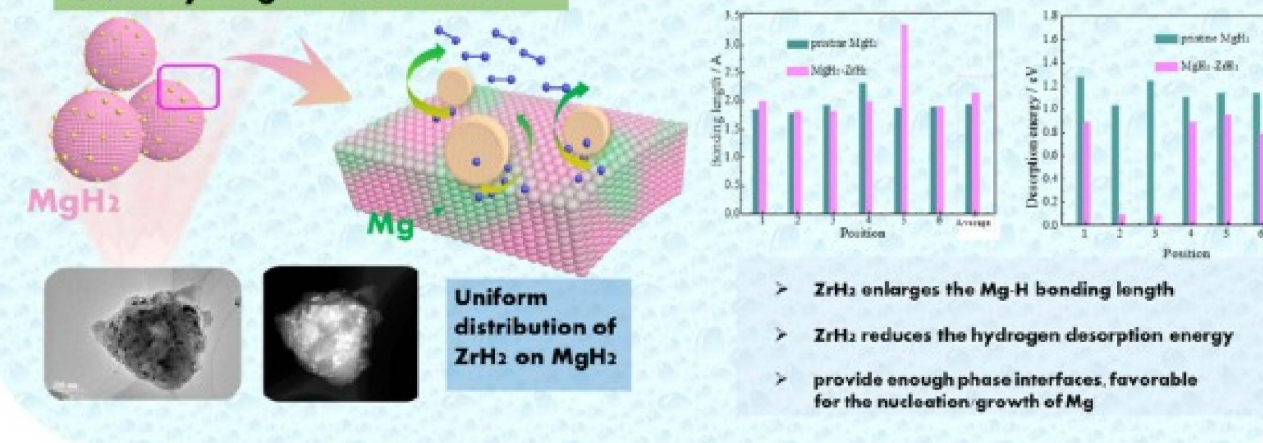

Figure 14. (a) The schematic of the rehydrogenation and (b) dehydrogenation processes of $\mathrm{MgH}_{2}-\mathrm{ZrH}_{2}$ [113]. (Reprinted with permission from Elsevier).

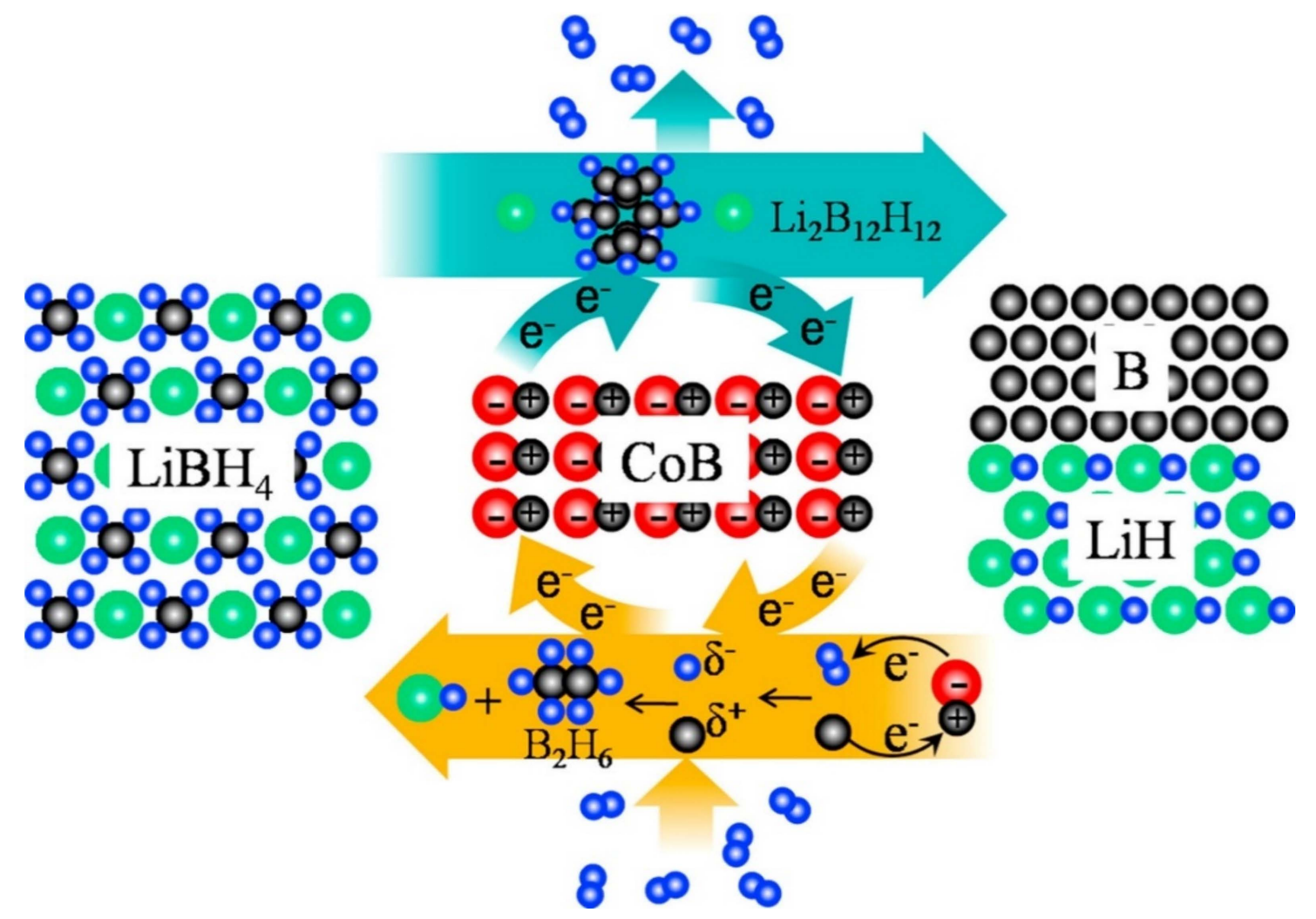

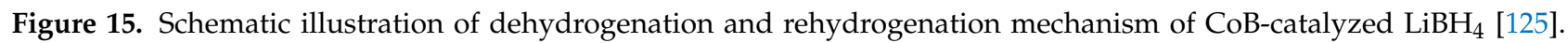
(Reprinted with permission from Elsevier). 


\subsection{D-block Ternary Metal Catalysts and Miscellaneous Catalysts}

After unary and binary metal catalysts, many other combinations such as ternary, quaternary and miscellaneous catalysts in the form of alloys and composites were also developed. In this section, we have focused on the use of such miscellaneous catalysts to improve the sorption kinetics of different hydrogen storage systems. As discussed for the binary metal catalyst system above, the Ti-based catalyst has always fascinated researchers due to its extremely good catalytic activity. Nafiseh Mahmoudi et al. synthesized nanosized particles and grain structures by addition of 5 at $\%\left(\mathrm{TiCr}_{1.2} \mathrm{Fe}_{0.6}\right)$ in $\mathrm{MgH}_{2}$ powder using mechanical milling [133]. The $4 \mathrm{~h}$ mechanically milled catalyzed $\mathrm{MgH}_{2}$ released $4 \mathrm{wt} \%$ hydrogen and reduced the decomposition temperature from $327^{\circ} \mathrm{C}$ to $241^{\circ} \mathrm{C}$. As shown in Figure 16a, Zhou et al. studied a series of Ti-based additives to improve the hydrogen storage properties of $\mathrm{MgH}_{2}$ [134]. A Ti-based ternary catalyst, TiVMn, showed the minimum desorption temperature (see Figure $16 \mathrm{~b}$ ) as $216.7^{\circ} \mathrm{C}$. They emphasized the difference between the dehydrogenation temperature of TiVMn-mixed $\mathrm{MgH}_{2}$ and milled $\mathrm{MgH}_{2}$ which was significant, i.e., approx. $120^{\circ} \mathrm{C}$. Recently, Berezovets et al. [119] reported the effect of Ti-based nanosized additives on the hydrogen storage properties of $\mathrm{MgH}_{2}$. As shown in Figure 17, $\mathrm{Ti}_{4} \mathrm{Fe}_{2} \mathrm{O}_{\mathrm{x}}$ additive has the most significant effect among all. Wang et al. [135] demonstrated the unary $(\mathrm{Ti}, \mathrm{Al}, \mathrm{C})$, binary ( $\mathrm{TiAl}, \mathrm{Ti}_{3} \mathrm{Al}, \mathrm{Ti}_{3} \mathrm{C}_{2}$ ) and ternary $\left(\mathrm{Ti}_{3} \mathrm{AlC}_{2}\right.$ ) catalysts for improving the reversible hydrogen storage properties of $\mathrm{MgH}_{2}$. It was noticed that the ternary $\mathrm{Ti}_{3} \mathrm{AlC}_{2}$ catalyst was better than the other unary catalysts in reducing the desorption temperature of $\mathrm{MgH}_{2}$. As shown in Figure 18, the hydrogen desorption temperature for $\mathrm{Ti}_{3} \mathrm{AlC}_{2}$-catalyst-mixed $\mathrm{MgH}_{2}$ was $250^{\circ} \mathrm{C}$, which was $12-57^{\circ} \mathrm{C}$ lower than those of the $7 \mathrm{wt} \%$ unary and binary catalysts. However, the catalytic effect of ternary $\mathrm{Ti}_{3} \mathrm{AlC}_{2}$ was found to be lower in comparison to $\mathrm{Ti}_{3} \mathrm{C}_{2}$ because of the unique $2 \mathrm{D}$ layered structure of $\mathrm{Ti}_{3} \mathrm{C}_{2}$ which helped it to maintain a large active surface area. Besides Ti-based additives, other catalysts such as NiMnAl [136], $\mathrm{Ni}_{3} \mathrm{FeMn}$ [137], FeCoNi [138], $\mathrm{CuFe}_{2} \mathrm{O}_{4}$ [139], $\mathrm{MgAgZn} \mathrm{[140],} \mathrm{LaFeO}_{3}$ [141], $\mathrm{ZrCrMn} \mathrm{[141],} \mathrm{ZrCrCu}$ [142], $\mathrm{ZrCrM} \mathrm{[143],}$ $\mathrm{ZrCrNi}$ [144], $\mathrm{Zr}_{0.4} \mathrm{Ti}_{0.6} \mathrm{Co}$ [145], $\mathrm{MgNiO}_{2}$ [146] and $\mathrm{SrTiO}_{3}$ [147] have been reported for a long time. We would like to focus on some of the effective ternary catalysts recently used to improve the sorption kinetics of $\mathrm{MgH}_{2}$. Singh et al. [138] developed a ternary catalyst, $\mathrm{FeCoNi}$, supported on graphene to improve the hydrogen sorption properties of $\mathrm{MgH}_{2}$. As can be seen in Figure 19i, they reported the earliest desorption temperature for $\mathrm{MgH}_{2}+5 \mathrm{wt} \% \mathrm{FeCoNi@GS}$ as $100^{\circ} \mathrm{C}, 25^{\circ} \mathrm{C}$ lower than that of milled uncatalyzed (B.M) $\mathrm{MgH}_{2}$ and $\mathrm{FeCoNi}$-catalyzed $\mathrm{MgH}_{2}$, respectively.
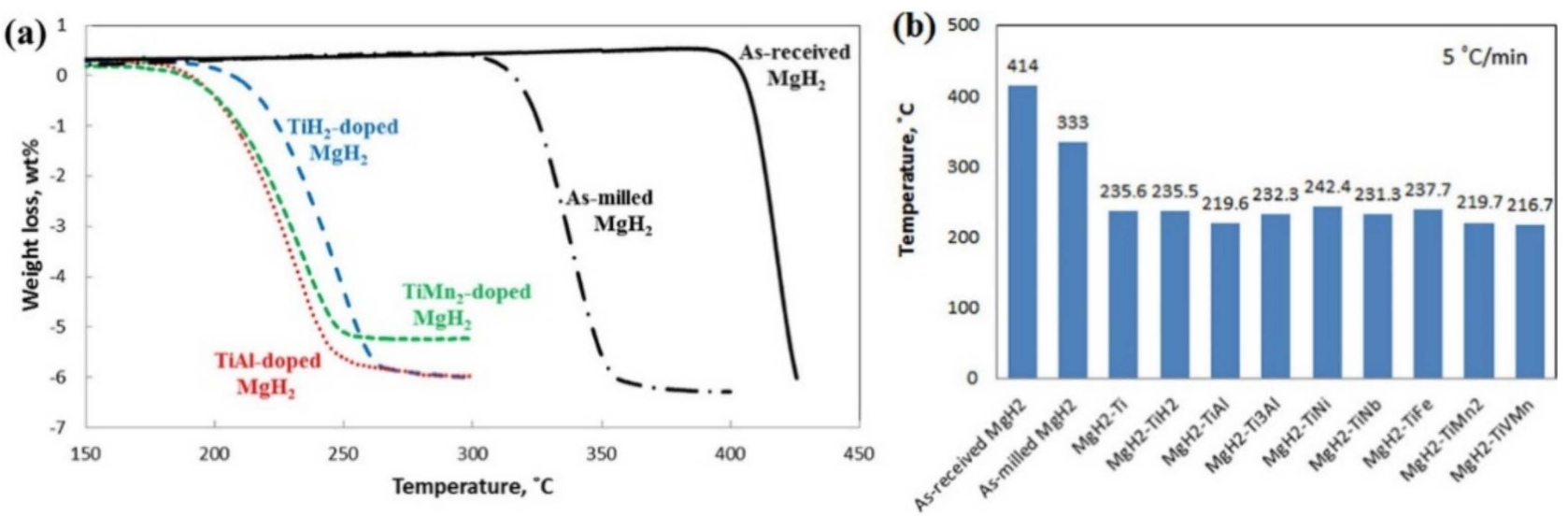

Figure 16. (a) TGA curves of as-received, as-milled, $\mathrm{TiH}_{2}$-doped, $\mathrm{TiMn}_{2}$-doped and $\mathrm{TiAl}$-doped $\mathrm{MgH}_{2}$ systems. (b) Dehydrogenation temperatures of different Ti-based catalyst-doped systems, determined by TGA profiles at fractional conversion $\alpha=0.4$ [134]. (Reprinted with permission from the American Chemical Society). 


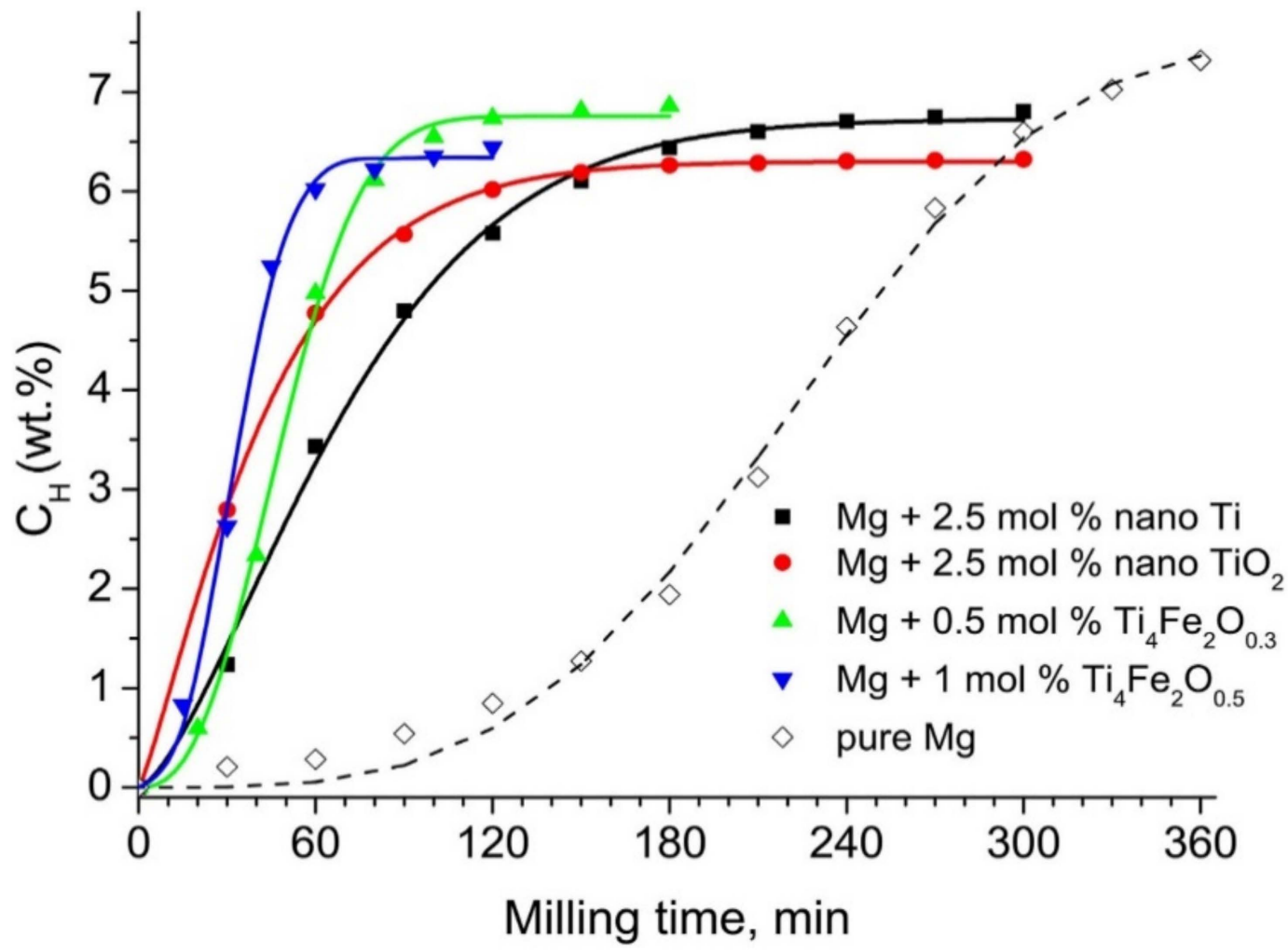

Figure 17. Hydrogen absorption by powder mixtures of $\mathrm{Mg}$ with Ti-based additives during reactive ball milling in hydrogen [119]. (Reprinted with permission from Elsevier).

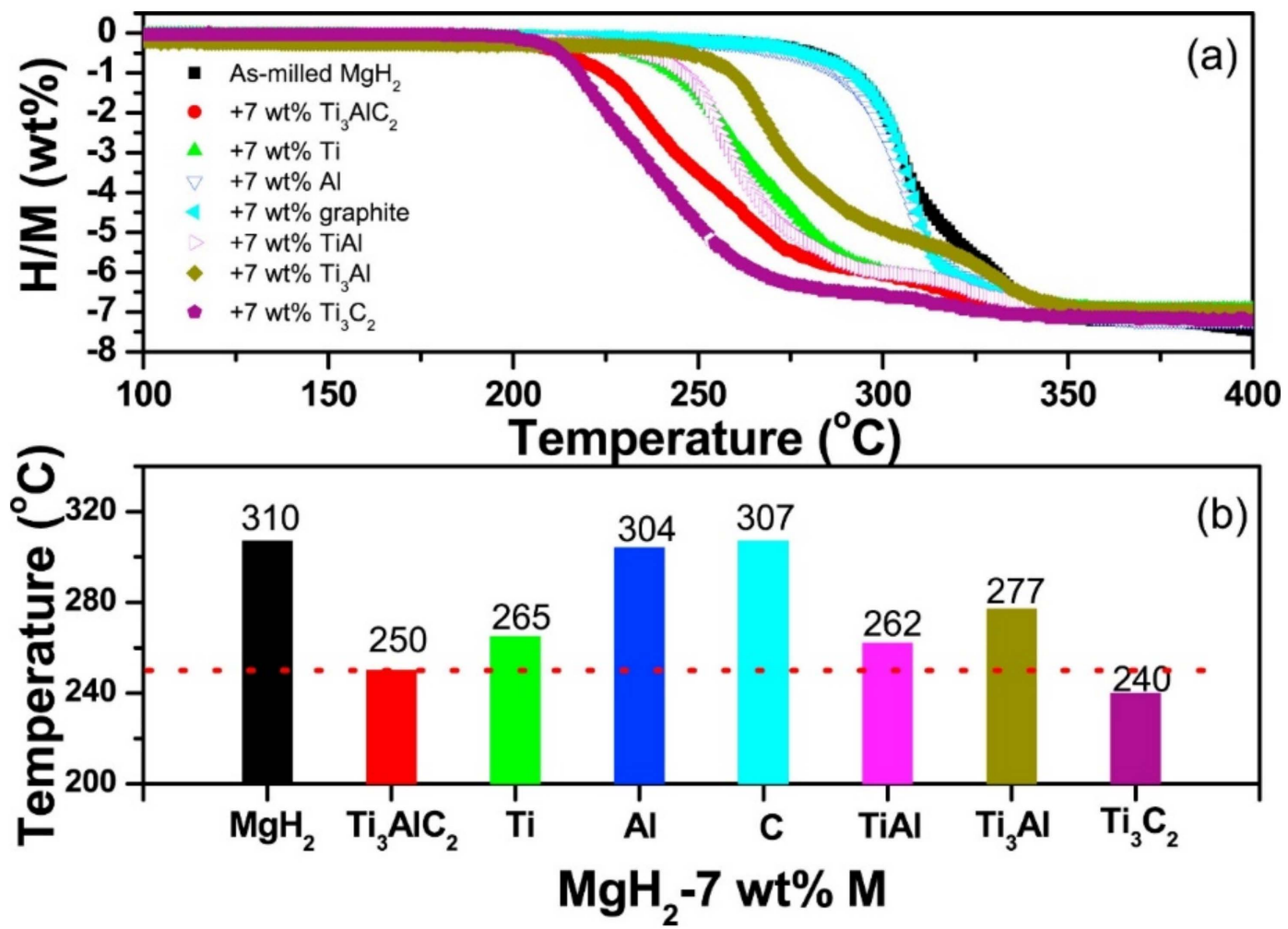

Figure 18. (a) Volumetric release and (b) midpoint dehydrogenation temperature of $\mathrm{MgH}_{2}-7 \mathrm{wt} \% \mathrm{M}\left(\mathrm{M}=\mathrm{Ti}_{3} \mathrm{AlC} 2, \mathrm{Ti}, \mathrm{Al}\right.$, graphite, $\mathrm{Ti}_{3} \mathrm{C}_{2}, \mathrm{TiAl}$ and $\mathrm{Ti}_{3} \mathrm{Al}$ ) composites [135]. (Reprinted with permission from Elsevier). 

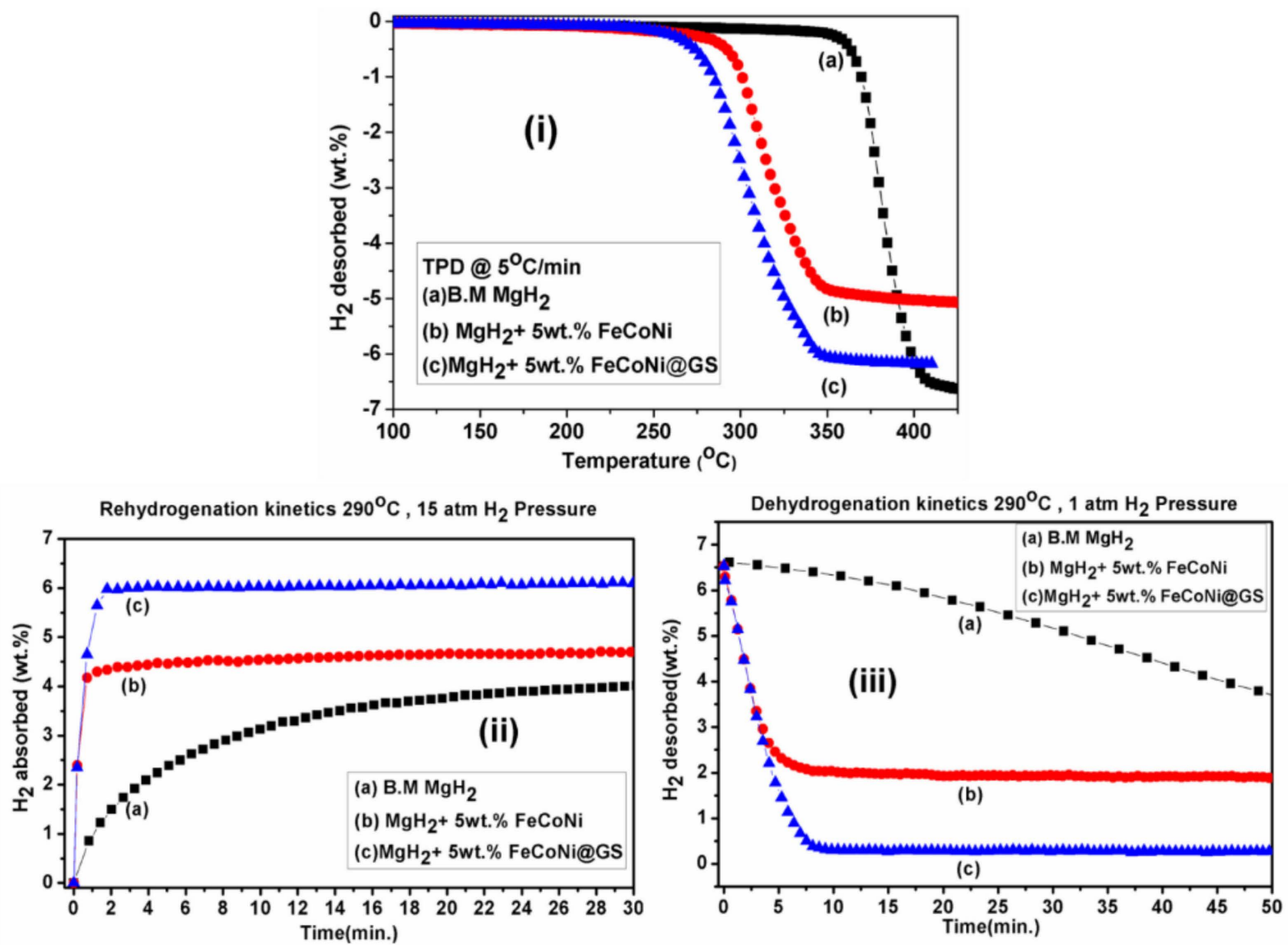

Figure 19. (i) TPD profile of (a) B.M MgH 2 (uncatalyzed sample); (b) $\mathrm{MgH}_{2}+5 \mathrm{wt} \% \mathrm{FeCoNi}$; (c) $\mathrm{MgH}_{2}+5 \mathrm{wt} \% \mathrm{FeCoNi} @ \mathrm{GS}$. (ii) Rehydrogenation kinetics curve of (a) $\mathrm{B} . \mathrm{M} \mathrm{MgH}_{2}$; (b) $\mathrm{MgH}_{2}+5 \mathrm{wt} \% \mathrm{FeCoNi}$; (c) $\mathrm{MgH}_{2}+5 \mathrm{wt} \% \mathrm{FeCoNi} @ \mathrm{GS}$ at $290{ }^{\circ} \mathrm{C}$ at $15 \mathrm{~atm}$. (iii) Dehydrogenation kinetics curve of (a) $\mathrm{B} \cdot \mathrm{M} \mathrm{MgH}_{2}$; (b) $\mathrm{MgH}_{2}+5 \mathrm{wt} \% \mathrm{FeCoNi}$; (c) $\mathrm{MgH}_{2}+5 \mathrm{wt} \% \mathrm{FeCoNi} @ \mathrm{GS}$ at $290{ }^{\circ} \mathrm{C}$ at $1 \mathrm{~atm}$ [138]. (Reprinted with permission from Elsevier.)

The rehydrogenation reversibility of $\mathrm{MgH}_{2}+5 \mathrm{wt} \%$ FeCoNi@GS was also found to be superior (see Figure 19ii). It was also found that $\mathrm{MgH}_{2}+5 \mathrm{wt} \% \mathrm{FeCoNi@GS}$ desorbed $6.14 \mathrm{wt} \%$ hydrogen (highest in comparison to others) within $8.5 \mathrm{~min}$ under similar conditions (Figure 19iii). Other than ternary metals catalysts, oxides catalysts have always been fascinating due to their extremely good performance with various hydrogen storage systems. $\mathrm{M}$. Ismail et al. achieved excellent dehydrogenation and hydrogenation kinetics of $\mathrm{MgH}_{2}$ by doping with $\mathrm{CuFe}_{2} \mathrm{O}_{4}$ catalyst [139]. They concluded that the $10 \mathrm{wt} \%$ $\mathrm{CuFe}_{2} \mathrm{O}_{4}$-doped $\mathrm{MgH}_{2}$ desorbed about $5.3 \mathrm{wt} \% \mathrm{H}_{2}$ within $10 \mathrm{~min}$ at $320^{\circ} \mathrm{C}$ and $5.0 \mathrm{wt} \%$ $\mathrm{H}_{2}$ was absorbed at $250{ }^{\circ} \mathrm{C}$ in $30 \mathrm{~min}$ by the catalyzed sample. The same group reported the study on $\mathrm{LaFeO}_{3}$ synthesized through the ball milling technique [141]. They reported that $\mathrm{LaFeO}_{3}$-catalyzed $\mathrm{MgH}_{2}$ sample was able to desorb about $3.7 \mathrm{wt} \%$ of $\mathrm{H}_{2}$ within $15 \mathrm{~min}$ at $320^{\circ} \mathrm{C}$. Zhang et al. reported the synergistic catalytic effects of Zr-based ternary metal catalyst $\mathrm{Zr}_{0.4} \mathrm{Ti}_{0.6}$ Co nanosheets and carbon nanotubes (see Figure 20) [145]. It was found that $\mathrm{MgH}_{2}+10 \mathrm{wt} \% \mathrm{Zr}_{0.4} \mathrm{Ti}_{0.6} \mathrm{Co} / 5 \mathrm{wt} \%$ CNTs composite quickly released $90 \%$ hydrogen within $10 \mathrm{~min}$ at $300{ }^{\circ} \mathrm{C}$. Moreover, after complete dehydrogenation, the same sample could absorb $3.51 \mathrm{wt} \%$ hydrogen within 20 min under $3 \mathrm{MPa}$ pressure at $125^{\circ} \mathrm{C}$ temperature. Ali et al. synthesized $\mathrm{MgNiO}_{2}$ nanoflakes via the hydrothermal method and investigated their catalytic roles on the hydrogen sorption performance of $\mathrm{MgH}_{2}$ [146] The enhanced absorption kinetics was found for the $\mathrm{MgNiO}_{2}$-nanoflakes-doped $\mathrm{MgH}_{2}$ sample with the capacity of hydrogen up to $6.1 \mathrm{wt} \%$ that could be reached within $10 \mathrm{~min}$ at $200{ }^{\circ} \mathrm{C}$. Yahya et al. studied the catalytic effects of $\mathrm{SrTiO}_{3}$ on the hydrogen storage properties of $\mathrm{MgH}_{2}$ [147]. The onset temperature was reduced by $55^{\circ} \mathrm{C}$ in comparison to 
as-milled $\mathrm{MgH}_{2}$ by the addition of $10 \mathrm{wt} \% \mathrm{SrTiO}_{3}$. The composite $\mathrm{MgH}_{2}-10 \mathrm{wt} \% \mathrm{SrTiO}_{3}$ was able to absorb $4.3 \mathrm{wt} \%$ of hydrogen within $60 \mathrm{~min}$. Besides $\mathrm{MgH}_{2}$, other systems such as $\mathrm{LiBH}_{4}, \mathrm{LiAlH}_{4}$ and $\mathrm{NaAlH}_{4}$ were also improved in their hydrogenation properties by the addition of oxide catalysts. Nanosized catalyst $\mathrm{NiFeO}_{4}$ was found suitable to lower the onset and peak temperature by $226{ }^{\circ} \mathrm{C}$ and $260{ }^{\circ} \mathrm{C}$ with respect to pristine $\mathrm{LiBH}_{4}$ [148]. Approximately $5 \mathrm{wt} \%$ hydrogen was released at $300{ }^{\circ} \mathrm{C}$ within $20 \mathrm{~min}$. First principle calculation suggested the reduction of energy required to release $\mathrm{H}$ atom by addition of d-block transition metals and hence promoted desorption of hydrogen [149]. Moreover, Wan et al. introduced $\mathrm{MnFe}_{2} \mathrm{O}_{4}$ nanoparticles to improve the catalytic activity of $\mathrm{NaAlH}_{4}$ [150]. Improved kinetics was shown for isothermal dehydrogenation from $7 \mathrm{~mol} \% \mathrm{MnFe}_{2} \mathrm{O}_{4}$-doped $\mathrm{NaAlH}_{4}$ with slightly reduced capacity. The onset decomposition temperatures for the $7 \mathrm{~mol} \% \mathrm{MnFe}_{2} \mathrm{O}_{4}$-doped $\mathrm{NaAlH}_{4}$ were significantly reduced to $95{ }^{\circ} \mathrm{C}, 152{ }^{\circ} \mathrm{C}$ and $327{ }^{\circ} \mathrm{C}$ for the three decomposition steps which were lowered by $84{ }^{\circ} \mathrm{C}, 88^{\circ} \mathrm{C}$ and $84{ }^{\circ} \mathrm{C}$, respectively, lower than that of undoped $\mathrm{NaAlH}_{4}$. Huang et al. demonstrated $\mathrm{NaAlH}_{4}+3 \mathrm{~mol} \% \mathrm{NiFe}_{2} \mathrm{O}_{4}$ having good cycle stability at only $150{ }^{\circ} \mathrm{C}$ with a slight capacity loss after five cycles [151]. They revealed that the enhanced catalytic performance of $\mathrm{NaAlH}_{4}$ by the addition of $3 \mathrm{~mol} \% \mathrm{NiFe}_{2} \mathrm{O}_{4}$ might be due to the small-sized particles. Nanosized particles might have provided active sites at the surface of $\mathrm{NaAlH}_{4}$, resulting in the improved kinetics. In addition to this, other d-block bimetallic oxides were also introduced to enhance the kinetics of $\mathrm{LiAlH}_{4}$ such as $\mathrm{CoFe}_{2} \mathrm{O}_{4}$ [152], $\mathrm{NiFe}_{2} \mathrm{O}_{4}$ [153] and $\mathrm{MgFe}_{2} \mathrm{O}_{4}$ [154]. Li et al. demonstrated $3 \mathrm{~mol} \%$ nanosized $\mathrm{NiFe}_{2} \mathrm{O}_{4}$-doped $\mathrm{LiAlH}_{4}$ sample could desorb $7 \mathrm{wt} \% \mathrm{H}_{2}$ within $91 \mathrm{~s}$ under $0.1 \mathrm{MPa}$ pressure at $120{ }^{\circ} \mathrm{C}$, which was $6.3 \mathrm{wt} \%$ higher than the pristine $\mathrm{LiAlH}_{4}$ [153]. The same group investigated the catalytic effects of $\mathrm{CoFe}_{2} \mathrm{O}_{4}$ nanoparticles and successfully achieved a lower onset temperature of $65{ }^{\circ} \mathrm{C}$, which was reduced by $90{ }^{\circ} \mathrm{C}$ in comparison to the as-received $\mathrm{LiAlH}_{4}$ [152]. In 2019, Ali et al. checked the catalytic effects of $\mathrm{MgFe}_{2} \mathrm{O}_{4}$ in $\mathrm{LiAlH}_{4}$ and obtained faster $3.5 \mathrm{wt} \% \mathrm{H}_{2}$ desorption within $30 \mathrm{~min}$ at $90{ }^{\circ} \mathrm{C}$ [154]. The synergistic effect of two metal combinations and formation of active species were found to be the reasons responsible for improving the dehydrogenation kinetics of $\mathrm{LiAlH}_{4}$. However, agglomeration remains a challenge sometimes to represent the fast kinetics and low desorption temperature. Some researchers tried to design d-block elemental catalysts decorated or mixed with graphene to solve such related issues. Tan et al. mentioned that the desorption temperature for $20 \mathrm{wt} \%$ MWCNTs/0.4Ni (multiwalled carbon nanotubes/0.4Ni)-mixed $\mathrm{LiAlH}_{4}$ could be decreased to $80{ }^{\circ} \mathrm{C}$, whereas $20 \mathrm{wt} \%$ MWCNTs/0.4-Co-doped $\mathrm{LiAlH}_{4}$ could desorb hydrogen at $100{ }^{\circ} \mathrm{C}$ [155]. Hence, they confirmed the superiority of Ni metal over Co for the dehydrogenation behavior of $\mathrm{LiAlH}_{4}$. In their point of view, carbon materials were also helpful for the confinement of hydrides; therefore, these were able to provide a relatively clear path for hydrogen diffusion. Moreover, the electron affinity of carbon materials could affect the hydrogen removal energy in the dehydrogenation reaction [155]. Jiao et al. designed the NiCo nanoalloy (4-6 nm) encapsulated in grapheme layers (NiCo@G) to investigate the catalytic effect of catalyst on $\mathrm{LiAlH}_{4}$ [156]. The $1 \mathrm{wt} \% \mathrm{NiCo@G-doped}$ $\mathrm{LiAlH}_{4}$ sample started releasing hydrogen at $43{ }^{\circ} \mathrm{C}$ (onset temperature) and $7.3 \mathrm{wt} \%$ hydrogen was liberated below $200{ }^{\circ} \mathrm{C}$ with reduced activation energy $54.8 \mathrm{~kJ} \mathrm{~mol}^{-1}$. Recently, $\mathrm{NiCo}_{2} \mathrm{O}_{4}$ nanorods anchored on $\mathrm{rGO}$, i.e., $\mathrm{NiCo}_{2} \mathrm{O}_{4} @ \mathrm{rGO}$, was synthesized by Xia et al. and dehydrogenation of $\mathrm{LiAlH}_{4}$ was evaluated [157]. For the isothermal dehydrogenation, $7 \mathrm{wt} \% \mathrm{NiCo}_{2} \mathrm{O}_{4} @ \mathrm{rGO}$-mixed $\mathrm{LiAlH}_{4}$ sample could release approx. 4 wt $\%$ hydrogen within $20 \mathrm{~min}$ at $150{ }^{\circ} \mathrm{C}$. This catalyzed sample showed $21.9 \%$ and $37.1 \%$ reduced activation energy of the two-step dehydrogenation of pure $\mathrm{LiAlH}_{4}$. DFT calculations were performed to investigate the mechanism of improved kinetics. They revealed that interfacial charge transfer and dehybridization of Al-H cluster provided the weakness in Al-H bonding. They also concluded that large surface area, mesoporous structure, cluster-surface interface and synergistic effects were the responsible events in facilitating the dehydrogenation of $\mathrm{NiCO}_{2} \mathrm{O}_{4} @ \mathrm{rGO}$-mixed $\mathrm{LiAlH}_{4}$ [157]. More recently, $\mathrm{NiFe}_{2} \mathrm{O}_{4}$ was supported on twodimensional hexagonal boron nitride $\left(\mathrm{NiFe}_{2} \mathrm{O}_{4} @ \mathrm{~h}-\mathrm{BN}\right)$ to increase the catalytic activity of 
$\mathrm{LiAlH}_{4}$ [158]. The onset desorption temperature for $7 w t \% \mathrm{NiFe}_{2} \mathrm{O}_{4} @$ h-BN-doped $\mathrm{LiAlH}_{4}$ was observed to be $77.1^{\circ} \mathrm{C}$ with $6.74 \mathrm{wt} \%$ hydrogen liberation. After dehydrogenation, $0.6 \mathrm{wt} \% \mathrm{H}_{2}$ was absorbed under 300 bar pressure at $300{ }^{\circ} \mathrm{C}$ temperature in $11 \mathrm{~h}$ by the dehydrogenated product. Zhao et al. designed a catalyst containing core-shell structure CoNi@C via hydrothermal and calcination reduction to improve the catalytic activity of $\mathrm{MgH}_{2}$ [159]. Prepared catalyst was found to efficiently desorb $5.83 \mathrm{wt} \%$ hydrogen within $1800 \mathrm{~s}$ started at $173{ }^{\circ} \mathrm{C}$ up to $\max 275^{\circ} \mathrm{C}$ temperature and released $4.83 \mathrm{wt} \% \mathrm{H}_{2}$ within $1800 \mathrm{~s}$ at the lowest temperature $100{ }^{\circ} \mathrm{C}$. Meng et al. investigated the superiority of designed 3D flower-like $\mathrm{TiO}_{2} @ \mathrm{C}$ nanostructured catalyst towards $\mathrm{MgH}_{2}$ [160]. They reported that the hydrogen sorption kinetics of $\mathrm{MgH}_{2}$ was enhanced by the flower-like $\mathrm{TiO}_{2} @ \mathrm{C}$ catalyst (6 wt \% hydrogen desorption within $7 \mathrm{~min}$ ). Liu et al. recently reported an interesting design for a catalyst, i.e., $\mathrm{Ni}_{3} \mathrm{Fe}$ was homogeneously loaded on reduced graphene oxide $\left(\mathrm{Ni}_{3} \mathrm{Fe} / \mathrm{rGO}\right)$ based on layered double hydroxide (LDH) precursor as shown in Figure 21 (upper panel) [161]. As shown in Figure $21 \mathrm{a}, \mathrm{b}, \mathrm{MgH}_{2}-5 \mathrm{wt} \% \mathrm{Ni}_{3} \mathrm{Fe} / \mathrm{rGO}$ composite could absorb $6 \mathrm{wt} \%$ hydrogen within $80 \mathrm{~s}$ at $100{ }^{\circ} \mathrm{C}$ and $6.2 \mathrm{wt} \%$ hydrogen could be achieved within $60 \mathrm{~s}$ at $125^{\circ} \mathrm{C}$. The mechanism was revealed for the catalysis and the proposed synergistic effect was attributed to $\mathrm{rGo}$ as well as in situ formation of active species $\mathrm{Mg}_{2} \mathrm{Ni}$ and Fe. In short, they happened to design such a catalyst with high efficiency based on $\mathrm{LDH}$ precursors. Ding et al. reported two different catalysts, $\mathrm{MgCNi}_{3}$ [162] in 2019 and $\mathrm{MgCCo}_{1.5} \mathrm{Ni}_{1.5}$ [160] in 2020, to improve the sorption kinetics of $\mathrm{MgH}_{2}$. They called it antiperovskite material $\mathrm{MgCNi}_{3}$ [162]; it was doped with $\mathrm{Mg}$ and approx. $4.42 \mathrm{wt} \%$ hydrogen was absorbed within $20 \mathrm{~min}$ at $423 \mathrm{~K}$, whereas $4.81 \mathrm{wt} \%$ hydrogen was reversibly released within $20 \mathrm{~min}$ at $593 \mathrm{~K}$. They revealed the formation of $\mathrm{Mg}_{2} \mathrm{NiH}_{4}$ hydride and carbon material during hydrogenation of composite where $\mathrm{Mg}_{2} \mathrm{NiH}_{4}$ induced dehydrogenation and carbonaceous material inhibited the growth and agglomeration of $\mathrm{MgH}_{2}$. Later they realized that addition of $\mathrm{Co}$ in the same composite could be beneficial to enhance the sorption kinetics of $\mathrm{MgH}_{2}$ due to the superior catalytic activity of $\mathrm{Co}$. Then further, they reported $\mathrm{Mg} / \mathrm{MgH}_{2}-\mathrm{MgCCo}_{1.5} \mathrm{Ni}_{1.5}$ composite releasing $\mathrm{H}_{2}$ at $217{ }^{\circ} \mathrm{C}, 160{ }^{\circ} \mathrm{C}$ lower than that of the $\mathrm{MgH}_{2}$, and it quickly absorbed $5.5 \mathrm{wt} \%$ hydrogen within $60 \mathrm{~min}$ at $150{ }^{\circ} \mathrm{C}$ temperature [163]. Moreover, they reported good cycling performance of $\mathrm{Mg} / \mathrm{MgH}_{2}-$ $\mathrm{MgCCO}_{1.5} \mathrm{Ni}_{1.5}$ composite and emphasized the formation of active species $\mathrm{MgC}_{0.5} \mathrm{Co}_{3}$ and carbon materials during de/absorption, which was the main reason for having good catalytic effects. Another multielement $\mathrm{NiMn}_{9.3} \mathrm{Al}_{4.0} \mathrm{Co}_{14.1} \mathrm{Fe}_{3.6}$ alloy was introduced by Meena et al. to enhance the dehydrogenation kinetics of $\mathrm{MgH}_{2}$ [164]. They reported that $50 \mathrm{wt} \% \mathrm{NiMn}_{9.3} \mathrm{Al}_{4.0} \mathrm{Co}_{14.1} \mathrm{Fe}_{3.6}$-alloy-doped $\mathrm{MgH}_{2}$ decreases desorption temperature by about $80{ }^{\circ} \mathrm{C}$ compared to the as-milled $\mathrm{MgH}_{2}$ sample at onset temperature $220{ }^{\circ} \mathrm{C}$. Some recent reports show that Mxenes-based materials have high potential to improve the kinetic sorption of $\mathrm{MgH}_{2}$ [165]. The Mxenes are basically a set of controlled spacious interlayers that can adsorb a number of hydrogen atoms / molecules on the (like 2D materials) structure by physisorption, chemisorption or Kubas interaction. It is believed that the unique 2D structure and formation of active species play an important role in destabilizing the $\mathrm{MgH}_{2}$ for hydrogen storage application. In 2019, $\mathrm{Li}$ et al. [166] prepared $\mathrm{Ti}_{2} \mathrm{C}$ Mxene by selective etching of $\mathrm{Al}$ layer from $\mathrm{Ti}_{2} \mathrm{AlC}$. The results showed that the starting dehydrogenation temperature and activation energies of $\mathrm{MgH}_{2}-5 \mathrm{wt} \% \mathrm{Ti}_{2} \mathrm{C}$ were decreased by $37^{\circ} \mathrm{C}$ and $36.5 \%$, respectively. In 2020, Zhu et al. [167] reported a novel $\mathrm{Ti}_{3} \mathrm{C}_{2}$ Mxene-based catalyst (Ni@Ti-MX) (see Figure 22) which could enable Mg to absorb 5.4 wt $\%$ hydrogen in $25 \mathrm{~s}$ at $125^{\circ} \mathrm{C}$ temperature and release $5.2 \mathrm{wt} \%$ hydrogen in $15 \mathrm{~min}$ at $250{ }^{\circ} \mathrm{C}$. The interesting point about this catalyst was that it enabled the absorption of $4 \mathrm{wt} \% \mathrm{H}_{2}$ in $5 \mathrm{~h}$ even at room temperature. Reduced kinetic energy barrier was found $\left(56 \pm 4\right.$ and $73 \pm 3.5 \mathrm{~kJ} / \mathrm{mol} \mathrm{H}_{2}$ for hydrogenation and dehydrogenation, respectively) for improved kinetics of catalyzed $\mathrm{MgH}_{2}$. The enhanced hydrogen sorption kinetics is basically attributed to the hybrid design and coupling of many metals together. Furthermore, two kinds of Mxenes were mixed: 2D vanadium carbide $\left(\mathrm{V}_{2} \mathrm{C}\right)$ and titanium carbide $\left(\mathrm{Ti}_{3} \mathrm{C}_{2}\right)$, in order to check the synergistic effects on decomposition of $\mathrm{MgH}_{2}$ (see Figure 23) [168]. According to this 
report, hydrogen atoms or molecules during the desorption process may pass through the $\mathrm{MgH}_{2} / \mathrm{V}_{2} \mathrm{C} / \mathrm{Ti}_{3} \mathrm{C}_{2}$ triple-grain boundaries and through the $\mathrm{Mg} / \mathrm{Ti}_{3} \mathrm{C}_{2}$ interfaces during the absorption process.

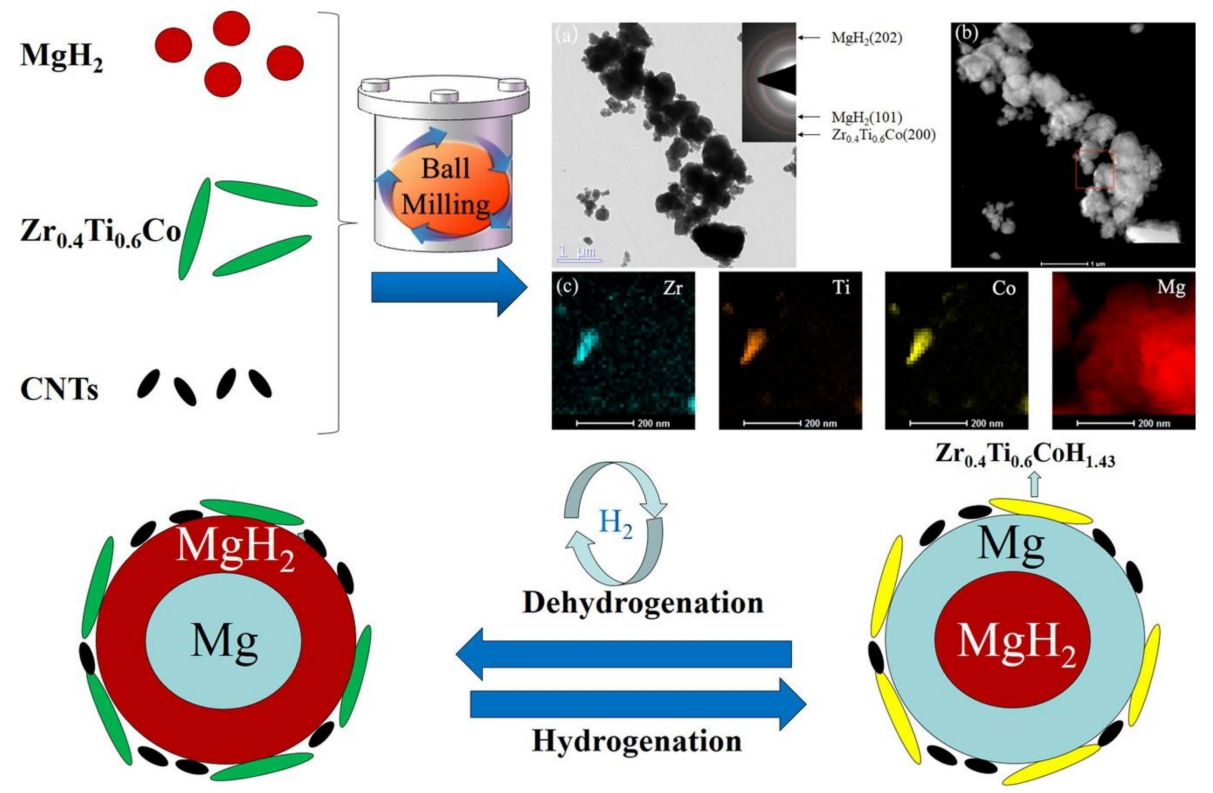

Figure 20. Preparation and investigation of $\mathrm{MgH}_{2}-\mathrm{Zr}_{0.4} \mathrm{Ti}_{0.6} \mathrm{Co}$ nanosheets and carbon nanotubes [145]. (Reprinted with permission from Elsevier.)

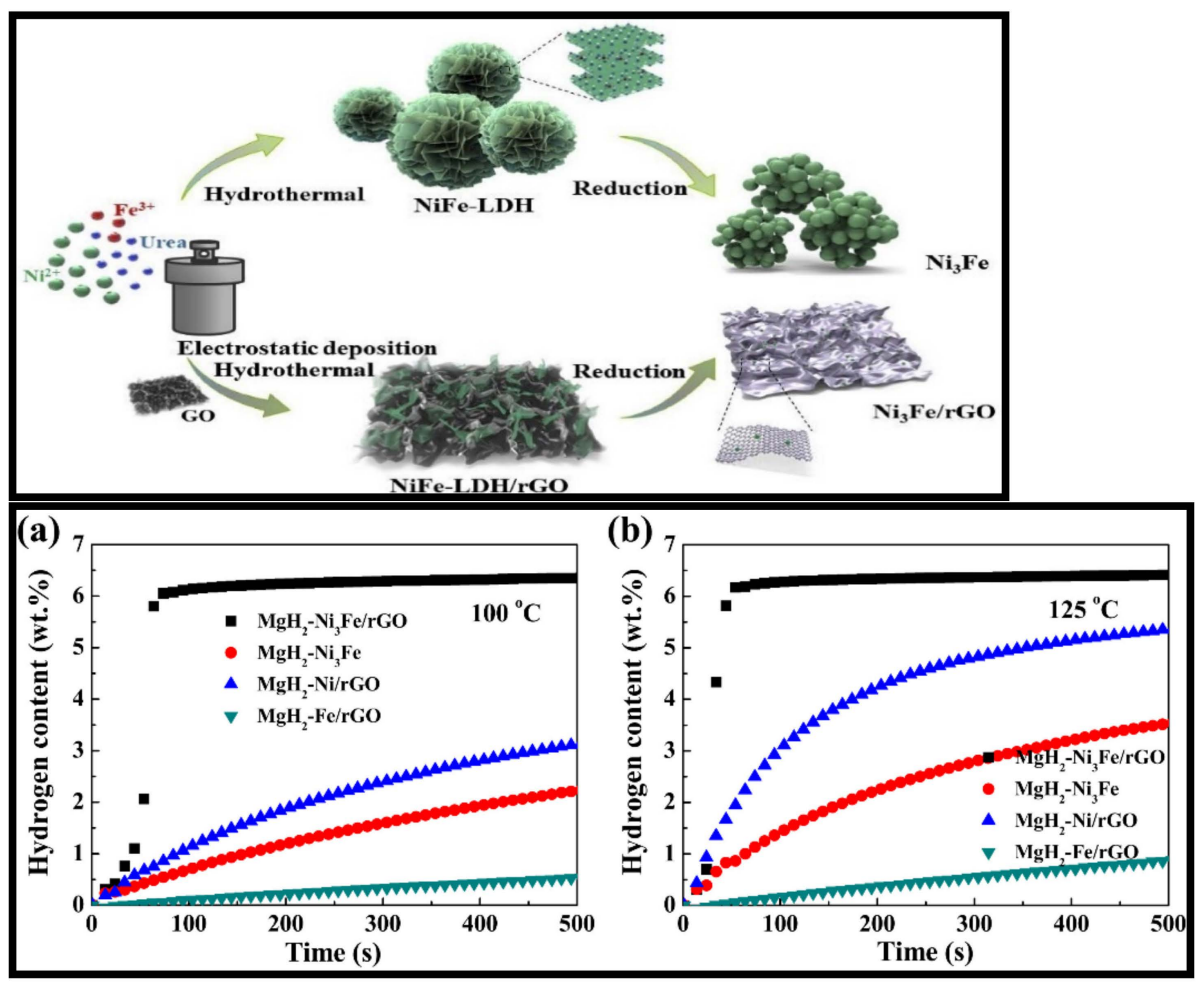

Figure 21. Synthesis procedure for the $\mathrm{Ni}_{3} \mathrm{Fe}$ and $\mathrm{Ni}_{3} \mathrm{Fe} / \mathrm{rGO}$. The strong electrostatic effect between GO and LDH results in the formation of a load structure rather than a flower shape (upper panel). Isothermal rehydrogenation curves of $\mathrm{MgH}_{2}-5 \mathrm{wt} \% \mathrm{Ni}_{3} \mathrm{Fe} / \mathrm{rGO}, \mathrm{MgH}_{2}-5 \mathrm{wt} \% \mathrm{Ni}_{3} \mathrm{Fe}, \mathrm{MgH}_{2}-5 \mathrm{wt} \%$ $\mathrm{Ni} / \mathrm{rGO}$ and $\mathrm{MgH}_{2}-5 \mathrm{wt} \% \mathrm{Fe} / \mathrm{rGO}$ at $100{ }^{\circ} \mathrm{C}(\mathbf{a})$ and $125^{\circ} \mathrm{C}(\mathbf{b})$ under $3.0 \mathrm{MPa}$ hydrogen pressure [161]. (Reprinted with permission from Elsevier.) 


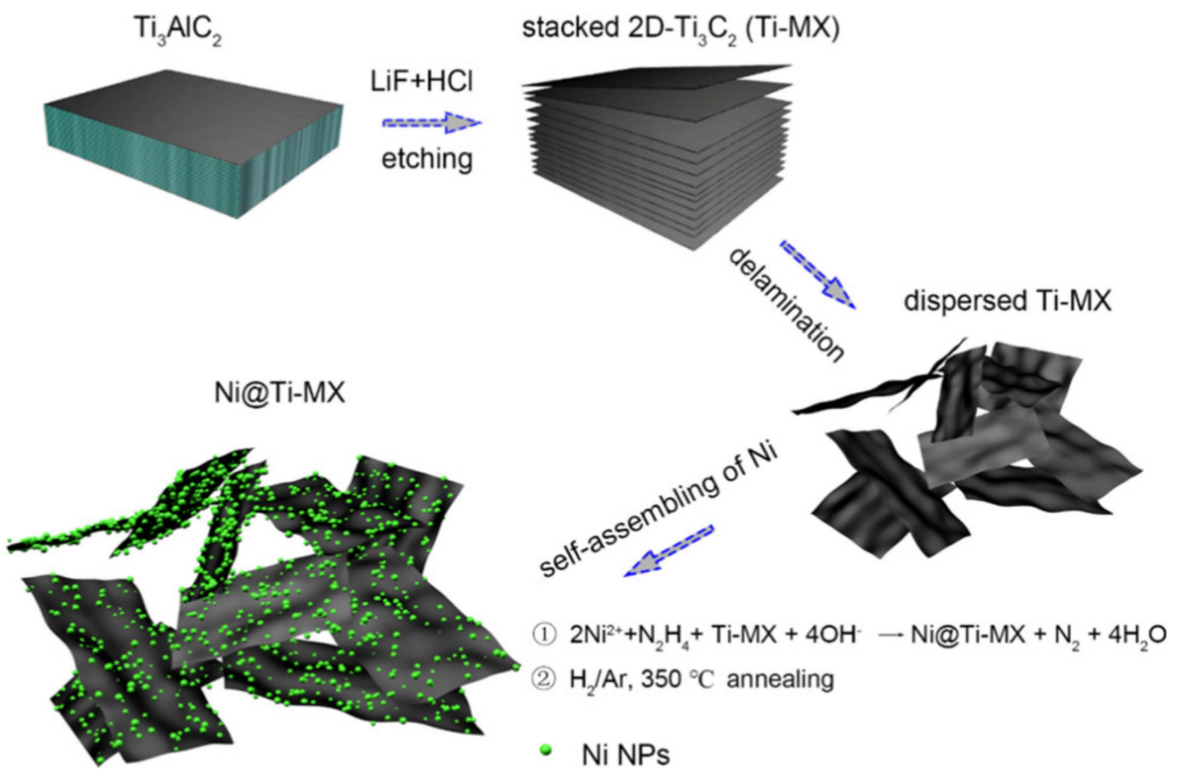

Figure 22. Schematic illustrations of the synthetic strategy applied for the Ni@Ti-MX catalyst [167]. (Reprinted with permission from American Chemical Society.)

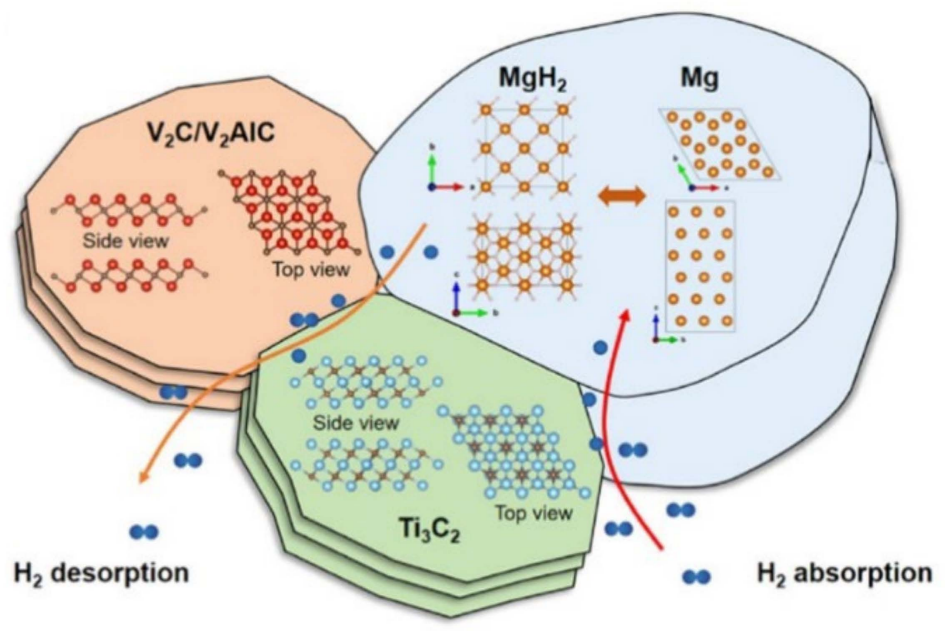

Figure 23. Schematic pictures showing the hydrogen desorption and absorption mechanisms of $\mathrm{MgH}_{2}$ with the addition of $\mathrm{V}_{2} \mathrm{C} / \mathrm{Ti}_{3} \mathrm{C}_{2}$ [168]. (Reprinted with permission from the American Chemical Society.)

Figure 24 shows the excellent cycling stability of $\mathrm{MgH}_{2} / \mathrm{V}_{2} \mathrm{C} / \mathrm{Ti}_{3} \mathrm{C}_{2}$ up to 10 cycles with reversible capacity $6.3 \mathrm{wt} \%$ hydrogen. These catalysts were found to be good for other complex hydrides also. As an example, the onset temperature was reduced for $40 \mathrm{wt} \% \mathrm{Ti}_{3} \mathrm{C}_{2}$-Mxene-catalyzed $\mathrm{LiBH}_{4}$ to $120{ }^{\circ} \mathrm{C}$ and a total $5.37 \mathrm{wt} \% \mathrm{H}_{2}$ was liberated within $1 \mathrm{~h}$ at $350{ }^{\circ} \mathrm{C}$ with a decreased activation energy $\left(70.3 \mathrm{~kJ} \mathrm{~mol}^{-1} \mathrm{H}_{2}\right)$ [169]. The two-dimensional layered titanium carbide (2D Mxene) was studied in order to facilitate the surface functionalization and to study the catalytic activity of hydrogen de/adsorption for $\mathrm{NaAlH}_{4}$ [170]. The $\mathrm{NaAlH}_{4}+10 \mathrm{wt} \%$ Mxene/A-TiO sample was found to be superior (than the $\mathrm{NaAlH}_{4}$ ) with the dehydrogenation temperature $90{ }^{\circ} \mathrm{C}$. At isothermal conditions $\left(140{ }^{\circ} \mathrm{C}\right), \mathrm{NaAlH}_{4}+10 \mathrm{wt} \%$ Mxene $/ \mathrm{A}-\mathrm{TiO}_{2}$ sample could release more than $3 \mathrm{wt} \%$ of hydrogen within $7 \mathrm{~min}$, and a total of $4.8 \mathrm{wt} \%$ of hydrogen could be released within $200 \mathrm{~min}$. The activation of $\mathrm{Mxene} / \mathrm{A}-\mathrm{TiO}_{2}$ sample was attained by the synergistic effect of homogeneously spread $\mathrm{Ti}-\mathrm{H}$ and $\mathrm{TiC}$ originating from $\mathrm{Mxene} / \mathrm{A}-\mathrm{TiO}_{2}$. Apart from these specific families, several other catalysts based on transition metals have been reported. As an example, $\mathrm{LiBH}_{4}-0.04\left(\mathrm{Li}_{3} \mathrm{BO}_{3}+\mathrm{NbH}\right)$ composite was designed to achieve good re- 
versibility and cyclic stability in comparison to pristine $\mathrm{LiBH}_{4}$ [171]. Li et al. reported the onset temperature as $190{ }^{\circ} \mathrm{C}$ and $8.2 \mathrm{wt} \% \mathrm{H}_{2}$ was released at $400{ }^{\circ} \mathrm{C}$ for this composite. Moreover, the dehydrogenated product was able to absorb $7.9 \mathrm{wt} \% \mathrm{H}_{2}$ in just $20 \mathrm{~min}$ under 50 bar at $500{ }^{\circ} \mathrm{C}$ in the rehydrogenation process. Excellent capacity retention of $7.2 \mathrm{wt} \%$ was found for 30 cycles. In another work, Yuan et al. studied the carbon-coated titanium dioxide supported on two-dimensional titanium carbide $\left(\mathrm{C} @ \mathrm{TiO}_{2} / \mathrm{Ti}_{3} \mathrm{C}_{2}\right)$ [172]. The desorption temperature was reduced by $70{ }^{\circ} \mathrm{C}$ in comparison to the pristine $\mathrm{NaAlH}_{4}$ sample. Approximately $4 \mathrm{wt} \% \mathrm{H}_{2}$ was liberated within $13 \mathrm{~min}$ at $140{ }^{\circ} \mathrm{C}$ temperature. The reduced activation energies $\left(E_{a}\right)$ were found as 72.41 and $64.27 \mathrm{~kJ} \mathrm{~mol}^{-1}$ for the first two steps of the catalyzed $\mathrm{NaAlH}_{4}$ sample. More recently, Jiang et al. also demonstrated the superior catalytic efficiency of $\mathrm{Ti}_{3} \mathrm{C}_{2}$-doped $\mathrm{NaH} / \mathrm{Al}$ composite which could desorb $4.2 \mathrm{wt} \% \mathrm{H}_{2}$ at $110^{\circ} \mathrm{C}$ within $4.5 \mathrm{~min}$ [173]. They reported one of the lowest initial desorption temperatures, $76{ }^{\circ} \mathrm{C}$, for Ti-doped $\mathrm{NaAlH}_{4}$. The activation energies of the first and second steps were calculated as $92.5 \mathrm{~kJ} / \mathrm{mol}$ and $58.1 \mathrm{~kJ} / \mathrm{mol}$, respectively, for $\mathrm{Ti}_{3} \mathrm{C}_{2}$-doped $\mathrm{NaH} / \mathrm{Al}$ composite, which were found to be lower than the uncatalyzed $\mathrm{NaAlH}_{4}$. It was revealed that titanium acted as a fast channel pathway for hydrogen absorption and desorption. Moreover, high-valence Ti was found to be the responsible event in $\mathrm{Ti}_{3} \mathrm{C}_{2}$-doped $\mathrm{NaH} / \mathrm{Al}$ composite, showing better storage properties in comparison to $\mathrm{Ti}_{3} \mathrm{C}_{2}$-doped $\mathrm{NaAlH}_{4}$ [173]. A balancing and coupling between nanoconfinement and catalysis were recently focused on to improve the hydrogen sorption properties of $\mathrm{NaAlH}_{4}$. Li et al. succeeded in a strategy to combine the confinement and catalysis (catalyzed sample denoted as $\mathrm{NaAlH}_{4} /$ Raney $\mathrm{Ni}$ ) to make possible $\mathrm{NaAlH}_{4}$ desorption at nearly $100{ }^{\circ} \mathrm{C}$ [174]. The $\mathrm{NaAlH}_{4} /$ Raney $\mathrm{Ni}$ desorbed $\mathrm{H}_{2}$ at initial temperature $85^{\circ} \mathrm{C}$ and finished at $260^{\circ} \mathrm{C}$ with the lowest activation energy $\sim 20 \mathrm{~kJ} \mathrm{~mol}^{-1}$. Dehydrogenated product $\mathrm{NaH}+\mathrm{Al}$ could be able to regenerate $\mathrm{NaAlH}_{4}$ at $150{ }^{\circ} \mathrm{C}$ and under $7 \mathrm{MPa}$ hydrogen pressure. The absorbed hydrogen could be released again at $70{ }^{\circ} \mathrm{C}$ upon second dehydrogenation. The remarkable performance was attributed to the lowering of the diffusion path by nanoconfinement on porous support and catalytic sites of $\mathrm{Ni}$, which could ensure an effective route for improving the sorption properties of complex hydride $\left(\mathrm{NaAlH}_{4}\right)$. Moreover, Chen et al. also developed a similar strategy to balance the synergistic effect between the catalyst and nanoconfinement using porous carbon scaffolds via the controllable etching of Co nanoparticles [175]. A $3.7 \mathrm{wt} \%$ hydrogen was released at $164{ }^{\circ} \mathrm{C}$ (peak temperature) with a loading ratio as high as $67 \%$. The reversibility was achieved for $3.3 \mathrm{wt} \%$ hydrogen up to five cycles at $170{ }^{\circ} \mathrm{C}$ desorption temperature. By designing such a combination of Co-doped nanoporous carbon as scaffolds, the formation of void space near the active Co nanoparticles could be achieved, leading to the enhanced catalytic effects and achieving the superior hydrogen storage performance of $\mathrm{NaAlH}_{4}$.

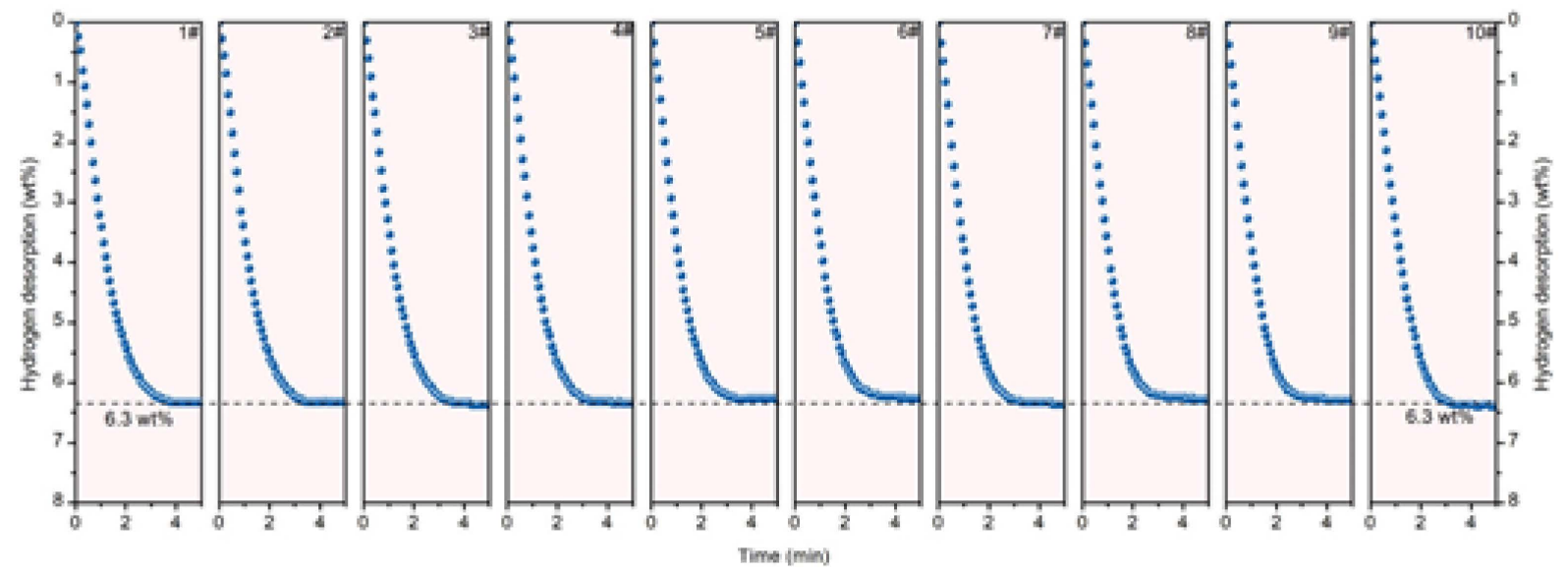

Figure 24. Cycling hydrogen desorption curves of $\mathrm{MgH}_{2}-2 \mathrm{~V}_{2} \mathrm{C} / \mathrm{Ti}_{3} \mathrm{C}_{2}$ at $300{ }^{\circ} \mathrm{C}$ for up to 10 cycles [168]. (Reprinted with permission from the American Chemical Society.) 
Thus, in summary, it can be understood that easy synthesized nanoparticles, hybrid structure, selection of suitable metal, core-shell designs, metal catalysts supported on a matrix which can provide high surface area and addition of graphene and carbon to prohibit the agglomeration of material are the key factors in designing the suitable catalysts for hydrogen storage application.

\section{Summary and Future Perspective}

Hydrogen storage is one of the biggest challenges in using hydrogen as a practical energy carrier. For onboard hydrogen storage, many factors need consideration, such as safety, affordability, handling and cost. The solid-state hydrogen storage technique is beneficial from a safety point of view, uses mild operating temperature and pressure and maintains a high capacity for storing hydrogen. Several metal hydrides and complex hydrides are promising candidates for solid-state hydrogen storage due to their high gravimetric and volumetric density. However, sluggish sorption kinetics and low reversibility put limitations on using them for hydrogen storage. The use of a suitable catalyst can improve the kinetics of hydride materials. The d-block transition metals play an important role as catalyst in the field of hydrogen storage. Thus, we discussed various types of dblock elements and their related compounds as a suitable catalyst to improve the hydrogen $\mathrm{ab} /$ desorption performances of various hydrogen storage systems. It can be concluded that by the addition of unary (metal) and binary catalysts (metal oxides, metal halides) and their combinations, hybrid designs containing porous structures, various metal-based Mxenes and designed nanoconfined catalysts could be used to enhance the dehydrogenation/rehydrogenation kinetics and cyclic performance of the abovementioned hydride materials. Moreover, the addition of the catalyst significantly reduces the activation energy of the composite in comparison to the pristine hydride materials. Reduced activation energy can lead to a decrease in the hydrogen desorption temperature. Several other factors such as nanosizing, synergistic effects and formation of active species are responsible for activating the catalyst and providing more nucleation sites at the surface of the material along with providing the clear path to hydrogen diffusion resulting in the enhancement of the early dehydrogenation. However, numerous efforts are still needed to achieve the DOE goal in order to satisfy the thirst for suitable hydrogen storage material in terms of fast desorption. This review paper is helpful for designing a new composite hydrogen system by the addition of d-block metals and their derivatives as suitable catalysts to improve the sorption properties for hydrogen storage material.

Conflicts of Interest: The authors declare no conflict of interest.

\section{References}

1. Fcto_Targets_onboard_Hydro_Storage_Explanation. Available online: http://www.doc88.com/p-7324389963306.html (accessed on 16 August 2021).

2. Schlapbach, L.; Züttel, A. Hydrogen-storage materials for mobile applications. Mater. Sustain. Energy 2010, 265-270. [CrossRef]

3. Zheng, J.; Wang, C.G.; Zhou, H.; Ye, E.; Xu, J.; Li, Z.; Loh, X.J. Current Research Trends and Perspectives on Solid-State Nanomaterials in Hydrogen Storage. Research 2021, 1-39. [CrossRef]

4. Mohan, M.; Sharma, V.K.; Kumar, E.A.; Gayathri, V. Hydrogen storage in carbon materials-A review. Energy Storage 2019, 1, e35. [CrossRef]

5. Jia, J.; Lin, X.; Wilson, C.; Blake, A.J.; Champness, N.R.; Hubberstey, P.; Walker, G.; Cussena, E.J; Schröder, M. Twelve-connected porous metal-organic frameworks with high $\mathrm{H}_{2}$ adsorption. Chem. Commun. 2007, 8, 840-842. [CrossRef]

6. Van den Berg, A.W.C.; Areán, C.O. Materials for hydrogen storage: Current research trends and perspectives. Chem. Commun. 2008, 6, 668-681. [CrossRef]

7. Budd, P.M.; Butler, A.; Selbie, J.; Mahmood, K.; McKeown, N.B.; Ghanem, B.; Msayib, K.; Book, D.; Waltonc, A. The potential of organic polymer-based hydrogen storage materials. Phys. Chem. Chem. Phys. 2007, 9, 1802-1808. [CrossRef]

8. Tedds, S.; Walton, A.; Broom, D.P.; Book, D. Characterisation of porous hydrogen storage materials: Carbons, zeolites, MOFs and PIMs. Faraday Discuss. 2011, 151, 75-94. [CrossRef]

9. Selvaraj, S.; Jain, A.; Miyaoka, H.; Kojima, Y.; Ichikawa, T. Hydrogen Sorption and Cyclic Compressor Performance of V40Ti21.5Cr33.5M5 (M= Nb, Zr, Fe) Alloys. J. Jpn. Inst. Energy 2019, 98, 157-164. [CrossRef] 
10. Guo, F.; Jain, A.; Miyaoka, H.; Kojima, Y.; Ichikawa, T. Critical Temperature and Pressure Conditions of Degradation during Thermochemical Hydrogen Compression: A Case Study of V-Based Hydrogen Storage Alloy. Energies 2020, 13, 2324. [CrossRef]

11. Guo, F.; Namba, K.; Miyaoka, H.; Jain, A.; Ichikawa, T. Hydrogen storage behavior of TiFe alloy activated by different methods. Mater. Lett. X 2021, 9, 100061.

12. Liang, G.; Huot, J.; Schulz, R. Hydrogen storage properties of the mechanically alloyed LaNi5-based materials. J. Alloys Compd. 2001, 320, 133-139. [CrossRef]

13. Grochala, W.; Edwards, P.P. Thermal Decomposition of the Non-Interstitial Hydrides for the Storage and Production of Hy-drogen. Chem. Rev. 2004, 104, 1283-1316. [CrossRef]

14. De Jongh, P.E.; Adelhelm, P. Nanosizing and Nanoconfinement: New Strategies Towards Meeting Hydrogen Storage Goals. ChemSusChem 2010, 3, 1332-1348. [CrossRef]

15. Jain, A.; Agarwal, S.; Ichikawa, T. Catalytic Tuning of Sorption Kinetics of Lightweight Hydrides: A Review of the Materials and Mechanism. Catalysts 2018, 8, 651. [CrossRef]

16. Adams, B.D.; Chen, A. The role of palladium in a hydrogen economy. Mater. Today 2011, 14, 282-289. [CrossRef]

17. Konda, S.K.; Chen, A. Palladium based nanomaterials for enhanced hydrogen spillover and storage. Mater. Today 2016, 19, 100-108. [CrossRef]

18. Wu, Y.; Yu, H.; Guo, Y.; Jiang, X.; Qi, Y.; Sun, B.; Li, H.; Zheng, J.; Li, X. A rare earth hydride supported ruthenium catalyst for the hydrogenation of $\mathrm{N}$-heterocycles: Boosting the activity via a new hydrogen transfer path and controlling the stereoselectivity. Chem. Sci. 2019, 10, 10459-10465. [CrossRef]

19. Chen, J.; Fu, J.; Fu, K.; Xiao, R.; Wu, Y.; Zheng, X.; Liu, Z.; Zheng, J.; Li, X. Combining catalysis and hydrogen storage in direct borohydride fuel cells: Towards more efficient energy utilization. J. Mater. Chem. A 2017, 5, 14310-14318. [CrossRef]

20. Yang, M.; Dong, Y.; Fei, S.; Ke, H.; Cheng, H. A comparative study of catalytic dehydrogenation of perhydro-N-ethylcarbazole over noble metal catalysts. Int. J. Hydrogen Energy 2014, 39, 18976-18983.

21. Huang, Y.; An, C.; Zhang, Q.; Zhag, L.; Shao, H.; Liu, Y.; Zhang, Y.; Yuan, H.; Wang, C.; Wang, Y. Cost-effective mechanochemical synthesis of highly dispersed supported transition metal catalysts for hydrogen storage. Nano Energy 2021, 80, 105535. [CrossRef]

22. Zhang, L.; Wang, A.; Wang, W.; Huang, Y.; Liu, X.; Miao, S.; Liu, J.; Zhang, T. Co-N-C Catalyst for C-C Coupling Reactions: On the Catalytic Performance and Active Sites. ACS Catal. 2015, 5, 6563-6572.

23. Zhang, J.; Yan, S.; Xia, G.; Zhou, X.; Lu, X.; Yu, L.; Yu, X.; Peng, P. Stabilization of low-valence transition metal towards advanced catalytic effects on the hydrogen storage performance of magnesium hydride. J. Magnes. Alloy. 2021, 9, 647-657. [CrossRef]

24. Sharma, S.; Guo, F.; Ichikawa, T.; Kojima, Y.; Agarwal, S.; Jain, A. Iron based catalyst for the improvement of the sorption properties of KSiH3. Int. J. Hydrogen Energy 2020, 45, 33681-33686. [CrossRef]

25. Agarwal, S.; Mangal, R.K.; Kumar, M.; Awasthi, K.; Kumar, S.; Jain, A. Hydrogen Sorption Characteristics of ZrCrAl Ternary Alloy as a Function of Milling Time. Macromol. Symp. 2017, 376, 1700047.

26. Pal, P.; Jain, A.; Miyaoka, H.; Kojima, Y.; Ichikawa, T. Eutectic melting in $\mathrm{x}\left(2 \mathrm{LiBH}_{4}-\mathrm{MgH}_{2}\right)$ hydrogen storage system by the addition of KH. Int. J. Hydrogen Energy 2020, 45, 17000-17005. [CrossRef]

27. Kumar, S.; Jain, A.; Kojima, Y. Thermodynamics and kinetics of hydrogen absorption-desorption of vanadium synthesized by aluminothermy. J. Therm. Anal. Calorim. 2017, 130, 721-726. [CrossRef]

28. Yoshino, M.; Komiya, K.; Takahashi, Y.; Shinzato, Y.; Yukawa, H.; Morinaga, M. Nature of the chemical bond in complex hydrides, $\mathrm{NaAlH}_{4}, \mathrm{LiAlH}_{4}, \mathrm{LiBH}_{4}$ and $\mathrm{LiNH}_{2}$. J. Alloys Compd. 2005, 404-406, 185-190. [CrossRef]

29. Schüth, F.; Bogdanović, B.; Felderhoff, M. Light metal hydrides and complex hydrides for hydrogen storage. Chem. Commun. 2004, 20, 2249-2258. [CrossRef]

30. Modi, P.; Aguey-Zinsou, K.-F. Room Temperature Metal Hydrides for Stationary and Heat Storage Applications: A Review. Front. Energy Res. 2021, 9, 128. [CrossRef]

31. Jain, I.P.; Jain, P.; Jain, A. Novel hydrogen storage materials: A review of lightweight complex hydrides. J. Alloys Compd. 2010, 503, 303-339. [CrossRef]

32. Sakintuna, B.; Lamari-Darkrim, F.; Hirscher, M. Metal hydride materials for solid hydrogen storage: A review. Int. J. Hydrogen Energy 2007, 32, 1121-1140. [CrossRef]

33. Bouaricha, S.; Dodelet, J.P.; Guay, D.; Huot, J.; Schulz, R. Study of the activation process of Mg-based hydrogen storage materials modified by graphite and other carbonaceous compounds. J. Mater. Res. 2001, 16, 2893-2905. [CrossRef]

34. Bellosta von Colbe, J.M.; Puszkiel, J.; Capurso, G.; Franz, A.; Ulrich Benz, H.; Zoz, H.; Klassen, T.; Dornheim, M. Scale-up of milling in a $100 \mathrm{~L}$ device for processing of TiFeMn alloy for hydrogen storage applications: Procedure and characterization. Int. J. Hydrogen Energy 2019, 44, 29282-29290. [CrossRef]

35. Shinzato, K.; Hamamoto, S.; Miyaoka, H.; Ichikawa, T. Room-Temperature Hydrogen Absorption of Titanium with Surface Modification by Organic Solvents. J. Phys. Chem. C 2019, 123, 19269-19274. [CrossRef]

36. Jain, I.P.; Lal, C.; Jain, A. Hydrogen storage in Mg: A most promising material. Int. J. Hydrogen Energy 2010, 35, 5133-5144. [CrossRef]

37. Vajeeston, P.; Ravindran, P.; Fichtner, M.; Fjellvåg, H. Influence of Crystal Structure of Bulk Phase on the Stability of Nanoscale Phases: Investigation on $\mathrm{MgH}_{2}$ Derived Nanostructures. J. Phys. Chem. 2012, 116, 18965-18972. [CrossRef]

38. Nogita, K.; Tran, X.Q.; Yamamoto, T.; Tanaka, E.; McDonald, S.D.; Gourlay, C.M.; Yasuda, K.; Matsumura, S. Evidence of the hydrogen release mechanism in bulk $\mathrm{MgH}_{2}$. Sci. Rep. 2015, 5, 8450. 
39. Wang, H.; Lin, H.J.; Cai, W.T.; Ouyang, L.Z.; Zhu, M. Tuning kinetics and thermodynamics of hydrogen storage in light metal element based systems-A review of recent progress. J. Alloys Compd. 2016, 658, 280-300. [CrossRef]

40. Kitagawa, Y.; Tanabe, K. Development of a kinetic model of hydrogen absorption and desorption in magnesium and analysis of the rate-determining step. Chem. Phys. Lett. 2018, 699, 132-138. [CrossRef]

41. Zhou, C.; Zhang, J.; Bowman, R.C., Jr.; Fang, Z.Z. Roles of Ti-Based Catalysts on Magnesium Hydride and Its Hydrogen Storage Properties. Inorganics 2021, 9, 36. [CrossRef]

42. Ruse, E.; Pevzner, S.; Bar, I.P.; Nadiv, R.M.; Skripnyuk, V.; Rabkin, E.; Regev, O. Hydrogen storage and spillover kinetics in carbon nanotube-Mg composites. Int. J. Hydrogen Energy 2016, 41, 2814-2819. [CrossRef]

43. Pevzner, S.; Pri-Bar, I.; Lutzky, I.; Ben-Yehuda, E.; Ruse, E.; Regev, O. Carbon Allotropes Accelerate Hydrogenation via Spillover Mechanism. J. Phys.Chem C 2014, 118, 27164-27169.

44. Zhou, W.; Zhao, Y.; Wang, Y.; Wang, S.; Ma, X. Glycerol Hydrogenolysis to 1,3-Propanediol on Tungstate/Zirconia-Supported Platinum: Hydrogen Spillover Facilitated by Pt(111) Formation. ChemCatChem 2016, 8, 3663-3671. [CrossRef]

45. Medford, J.A.; Vojvodic, A.S.; Hummelshøj, J.; Voss, J.; Abild-Pedersen, F.; Studt, F.; Bligaard, T.; Nilsson, A.; Nørskov, J.K. From the Sabatier principle to a predictive theory of transition-metal heterogeneous catalysis. J. Catal. 2015, 328, 36-42. [CrossRef]

46. Trasatti, S. Work function, electronegativity, and electrochemical behaviour of metals: III. Electrolytic hydrogen evolution in acid solutions. J. Electroanal. Chem. Interfacial Electrochem. 1972, 39, 163-184. [CrossRef]

47. Litovchenko, V.G.; Efremov, A.A. The enhanced catalytic dissociation of adsorbed hydrogen containing molecules. Condens. Matter Phys. 1999, 2, 561. [CrossRef]

48. Zeradjanin, A.R.; Grote, J.P.; Polymeros, G.; Mayrhofer, K.J.J. A Critical Review on Hydrogen Evolution Electrocatalysis: Reexploring the Volcano-relationship. Electroanalysis 2016, 28, 2256-2269. [CrossRef]

49. Pelletier, J.F.; Huot, J.; Sutton, M.; Schulz, R.; Sandy, A.R.; Lurio, L.B.; Mochrie, S.G.J. Hydrogen desorption mechanism in $\mathrm{MgH}_{2}-\mathrm{Nb}$ nanocomposites. Phys. Rev. B 2001, 63, 052103. [CrossRef]

50. Borgschulte, A.; Bösenberg, U.; Barkhordarian, G.; Dornheim, M.; Bormann, R. Enhanced hydrogen sorption kinetics of magnesium by destabilized $\mathrm{MgH}_{2}-\delta$. Catal. Today 2007, 120, 262-269. [CrossRef]

51. Charbonnier, J.; Rango, P.D.; Fruchart, D.; Miraglia, S.; Skryabina, N.; Huot, J.; Hauback, B.; Pitt, M.; Rivoirard, S. Structural analysis of activated $\mathrm{Mg}(\mathrm{Nb}) \mathrm{H}_{2}$. J. Alloys Compd. 2005, 404-406, 541-544. [CrossRef]

52. Zhang, X.L.; Liu, Y.F.; Zhang, X.; Hu, J.J.; Gao, M.X.; Pan, H.G. Empowering hydrogen storage performance of $\mathrm{MgH}_{2}$ by nanoengineering and nanocatalysis. Mater. Today Nano 2020, 9, 100064. [CrossRef]

53. Pozzo, M.; Alfè, D. Hydrogen dissociation and diffusion on transition metal (=Ti, Zr, V, Fe, Ru, Co, Rh, Ni, Pd, Cu, Ag)-doped $\mathrm{Mg}(0001)$ surfaces. Int. J. Hydrogen Energy 2009, 34, 1922-1930. [CrossRef]

54. Andrés, T.B.; Zélis Luis, M.; Marcos, M. Differences in the heterogeneous nature of hydriding/dehydriding kinetics of $\mathrm{MgH}_{2}-$ $\mathrm{TiH}_{2}$ nanocomposites. Int. J. Hydrogen Energy 2020, 45, 27421-27433. [CrossRef]

55. Ren, C.; Fang, Z.Z.; Zhou, C.; Lu, J.; Ren, Y.; Zhang, X.; Luo, X. In situ X-ray diffraction study of dehydrogenation of MgH $\mathrm{H}_{2}$ with Ti-based additives. Int. J. Hydrogen Energy 2014, 39, 5868-5873. [CrossRef]

56. Ponthieu, M.; Calizzi, M.; Pasquini, L.; Fernandez, J.F.; Cuevas, F. Synthesis by reactive ball milling and cycling properties of $\mathrm{MgH}_{2}-\mathrm{TiH}_{2}$ nanocomposites: Kinetics and isotopic effects. Int. J. Hydrogen Energy 2014, 39, 9918-9923. [CrossRef]

57. Friedrichs, O.; Sánchez-López, J.C.; López-Cartes, C.; Klassen, T.; Bormann, R.; Fernández, A. $\mathrm{Nb}_{2} \mathrm{O}_{5}$ "Pathway Effect” on Hydrogen Sorption in Mg. J. Phys. Chem. B 2006, 110, 7845-7850. [CrossRef]

58. Crivello, J.-C.; Dam, B.; Denys, R.V.; Dornheim, M.; Grant, D.M.; Huot, J.; Jensen, T.R.; Jongh, P.D.; Milanese, C.; Milčius, D.; et al. Review of magnesium hydride-based materials: Development and optimisation. Appl. Phys. A 2016, 122, 97. [CrossRef]

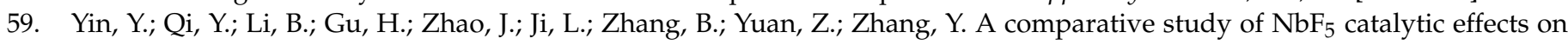
hydrogenation/dehydrogenation kinetics of Mg-Zn-Ni and Mg-Cu-Ni systems. Mater. Charact. 2021, 174, 110993. [CrossRef]

60. Lakhnik, A.M.; Kirian, I.M.; Rud, A.D. The Mg/MAX-phase composite for hydrogen storage. Int. J. Hydrogen Energy 2021, in press. [CrossRef]

61. Luo, Q.; An, X.H.; Pan, Y.B.; Zhang, X.; Zhang, J.-Y.; Li, Q. The hydriding kinetics of Mg-Ni based hydrogen storage alloys: A comparative study on Chou model and Jander model. Int. J. Hydrogen Energy 2010, 35, 7842-7849. [CrossRef]

62. Luo, Q.; Li, J.; Li, B.; Liu, B.; Shao, H.; Li, Q. Kinetics in Mg-based hydrogen storage materials: Enhancement and mechanism. J. Magnes. Alloy 2019, 7, 58-71. [CrossRef]

63. Mooij, L.; Dam, B. Nucleation and growth mechanisms of nano magnesium hydride from the hydrogen sorption kinetics. Phys. Chem. Chem. Phys. 2013, 15, 11501-11510. [CrossRef]

64. Ouyang, L.; Liu, F.; Wang, H.; Liu, J.; Yang, X.-S.; Sun, L.; Zhu, M. Magnesium-based hydrogen storage compounds: A review. J. Alloys Compd. 2020, 832, 154865. [CrossRef]

65. Jain, A.; Jain, R.K.; Agarwal, S.; Jain, I.P. Structural and thermodynamical investigations of La0.23Ni0.34Co0.33Nd0.08Ti0.01Al0.01 hydrogen storage alloy. Int. J. Hydrogen Energy 2008, 33, 356-359. [CrossRef]

66. Pal, P.; Kumari, P.; Wang, Y.; Isobe, S.; Kumar, M.; Ichikawa, T.; Jain, A. Destabilization of $\mathrm{LiBH}_{4}$ by the infusion of Bi ${ }_{2} \mathrm{X}_{3}(\mathrm{X}=\mathrm{S}$, Se, Te): An in situ TEM investigation. J. Mater. Chem. A 2020, 8, 25706-25715. [CrossRef]

67. Jangir, M.; Jain, A.; Yamaguchi, S.; Ichikawa, T.; Lal, C.; Jain, I.P. Catalytic effect of $\mathrm{TiF}_{24}$ in improving hydrogen storage properties of $\mathrm{MgH}_{2}$. Int. J. Hydrogen Energy 2016, 41, 14178-14183. [CrossRef] 
68. Jain, A.; Miyaoka, H.; Ichikawa, T. Destabilization of lithium hydride by the substitution of group 14 elements: A review. Int. J. Hydrogen Energy 2016, 41, 5969-5978. [CrossRef]

69. Jain, A.; Miyaoka, H.; Ichikawa, T. Two-Peak Mystery of $\mathrm{LiNH}_{2}-\mathrm{NaH}$ Dehydrogenation Is Solved? A Study of the Analogous Sodium Amide/Lithium Hydride System. J. Phys. Chem. C 2016, 120, 27903-27909. [CrossRef]

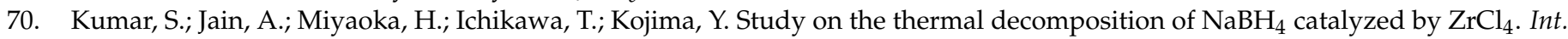
J. Hydrogen Energy 2017, 42, 22432-22437. [CrossRef]

71. Selvaraj, S.; Jain, A.; Kumar, S.; Zhang, T.; Isobe, S.; Miyaoka, H.; Kojima, Y.; Ichikawa, T. Study of cyclic performance of V-Ti-Cr alloys employed for hydrogen compressor. Int. J. Hydrogen Energy 2018, 43, 2881-2889. [CrossRef]

72. Vyas, D.; Jain, P.; Khan, J.; Kulshrestha, V.; Jain, A.; Jain, I.P. Effect of Cu catalyst on the hydrogenation and thermodynamic properties of $\mathrm{Mg}_{2} \mathrm{Ni}$. Int. J. Hydrogen Energy 2012, 37, 3755-3760. [CrossRef]

73. Barkhordarian, G.; Klassen, T.; Bormann, R. Catalytic Mechanism of Transition-Metal Compounds on Mg Hydrogen Sorption Reaction. J. Phys. Chem. B 2006, 110, 11020-11024. [CrossRef] [PubMed]

74. Wang, Y.; Liang, Z.; Zheng, H.; Cao, R. Recent Progress on Defect-rich Transition Metal Oxides and Their Energy-Related Applications. Chem. Asian J. 2020, 15, 3717-3736. [CrossRef] [PubMed]

75. Kumar, S.; Jain, A.; Miyaoka, H.; Ichikawa, T.; Kojima, Y. Catalytic effect of bis (cyclopentadienyl) nickel II on the improvement of

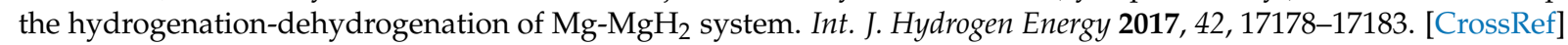

76. Vyas, D.; Jain, P.; Agarwal, G.; Jain, A.; Jain, I.P. Hydrogen storage properties of $\mathrm{Mg}_{2} \mathrm{Ni}$ affected by Cr catalyst. Int. J. Hydrogen Energy 2012, 37, 16013-16017. [CrossRef]

77. Ma, X.; Liu, S.; Huang, S. Hydrogen adsorption and dissociation on the TM-doped (TM=Ti, Nb) Mg55 nanoclusters: A DFT study. Int. J. Hydrogen Energy 2017, 42, 24797-24810. [CrossRef]

78. Jain, A.; Miyaoka, H.; Ichikawa, T.; Kojima, Y. Tailoring the absorption-desorption properties of $\mathrm{KSiH}_{3} \mathrm{compound}$ using nano-metals (Ni, Co, Nb) as catalyst. J. Alloys Compd. 2015, 645, S144-S147. [CrossRef]

79. Mao, J.F.; Wu, Z.; Chen, T.J.; Weng, B.C.; Xu, N.X.; Huang, T.S.; Guo, Z.P.; Liu, H.K.; Grant, D.M.; Walker, G.S.; et al. Improved Hydrogen Storage of $\mathrm{LiBH}_{4}$ Catalyzed Magnesium. J. Phys. Chem. C 2007, 111, 12495-12498. [CrossRef]

80. Lillo-Ródenas, M.A.; Aguey-Zinsou, K.F.; Cazorla-Amorós, D.; Linares-Solano, A.; Guo, Z.X. Effects of Carbon-Supported Nickel Catalysts on $\mathrm{MgH}_{2}$ Decomposition. J. Phys. Chem. C 2008, 112, 5984-5992. [CrossRef]

81. Kaupp, G. Reactive milling with metals for environmentally benign sustainable production. CrystEngCom. 2011, 13, 3108-3121. [CrossRef]

82. Hudson, M.S.L.; Takahashi, K.; Ramesh, A.; Awasthi, S.; Ghosh, A.K.; Ravindran, P.; Srivastava, O.N. Graphene decorated with Fe nanoclusters for improving the hydrogen sorption kinetics of $\mathrm{MgH}_{2}-$ Experimental and theoretical evidence. Catal. Sci. Technol. 2016, 6, 261-268. [CrossRef]

83. Zhang, L.; Ji, L.; Yao, Z.; Yan, N.; Sun, Z.; Yang, X.; Zhu, X.; Hu, S.; Chen, L. Facile synthesized Fe nanosheets as superior active catalyst for hydrogen storage in $\mathrm{MgH}_{2}$. Int. J. Hydrogen Energy 2019, 44, 21955-21964. [CrossRef]

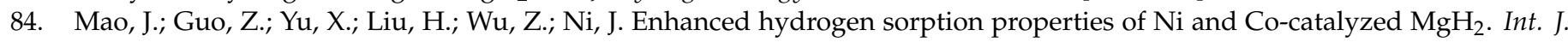
Hydrogen Energy 2010, 35, 4569-4575. [CrossRef]

85. Zaluska, A.; Zaluski, L.; Ström-Olsen, J.O. Nanocrystalline magnesium for hydrogen storage. J. Alloys Compd. 1999, 288, 217-225. [CrossRef]

86. Webb, C.J. A review of catalyst-enhanced magnesium hydride as a hydrogen storage material. J. Phys. Chem. Solids 2015, 84, 96-106. [CrossRef]

87. Wang, Y.; Lan, Z.; Fu, H.; Liu, H.; Guo, J. Synergistic catalytic effects of ZIF-67 and transition metals (Ni, Cu, Pd, and Nb) on hydrogen storage properties of magnesium. Int. J. Hydrogen Energy 2020, 45, 13376-13386. [CrossRef]

88. Pukazhselvan, D.; Nasani, N.; Pérez, J.; Hortigüela, M.J.; Yang, T.; Bdikin, I.; Fagg, D.P. Two step mechanochemical synthesis of $\mathrm{Nb}$ doped $\mathrm{MgO}$ rock salt nanoparticles and its application for hydrogen storage in $\mathrm{MgH}_{2}$. Int. J. Hydrogen Energy 2016, 41, 11716-11722. [CrossRef]

89. Hanada, N.; Ichikawa, T.; Fujii, H. Catalytic effect of Ni nano-particle and $\mathrm{Nb}$ oxide on $\mathrm{H}$-desorption properties in $\mathrm{MgH}_{2} \mathrm{prepared}$ by ball milling. J. Alloys Compd. 2005, 404-406, 716-719. [CrossRef]

90. Yang, W.N.; Shang, C.X.; Guo, Z.X. Site density effect of Ni particles on hydrogen desorption of MgH 2 . Int. J. Hydrogen Energy 2010, 35, 4534-4542. [CrossRef]

91. Liu, Y.; Zou, J.; Zeng, X.; Wu, X.; Li, D.; Ding, W. Hydrogen Storage Properties of a Mg-Ni Nanocomposite Coprecipitated from Solution. J. Phys. Chem. C 2014, 118, 18401-18411. [CrossRef]

92. Sun, Y.; Ma, T.; Aguey-Zinsou, K.-F. Magnesium Supported on Nickel Nanobelts for Hydrogen Storage: Coupling Nanosizing and Catalysis. ACS Appl. Nano Mater. 2018, 1, 1272-1279. [CrossRef]

93. Yang, X.; Hou, Q.; Yu, L.; Zhang, J. Improvement of the hydrogen storage characteristics of $\mathrm{MgH}_{2}$ with a flake Ni nano-catalyst composite. Dalton Trans. 2021, 50, 1797-1807. [CrossRef] [PubMed]

94. Gasnier, A.; Amica, G.; Juan, J.; Troiani, H.; Gennari, F.C. N-Doped Graphene-Rich Aerogels Decorated with Nickel and Cobalt Nanoparticles: Effect on Hydrogen Storage Properties of Nanoconfined LiBH 4 . J. Phys. Chem. C 2020, 124, 115-125. [CrossRef]

95. Meng, X.; Wan, C.B.; Wang, Y.T.; Ju, X. Porous Ni@C derived from bimetallic Metal-Organic Frameworks and its application for improving $\mathrm{LiBH}_{4}$ dehydrogenation. J. Alloys Compd. 2018, 735, 1637-1647. [CrossRef] 
96. Montone, A.; Aurora, A.; Mirabile Gattia, D.; Vittori Antisari, M. Microstructural and Kinetic Evolution of Fe Doped MgH 2 during $\mathrm{H}_{2}$ Cycling. Catalysts 2012, 2, 400-411. [CrossRef]

97. Gattia, D.M.; Jangir, M.; Jain, I.P. Study on nanostructured $\mathrm{MgH}_{2}$ with Fe and its oxides for hydrogen storage applications. J. Alloys Compd. 2019, 801, 188-191. [CrossRef]

98. Antiqueira, F.J.; Leiva, D.R.; Zepon, G.; de Cunha, B.F.R.F.; Figueroa, S.J.A.; Botta, W.J. Fast hydrogen absorption/desorption kinetics in reactive milled Mg-8 mol\% Fe nanocomposites. Int. J. Hydrogen Energy 2020, 45, 12408-12418. [CrossRef]

99. Liu, T.; Ma, X.; Chen, C.; Xu, L.; Li, X. Catalytic Effect of Nb Nanoparticles for Improving the Hydrogen Storage Properties of Mg-Based Nanocomposite. J. Phys. Chem. C 2015, 119, 14029-14037. [CrossRef]

100. Wang, P.; Jensen, C.M. Method for preparing Ti-doped $\mathrm{NaAlH}_{4}$ using $\mathrm{Ti}$ powder: Observation of an unusual reversible dehydrogenation behavior. J. Alloys Compd. 2004, 379, 99-102. [CrossRef]

101. Chaudhuri, S.; Muckerman, J.T. First-Principles Study of Ti-Catalyzed Hydrogen Chemisorption on an Al Surface: A Critical First Step for Reversible Hydrogen Storage in $\mathrm{NaAlH}_{4}$. J. Phys. Chem. B 2005, 109, 6952-6957. [CrossRef]

102. Blomqvist, A.; Araujo, C.M. Dehydrogenation from 3d-transition-metal-doped $\mathrm{NaAlH}_{4}$ : Prediction of catalysts. Appl. Phys. Lett. 2007, 90, 141904. [CrossRef]

103. Huang, C.; Zhao, Y.-J.; Sun, T.; Guo, J.; Sun, L.-X.; Zhu, M. Influence of Transition Metal Additives on the Hydriding/Dehydriding Critical Point of $\mathrm{NaAlH}_{4}$. J. Phys. Chem. C 2009, 113, 9936-9943. [CrossRef]

104. Cui, J.; Liu, J.; Wang, H.; Ouyang, L.; Sun, D.; Zhu, M.; Yao, X. Mg-TM (TM: Ti, Nb, V, Co, Mo or Ni) core-shell like nanostructures: Synthesis, hydrogen storage performance and catalytic mechanism. J. Mater. Chem. 2014, 2, 9645-9655. [CrossRef]

105. Korablov, D.; Besenbacher, F.; Jensen, T.R. Kinetics and thermodynamics of hydrogenation-dehydrogenation for Mg- $25 \% \mathrm{TM}$ $(\mathrm{TM}=\mathrm{Ti}, \mathrm{Nb}$ or $\mathrm{V})$ composites synthesized by reactive ball milling in hydrogen. Int. J. Hydrogen Energy 2018, 43, 16804-16814. [CrossRef]

106. Xie, W.; West, D.J.; Sun, Y.; Zhang, S. Role of nano in catalysis: Palladium catalyzed hydrogen desorption from nanosized magnesium hydride. Nano Energy 2013, 2, 742-748. [CrossRef]

107. Liu, Y.; Zhu, J.; Liu, Z.; Zhu, Y.; Zhang, J.; Li, L. Magnesium Nanoparticles with Pd Decoration for Hydrogen Storage. Front. Chem. 2020, 7, 949. [CrossRef]

108. Rosi, N.L.; Eckert, J.; Eddaoudi, M.; Vodak, D.T.; Kim, J.; O’Keeffe, M.; Yaghi, O.M. Hydrogen Storage in Microporous MetalOrganic Frameworks. Science 2003, 300, 1127-1129. [CrossRef] [PubMed]

109. Wang, Y.; Lan, Z.; Huang, X.; Liu, H.; Guo, J. Study on catalytic effect and mechanism of MOF (MOF = ZIF-8, ZIF-67, MOF-74) on hydrogen storage properties of magnesium. Int. J. Hydrogen Energy 2019, 44, 28863-28873. [CrossRef]

110. Ma, Z.; Zou, J.; Hu, C.; Zhu, W.; Khan, D.; Zeng, X.; Ding, W. Effects of trimesic acid-Ni based metal organic framework on the hydrogen sorption performances of $\mathrm{MgH}_{2}$. Int. J. Hydrogen Energy 2019, 44, 29235-29248. [CrossRef]

111. Ma, Z.; Zou, J.; Khan, D.; Zhu, W.; Hu, C.; Zeng, X.; Ding, W. Preparation and hydrogen storage properties of $\mathrm{MgH}_{2}$-trimesic acid-TM MOF (TM=Co, Fe) composites. J. Mater. Sci. Technol. 2019, 35, 2132-2143. [CrossRef]

112. Zhang, J.; He, L.; Yao, Y.; Zhou, X.J.; Yu, L.P.; Lu, X.Z.; Zhou, D.W. Catalytic effect and mechanism of NiCu solid solutions on hydrogen storage properties of $\mathrm{MgH}_{2}$. Renew. Energy 2020, 154, 1229-1239.

113. Chen, M.; Wang, Y.; Xiao, X.; Lu, Y.; Zhang, M.; Zheng, J.; Chen, L. Highly efficient $\mathrm{ZrH}_{2}$ nanocatalyst for the superior hydrogenation kinetics of magnesium hydride under moderate conditions: Investigation and mechanistic insights. Appl. Surf. Sci. 2021, 541, 148375. [CrossRef]

114. Ismail, M. Effect of adding different percentages of $\mathrm{HfCl}_{4}$ on the hydrogen storage properties of $\mathrm{MgH}_{2}$. Int. J. Hydrogen Energy 2021, 46, 8621-8628. [CrossRef]

115. Zhang, X.; Wang, K.; Zhang, X.; Hu, J.; Gao, M.; Pan, H.; Liu, Y. Synthesis process and catalytic activity of $\mathrm{Nb}_{2} \mathrm{O}_{5}$ hollow spheres for reversible hydrogen storage of $\mathrm{MgH}_{2}$. Int. J. Energy Res. 2021, 45, 3129-3141. [CrossRef]

116. Gi, H.; Shinzato, K.; Balgis, R.; Ogi, T.; Sadakane, M.; Wang, Y.; Isobe, S.; Miyaoka, H.; Ichikawa, T. Effective Factor on Catalysis of Niobium Oxide for Magnesium. ACS Omega 2020, 5, 21906-21912. [CrossRef] [PubMed]

117. Zhang, L.; Sun, Z.; Yao, Z.; Yang, L.; Yan, N.; Lu, X.; Xiao, B.; Zhu, X.; Chen, L. Excellent catalysis of $\mathrm{Mn}_{3} \mathrm{O}_{4}$ nanoparticles on the hydrogen storage properties of $\mathrm{MgH}_{2}$ : An experimental and theoretical study. Nanoscale Adv. 2020, 2, 1666-1675. [CrossRef]

118. Yang, X.; Ji, L.; Yan, N.; Sun, Z.; Lu, X.; Zhang, L.; Zhu, X.; Chen, L. Superior catalytic effects of FeCo nanosheets on MgH $\mathrm{H}_{2}$ for hydrogen storage. Dalton Trans. 2019, 48, 12699-12706. [CrossRef] [PubMed]

119. Berezovets, V.V.; Denys, R.V.; Zavaliy, I.Y.; Kosarchyn, Y.V. Effect of Ti-based nanosized additives on the hydrogen storage properties of $\mathrm{MgH}_{2}$. Int. J. Hydrogen Energy 2021, 19. [CrossRef]

120. Liu, Y.; Du, H.; Zhang, X.; Yang, Y.; Gao, M.; Pan, H. Superior catalytic activity derived from a two-dimensional Ti ${ }_{3} \mathrm{C}_{2}$ precursor towards the hydrogen storage reaction of magnesium hydride. Chem. Commun. 2016, 52, 705-708. [CrossRef]

121. Ismail, $\mathrm{M}$. Influence of different amounts of $\mathrm{FeCl}_{3}$ on decomposition and hydrogen sorption kinetics of $\mathrm{MgH}_{2}$. Int. J. Hydrogen Energy 2014, 39, 2567-2574. [CrossRef]

122. Ojeda, X.A.; Castro, F.J.; Pighin, S.A.; Troiani, H.E.; Moreno, M.S.; Urretavizcaya, G. Hydrogen absorption and desorption properties of $\mathrm{Mg} / \mathrm{MgH}_{2}$ with nanometric dispersion of small amounts of $\mathrm{Nb}(\mathrm{V})$ ethoxide. Int. J. Hydrogen Energy 2021, 46, 4126-4136. [CrossRef]

123. Zhang, L.; Cai, Z.; Zhu, X.; Yao, Z.; Sun, Z.; Ji, L.; Yan, N.; Xiao, B.; Chen, L. Two-dimensional ZrCo nanosheets as highly effective catalyst for hydrogen storage in $\mathrm{MgH}_{2}$. J. Alloys Compd. 2019, 805, 295-302. [CrossRef] 
124. Song, M.Y.; Kwak, Y.J. Hydrogen charging kinetics of $\mathrm{Mg}-10 \mathrm{wt} \% \mathrm{Fe}_{2} \mathrm{O}_{3}$ prepared via $\mathrm{MgH}_{2}$-forming mechanical milling. Mater. Res. Bull. 2021, 140, 111304. [CrossRef]

125. Cai, W.; Wang, H.; Liu, J.; Jiao, L.; Wang, Y.; Ouyang, L.; Sun, T.; Sun, D.; Wang, H.; Yao, X.; et al. Towards easy reversible dehydrogenation of $\mathrm{LiBH}_{4}$ by catalyzing hierarchic nanostructured CoB. Nano Energy 2014, 10, 235-244. [CrossRef]

126. Rafi-ud-din, Xuanhui, Q.; Ping, L.; Zhang, L.; Qi, W.; Iqbal, M.Z.; Rafique, M.Y.; Farooq, M.H.; Islam-ud-din. Superior Catalytic Effects of $\mathrm{Nb}_{2} \mathrm{O}_{5}, \mathrm{TiO}_{2}$, and $\mathrm{Cr}_{2} \mathrm{O}_{3}$ Nanoparticles in Improving the Hydrogen Sorption Properties of $\mathrm{NaAlH}_{4}$. J. Phys. Chem. C 2012, 116, 11924-11938. [CrossRef]

127. Khan, J.; Jain, I.P. Catalytic effect of $\mathrm{Nb}_{2} \mathrm{O}_{5}$ on dehydrogenation kinetics of $\mathrm{NaAlH}_{4}$. Int. J. Hydrogen Energy 2016, 41, 8264-8270. [CrossRef]

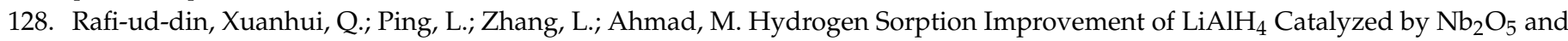
$\mathrm{Cr}_{2} \mathrm{O}_{3}$ Nanoparticles. J. Phys. Chem. C 2011, 115, 13088-13099. [CrossRef]

129. Ismail, M.; Zhao, Y.; Yu, X.B.; Nevirkovets, I.P.; Dou, S.X. Significantly improved dehydrogenation of $\mathrm{LiAlH}_{4} \mathrm{catalysed} \mathrm{with} \mathrm{TiO}_{2}$ nanopowder. Int. J. Hydrogen Energy 2011, 36, 8327-8334. [CrossRef]

130. Jain, A.; Agarwal, S.; Kumar, S.; Yamaguchi, S.; Miyaoka, H.; Kojimaa, Y.; Ichikawa, T. How does TiF4 affect the decomposition of $\mathrm{MgH}_{2}$ and its complex variants?-An XPS investigation. J. Mater. Chem. A. 2017, 5, 15543-15551. [CrossRef]

131. Zhang, L.; Cai, Z.; Yao, Z.; Ji, L.; Sun, Z.; Yan, N.; Zhang, B.; Xiao, B.; Du, J.; Zhu, X.; et al. A striking catalytic effect of facile synthesized $\mathrm{ZrMn}_{2}$ nanoparticles on the de/rehydrogenation properties of $\mathrm{MgH}_{2}$. J. Mater. Chem. A 2019, 7, 5626-5634. [CrossRef]

132. El-Eskandarany, M.S.; Saeed, M.; Al-Nasrallah, E.; Al-Ajmi, F.; Banyan, M. Effect of $\mathrm{LaNi}_{3}$ Amorphous Alloy Nanopowders on the Performance and Hydrogen Storage Properties of $\mathrm{MgH}_{2}$. Energies 2019, 12, 1005. [CrossRef]

133. Mahmoudi, N.; Kaflou, A.; Simchi, A. Hydrogen desorption properties of $\mathrm{MgH}_{2}-\mathrm{TiCr} 1.2 \mathrm{Fe} 0.6$ nanocomposite prepared by high-energy mechanical alloying. J. Power Sources 2011, 196, 4604-4608. [CrossRef]

134. Zhou, C.; Fang, Z.-Z.; Ren, C.; Li, J.; Lu, J. Effect of Ti Intermetallic Catalysts on Hydrogen Storage Properties of Magnesium Hydride. J. Phys. Chem. C 2013, 117, 12973-12980. [CrossRef]

135. Wang, K.; Du, H.; Wang, Z.; Gao, M.; Pan, H.; Liu, Y. Novel MAX-phase $\mathrm{Ti}_{3} \mathrm{AlC}_{2}$ catalyst for improving the reversible hydrogen storage properties of $\mathrm{MgH}_{2}$. Int. J. Hydrogen Energy 2017, 42, 4244-4251. [CrossRef]

136. Meena, P.; Jangir, M.; Kumar, A.; Singh, R.; Sharma, V.K.; Jain, I.P. Improved dehydrogenation kinetics of $\mathrm{MgH}_{2}$ due to NiMnAl. Mater. Res. Express 2017, 4, 116520. [CrossRef]

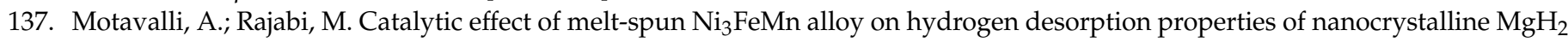
synthesized by mechanical alloying. Int. J. Hydrogen Energy 2014, 39, 17047-17053. [CrossRef]

138. Singh, S.; Bhatnagar, A.; Shukla, V.; Vishwakarma, A.K.; Soni, P.K.; Verma, S.K.; Shaz, M.A.; Sinha, A.S.K.; Srivastavaa, O.N. Ternary transition metal alloy FeCoNi nanoparticles on graphene as new catalyst for hydrogen sorption in $\mathrm{MgH}_{2}$. Int. J. Hydrogen Energy 2020, 45, 774-786. [CrossRef]

139. Ismail, M.; Mustafa, N.S.; Ali, N.A.; Sazelee, N.A.; Yahya, M.S. The hydrogen storage properties and catalytic mechanism of the $\mathrm{CuFe}_{2} \mathrm{O}_{4}$-doped $\mathrm{MgH}_{2}$ composite system. Int. J. Hydrogen Energy 2019, 44, 318-324. [CrossRef]

140. Lu, Y.; Wang, H.; Liu, J.; Ouyang, L.; Zhu, M. Destabilizing the dehydriding thermodynamics of $\mathrm{MgH}_{2}$ by reversible intermetallics formation in $\mathrm{Mg}-\mathrm{Ag}-\mathrm{Zn}$ ternary alloys. J. Power Sources 2018, 396, 796-802. [CrossRef]

141. Sazelee, N.A.; Idris, N.H.; Md Din, M.F.; Yahya, M.S.; Ali, N.A.; Ismaila, M. $\mathrm{LaFeO}_{3}$ synthesised by solid-state method for enhanced sorption properties of $\mathrm{MgH}_{2}$. Results Physics. 2020, 16, 102844. [CrossRef]

142. Agarwal, S.; Jain, A.; Jain, P.; Jangir, M.; Jain, I.P. Kinetic Enhancement in the Sorption Properties by Forming $\mathrm{Mg}-\mathrm{x} \mathrm{wt} \% \mathrm{ZrCrCu}$ Composites. J. Phys. Chem. C 2013, 117, 11953-11959. [CrossRef]

143. Agarwal, S.; Aurora, A.; Jain, A.; Montone, A. Structural and $\mathrm{H}_{2}$ sorption properties of $\mathrm{MgH}_{2}-10 \mathrm{wt} \% \mathrm{ZrCrM}(\mathrm{M}=\mathrm{Cu}, \mathrm{Ni})$ nano-composites. J. Nanoparticle Res. 2011, 13, 5719-5726. [CrossRef]

144. Agarwal, S.; Aurora, A.; Jain, A.; Jain, I.P.; Montone, A. Catalytic effect of $\mathrm{ZrCrNi}$ alloy on hydriding properties of $\mathrm{MgH}_{2}$. Int. J. Hydrogen Energy 2009, 34, 9157-9162. [CrossRef]

145. Zhang, L.; Sun, Z.; Cai, Z.; Yan, N.; Lu, X.; Zhu, X.; Chen, L. Enhanced hydrogen storage properties of $\mathrm{MgH}_{2}$ by the synergetic catalysis of Zr0.4Ti0.6Co nanosheets and carbon nanotubes. Appl. Surf. Sci. 2020, 504, 144465. [CrossRef]

146. Ali, N.A.; Idrisa, N.H.; Md Din, M.F.; Yahya, M.S.; Ismail, M. Nanoflakes $\mathrm{MgNiO}_{2}$ synthesised via a simple hydrothermal method and its catalytic roles on the hydrogen sorption performance of $\mathrm{MgH}_{2}$. J. Alloys Compd. 2019, 796, 279-286. [CrossRef]

147. Yahya, M.S.; Ismail, M. Catalytic effect of $\mathrm{SrTiO}_{3}$ on the hydrogen storage behaviour of $\mathrm{MgH}_{2}$. J. Energy Chem. 2019, $28,46-53$. [CrossRef]

148. Zhang, J.; Li, P.; Wan, Q.; Zhai, F.; Volinskyd, A.A.; Qu, X. Superior destabilization effects of $\mathrm{LiBH}_{4}$ with the addition of nano-sized nickel ferrite $\mathrm{NiFe}_{2} \mathrm{O}_{4}$. RSC Adv. 2015, 5, 81212-81219. [CrossRef]

149. Mo, X.; Jiang, W.; Cao, S. First-principles study on the dehydrogenation characteristics of $\mathrm{LiBH}_{4}$ modified by Ti. Results Phys. 2017, 7, 3236-3242. [CrossRef]

150. Wan, Q.; Li, P.; Li, Z.; Zhao, K.; Liu, Z.; Wang, L.; Zhai, F.; Qu, X.; Volinsky, A.A. NaAlH 4 dehydrogenation properties enhanced by $\mathrm{MnFe}_{2} \mathrm{O}_{4}$ nanoparticles. J. Power Sources 2014, 248, 388-395. [CrossRef]

151. Huang, Y.; Li, P.; Wan, Q.; Zhang, J.; Li, Y.; Li, R.; Dong, R.; Qu, X. Improved dehydrogenation performance of $\mathrm{NaAlH}_{4}$ using $\mathrm{NiFe}_{2} \mathrm{O}_{4}$ nanoparticles. J. Alloys Compd. 2017, 709, 850-856. [CrossRef] 
152. Li, Z.; Zhai, F.; Wan, Q.; Liu, Z.; Shan, J.; Li, P.; Volinskyc, A.A.; Qua, X. Enhanced hydrogen storage properties of $\mathrm{LiAlH}_{4}$ catalyzed by $\mathrm{CoFe}_{2} \mathrm{O}_{4}$ nanoparticles. RSC Adv. 2014, 4, 18989-18997. [CrossRef]

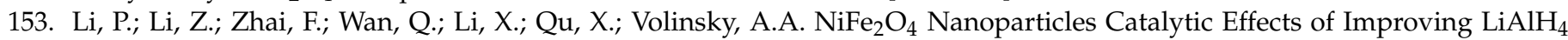
Dehydrogenation Properties. J. Phys. Chem. C 2013, 117, 25917-25925. [CrossRef]

154. Ali, N.A.; Idris, N.H.; Sazelee, N.A.; Yahya, M.S.; Halim Yap, F.A.; Ismaila, M. Catalytic effects of $\mathrm{MgFe}_{2} \mathrm{O}_{4}$ addition on the dehydrogenation properties of $\mathrm{LiAlH}_{4}$. Int. J. Hydrogen Energy 2019, 44, 28227-28234. [CrossRef]

155. Tan, C.-Y.; Tsai, W.-T. Effects of Ni and Co-decorated MWCNTs addition on the dehydrogenation behavior and stability of LiAlH 4 . Int. J. Hydrogen Energy 2015, 40, 14064-14071. [CrossRef]

156. Jiao, C.; Sun, L.; Xu, F.; Liu, S.-S.; Zhang, J.; Jiang, X.; Yang, L. NiCo nanoalloy encapsulated in graphene layers for improving hydrogen storage properties of $\mathrm{LiAlH}_{4}$. Sci. Rep. 2016, 6, 27429. [CrossRef]

157. Xia, Y.; Wei, S.; Huang, Q.; Li, J.; Cen, X.; Zhang, H.; Chu, H.; Sun, L.; Xu, L.; Huang, P. Facile synthesis of $\mathrm{NiCo}_{2} \mathrm{O}_{4}$-anchored reduced graphene oxide nanocomposites as efficient additives for improving the dehydrogenation behavior of lithium alanate. Inorg. Chem. Front. 2020, 7, 1257-1272. [CrossRef]

158. Wei, S.; Xue, S.; Huang, C.; Che, B.; Zhang, H.; Sun, L.; Xu, F.; Xia, Y.; Cheng, R.; Zhang, C.; et al. Multielement synergetic effect of $\mathrm{NiFe}_{2} \mathrm{O}_{4}$ and h-BN for improving the dehydrogenation properties of $\mathrm{LiAlH}_{4}$. Inorg. Chem. Front. 2021, 8, 3111-3126. [CrossRef]

159. Zhao, Y.; Zhu, Y.; Liu, J.; Ma, Z.; Zhang, J.; Liu, Y.; Li, Y.; Li, L. Enhancing hydrogen storage properties of $\mathrm{MgH}_{2}$ by core-shell CoNi@C. J. Alloys Compd. 2021, 862, 158004. [CrossRef]

160. Meng, Z.; Zhang, X.; Bosang, L.; Meijia, L.; Man, C.; Lixin, C. Superior de/hydrogenation performances of $\mathrm{MgH}_{2}$ catalyzed by 3D flower-like TiO2@C nanostructures. J. Energy Chem. 2020, 46, 191-198.

161. Liu, J.; Ma, Z.; Liu, Z.; Tang, Q.; Zhu, Y.; Lin, H.; Zhang, Y.; Zhang, J.; Liu, Y.; Li, L. Synergistic effect of rGO supported Ni 3 Fe on hydrogen storage performance of $\mathrm{MgH}_{2}$. Int. J. Hydrogen Energy 2020, 45, 16622-16633. [CrossRef]

162. Ding, Z.; Fu, Y.; Wang, Y.; Bi, J.; Zhang, L.; Peng, D.; Li, Y.; Han, S. MgCNi3 prepared by powder metallurgy for improved hydrogen storage properties of $\mathrm{MgH}_{2}$. Int. J. Hydrogen Energy 2019, 44, 8347-8356. [CrossRef]

163. Ding, Z.; Zhang, L.; Fu, Y.; Wang, W.; Wang, Y.; Bi, J.; Li, Y.; Han, S. Enhanced kinetics of $\mathrm{MgH}_{2}$ via in situ formed catalysts derived from MgCCo1.5Ni1.5. J. Alloys Compd. 2020, 822, 153621. [CrossRef]

164. Meena, P.; Singh, R.; Sharma, V.K.; Jain, I.P. Role of NiMn9.3Al4.0Co14.1Fe3.6 alloy on dehydrogenation kinetics of MgH 2 . J. Magnes. Alloy. 2018, 6, 318-325. [CrossRef]

165. Kumar, P.; Singh, S.; Hashmi, S.A.R.; Kim, K.-H. MXenes: Emerging 2D materials for hydrogen storage. Nano Energy 2021, 85, 105989. [CrossRef]

166. Li, J.; Wang, S.; Du, Y.; Liao, W. Catalytic effect of $\mathrm{Ti}_{2} \mathrm{C}$ MXene on the dehydrogenation of $\mathrm{MgH}_{2}$. Int. J. Hydrogen Energy 2019, 44, 6787-6794. [CrossRef]

167. Zhu, W.; Panda, S.; Lu, C.; Ma, Z.; Khan, D.; Dong, J.; Sun, F.; Xu, H.; Zhang, Q.; Zou, J. Using a Self-Assembled Two-Dimensional MXene-Based Catalyst (2D-Ni@ $\mathrm{Ti}_{3} \mathrm{C}_{2}$ ) to Enhance Hydrogen Storage Properties of $\mathrm{MgH}_{2}$. ACS Appl. Mater. Interfaces 2020, 12, 50333-50343. [CrossRef] [PubMed]

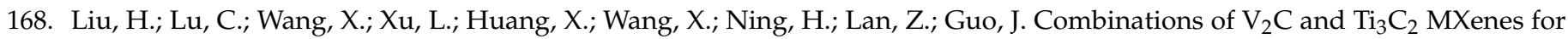
Boosting the Hydrogen Storage Performances of $\mathrm{MgH}_{2}$. ACS Appl. Mater. Interfaces 2021, 13, 13235-13247. [CrossRef]

169. Fan, Y.; Chen, D.; Liu, X.; Fan, G.; Liu, B. Improving the hydrogen storage performance of lithium borohydride by $\mathrm{Ti}_{3} \mathrm{C}_{2} \mathrm{MXene}$ Int. J. Hydrogen Energy 2019, 44, 29297-29303. [CrossRef]

170. Fan, Y.; Yuan, Z.; Zou, G.; Zhang, Q.; Liu, B.; Peng, Q. Two-dimensional MXene/A-TiO 2 composite with unprecedented catalytic activation for sodium alanate. Catal. Today 2018, 318, 167-174. [CrossRef]

171. Li, Z.; Gao, M.; Gu, J.; Xian, K.; Yao, Z.; Shang, C.; Liu, Y.; Guo, Z.; Pan, H. In Situ Introduction of $\mathrm{Li}_{3} \mathrm{BO}_{3}$ and $\mathrm{NbH}$ Leads to Superior Cyclic Stability and Kinetics of a $\mathrm{LiBH}_{4}$-Based Hydrogen Storage System. ACS Appl. Mater. Interfaces 2020, 12, 893-903. [CrossRef]

172. Yuan, Z.; Fan, Y.; Chen, Y.; Liu, X.; Liu, B.; Han, S. Two-dimensional C@ $\mathrm{TiO}_{2} / \mathrm{Ti}_{3} \mathrm{C}_{2}$ composite with superior catalytic performance for $\mathrm{NaAlH}_{4}$. Int. J. Hydrogen Energy 2020, 45, 21666-21675. [CrossRef]

173. Jiang, R.; Xiao, X.; Zheng, J.; Chen, M.; Chen, L. Remarkable hydrogen absorption/desorption behaviors and mechanism of sodium alanates in-situ doped with Ti-based 2D MXene. Mater. Chem. Phys. 2020, 242, 122529. [CrossRef]

174. Li, Z.; Yu, J.Z.; Zhang, Y.; Liu, D.M.; Wang, C.Y.; Si, T.Z.; Li, Y.T.; Zhang, Q.A. Coupling of nanoconfinement with metallic catalysis in supported $\mathrm{NaAlH}_{4}$ for low-temperature hydrogen storage. J. Power Sources 2021, 491, 229611. [CrossRef]

175. Chen, W.; You, L.; Xia, G.; Yu, X. A balance between catalysis and nanoconfinement towards enhanced hydrogen storage performance of $\mathrm{NaAlH}_{4}$. J. Mater. Sci. Technol. 2021, 79, 205-211. [CrossRef] 